\title{
Environmental Science and Pollution Research
}

\section{Ligand-enhanced electrokinetic remediation of metal-contaminated marine sediments with high acid buffering capacity \\ --Manuscript Draft--}

\begin{tabular}{|c|c|}
\hline Manuscript Number: & ESPR-D-15-02950R1 \\
\hline Full Title: & $\begin{array}{l}\text { Ligand-enhanced electrokinetic remediation of metal-contaminated marine sediments } \\
\text { with high acid buffering capacity }\end{array}$ \\
\hline Article Type: & Research Article \\
\hline Corresponding Author: & $\begin{array}{l}\text { Renato lannelli, prof. } \\
\text { ITALY }\end{array}$ \\
\hline \multicolumn{2}{|l|}{$\begin{array}{l}\text { Corresponding Author Secondary } \\
\text { Information: }\end{array}$} \\
\hline \multicolumn{2}{|l|}{ Corresponding Author's Institution: } \\
\hline \multicolumn{2}{|l|}{$\begin{array}{l}\text { Corresponding Author's Secondary } \\
\text { Institution: }\end{array}$} \\
\hline First Author: & Matteo Masi, Dr \\
\hline \multicolumn{2}{|l|}{ First Author Secondary Information: } \\
\hline \multirow[t]{3}{*}{ Order of Authors: } & Matteo Masi, Dr \\
\hline & Renato lannelli, prof. \\
\hline & Gabriella Losito, Dr. \\
\hline \multicolumn{2}{|l|}{ Order of Authors Secondary Information: } \\
\hline \multicolumn{2}{|l|}{ Funding Information: } \\
\hline Abstract: & $\begin{array}{l}\text { The suitability of electrokinetic remediation for removing heavy metals from dredged } \\
\text { marine sediments with high acid buffering capacity was investigated. Laboratory scale } \\
\text { electrokinetic remediation experiments were carried out by applying two different } \\
\text { voltage gradients to the sediment }(0.5 \text { and } 0.8 \mathrm{~V} / \mathrm{cm} \text { ) while circulating water or two } \\
\text { different chelating agents at the electrode compartments. Tap water, } 0.1 \mathrm{M} \text { citric acid } \\
\text { and } 0.1 \mathrm{M} \text { ethylenediaminetetraacetic acid (EDTA) solutions were used respectively. } \\
\text { The investigated metals were } \mathrm{Zn}, \mathrm{Pb}, \mathrm{V}, \mathrm{Ni} \text { and } \mathrm{Cu} \text {. In the unenhanced experiment the } \\
\text { acid front could not propagate due to the high acid buffering capacity of the sediments; } \\
\text { the production of OH- ions at the cathode resulted in a high-pH environment causing } \\
\text { the precipitation of } \mathrm{CaCO} 3 \text { and metal hydroxides. The use of citric acid prevented the } \\
\text { formation of precipitates but solubilisation and mobilisation of metal species were not } \\
\text { sufficiently achieved. Metal removal was relevant when EDTA was used as the } \\
\text { conditioning agent and the electric potential was raised up to } 0.8 \mathrm{~V} / \mathrm{cm} \text {. EDTA led to } \\
\text { the formation of negatively charged complexes with metals which migrated toward the } \\
\text { anode compartment by electromigration. This result shows that metal removal from } \\
\text { sediments with high acid buffering capacity may be achieved by enhancing the } \\
\text { electrokinetic process by EDTA addition when the acidification of the medium is not } \\
\text { economically and/or environmentally sustainable. }\end{array}$ \\
\hline Response to Reviewers: & See attachment \\
\hline \multicolumn{2}{|l|}{ Additional Information: } \\
\hline Question & Response \\
\hline$\S$ Are you submitting to a Special Issue? & Yes \\
\hline $\begin{array}{l}\text { (If 'Yes') Please select a Special Issue } \\
\text { from the following list. } \\
\text { as follow-up to "§ Are you submitting to } \\
\text { a Special Issue? " }\end{array}$ & SI: CONTASED \\
\hline
\end{tabular}




\title{
Ligand-enhanced electrokinetic remediation of metal-contaminated marine sediments with high acid buffering capacity
}

\author{
Matteo Masi, PhD Student \\ Department of Energy, Systems, Territory, and Construction Engineering \\ University of Pisa \\ Via C.F. Gabba, 22 \\ 56122 Pisa (PI), Italy \\ Tel. +390502217926 \\ email: m.masi@ing.unipi.it
}

12

Renato Iannelli*, Associate professor

Department of Energy, Systems, Territory, and Construction Engineering University of Pisa Via C.F. Gabba, 22 56122 Pisa (PI), Italy Tel. +390502217 718

*Corresponding author, email: r.iannelli@ing.unipi.it

Gabriella Losito, Senior Researcher Department of Civil and Environmental Engineering University of Firenze

Via di Santa Marta, 3 50139 Firenze (FI), Italy Tel. +390554796323 


\section{Abstract}

31 The suitability of electrokinetic remediation for removing heavy metals from dredged marine

32 sediments with high acid buffering capacity was investigated. Laboratory scale electrokinetic

33 remediation experiments were carried out by applying two different voltage gradients to the sediment

$34(0.5$ and $0.8 \mathrm{~V} / \mathrm{cm})$ while circulating water or two different chelating agents at the electrode

35 compartments. Tap water, $0.1 \mathrm{M}$ citric acid and $0.1 \mathrm{M}$ ethylenediaminetetraacetic acid (EDTA)

36 solutions were used respectively. The investigated metals were $\mathrm{Zn}, \mathrm{Pb}, \mathrm{V}, \mathrm{Ni}$ and $\mathrm{Cu}$. In the

37 unenhanced experiment the acid front could not propagate due to the high acid buffering capacity of

38 the sediments; the production of $\mathrm{OH}^{-}$ions at the cathode resulted in a high-pH environment causing

39 the precipitation of $\mathrm{CaCO}_{3}$ and metal hydroxides. The use of citric acid prevented the formation of

40 precipitates but solubilisation and mobilisation of metal species were not sufficiently achieved. Metal

41 removal was relevant when EDTA was used as the conditioning agent and the electric potential was

42 raised up to $0.8 \mathrm{~V} / \mathrm{cm}$. EDTA led to the formation of negatively charged complexes with metals which

43 migrated toward the anode compartment by electromigration. This result shows that metal removal

44 from sediments with high acid buffering capacity may be achieved by enhancing the electrokinetic

45 process by EDTA addition when the acidification of the medium is not economically and/or

46 environmentally sustainable.

48 Keywords: Electroremediation; heavy metals; dredged sediments; enhanced electrokinetics;

49 buffering capacity; EDTA; citric acid 


\section{Introduction}

53

The management of contaminated sediments is of great concern particularly in harbours and adjacent areas where dredging is essential for the maintenance of harbour waterways. Dredged sediments are often severely contaminated by a variety of hazardous pollutants, mostly heavy metals and hydrocarbons, originated from different sources such as ships, harbour activities, industry, municipal sewage and other upstream sources (Mulligan et al. 2001). When no contamination is found or the contamination levels comply with regulatory standards, traditional management strategies include alternatives such as dumping at open sea or disposal in longshore confined disposal facilities. Beneficial reuse of sediments, e.g. for construction materials in civil engineering (Dubois et al. 2011), also represents a viable solution, as long as the sediments do not pose a risk. When the regulatory standards are not met, disposal in landfill is a widespread solution. However, storage on disposal sites is not sustainable because of the large amount of sediments to be disposed and because of the risk of contaminant to be transferred to the environment (Ammami et al. 2015). Consequently, sediment treatment is required.

In marine sediment remediation, heavy metal pollution is a major issue because most sediments consist of clay minerals and organic matter. Metals can be bound to clay surfaces or complexed with organic matter thus reducing their mobility through the porous matrix (Peng et al. 2009). Furthermore, marine sediments are frequently characterized by low hydraulic permeability and high buffering capacity (Reddy and Ala 2006). These conditions pose severe limitations to remediation efficiency as traditional decontamination techniques available for treating high permeability soils are not effective for fine-grained matrices. In this context, electrokinetic remediation (EKR) is widely recognised as an efficient technique for removing a broad range of organic and inorganic contaminants from lowpermeability materials (Probstein and Hicks 1993; Lageman 1993; Virkutyte et al. 2002; Reddy and Cameselle 2009; Yeung 2011). EKR technology is based on the application of a low-intensity electric field which induces the mobilization of charged species through the porous media toward the electrodes, due to three main transport mechanisms (Acar and Alshawabkeh 1993): electromigration (movement of ions and charged molecules), electroosmosis (movement of fluid), and electrophoresis (movement of colloids). The application of an electric field to a porous matrix also results in water electrolysis reactions at the electrodes, producing $\mathrm{H}^{+}$ions at the anode and $\mathrm{OH}^{-}$at the cathode, which, if not buffered with external chemical agents, generate a $\mathrm{pH}$ gradient along the material under treatment.

In general, pollutant speciation is $\mathrm{pH}$-dependent and it is often required to adjust the sediment $\mathrm{pH}$ to keep the system performance controlled and avoid undesired effects such as precipitation of species (e.g. carbonates or hydroxides) which can hinder the transport processes. This is usually carried out 
by acid/base addition at the electrode compartments (Acar et al. 1995; Zhou et al. 2005; Kim et al. 2011). This approach was also one of the first to be implemented in full scale in-situ EKR systems (Pool 1989; Pool 1996). However, when the material under treatment is characterized by a high acid/base buffering capacity, particularly marine sediments, more energy expenditure and greater amount of reagents are required in order to reach the $\mathrm{pH}$ target levels and the costs and effectiveness of the treatment can be strongly affected (Altaee et al. 2008). In most cases, the buffer capacity is due to the presence of calcite which buffers the system, as observed by Grundl and Reese (1997).

In case of high buffering capacity, the mobility of metals can be improved by other possible enhancement strategies in order to reduce remediation time and costs (Yeung and Gu 2011). Among these strategies, one involves the use of chelating agents to achieve the solubilisation of metals. Other authors proposed the use of ion-exchange membranes to isolate reactions occurring at the electrodes and remediation phenomena occurring inside the porous matrix (Hansen et al. 2005; Kim et al. 2005).

The use of chelating agents has been shown to be effective for improving metal solubility and removal rates in high acid buffering capacity soils and sediments (Wong et al. 1997; Amrate and Akretche 2005; Gidarakos and Giannis 2006; Colacicco et al. 2010). When the natural pH of the material is in the alkaline range, the use of chelating agents, such as EDTA, may be advantageous as they are found to be more efficient at alkaline $\mathrm{pH}$ (Lestan et al. 2008). However, in many situations the use of EDTA is not recommended because of the potential toxicity and poor biodegradability (Sillanpää and Oikari 1996). Conversely, Voglar and Lestan (2013) have demonstrated that it is possible to implement a method for EDTA recycling, with lower generation of wastewater or other toxic wastes and with technical and economical feasibility. The economic value of chelant-enhanced electrokinetic remediation would greatly be increased by the development of more efficient recycling methods.

Many recent studies have examined the effects of different enhancing agents on electrokinetic remediation of marine sediments, showing that the remediation of real contaminated sediments is particularly dependent on the characteristics of the solid matrix and on the specific interactions between pollutants and sediment constituents (Hahladakis et al. 2014). Therefore, the selection of operating parameters and conditioning agents must be carefully evaluated in order to choose the best remediation strategy.

Kim et al. (2011) investigated the suitability of various processing fluids (EDTA, citric acid, $\mathrm{HCl}$ and $\mathrm{NO}_{3}$ ) for the enhancement of the electrokinetic remediation of dredged marine sediments contaminated by $\mathrm{Ni}, \mathrm{Cu}, \mathrm{Zn}$ and $\mathrm{Pb}$. Tap water was used as anolyte and the processing fluids were circulated at the cathode at $0.1 \mathrm{M}$ concentration. The experiments were performed under a constant voltage gradient of $1 \mathrm{~V} / \mathrm{cm}$ for 15 days. They obtained the best removal rates with citric acid and $\mathrm{HCl}$, showing extraction efficiencies up to about $70 \%$. 
122 Rozas and Castellote (2012) carried out electrokinetic removal of $\mathrm{Cu}, \mathrm{Zn}, \mathrm{Cd}, \mathrm{Cr}, \mathrm{Pb}$ and $\mathrm{Ni}$ from

123 contaminated dredged material testing the effectiveness of different enhancing solutions (distilled 124 water, citric acid, acetic acid, humic acid and EDTA). They performed a multiple regression analysis 125 on the measured parameters and they found that the main factors affecting the efficiency of the 126 treatments were the $\mathrm{pH}$ of the cathodic solution, chelating ability of the conditioning agent and the 127 zeta potential of the sediment.

128 Iannelli et al. (2015) performed an extensive set of laboratory experiments aimed at designing a pilot129 scale demonstrative electrokinetic plant for extracting heavy metals from marine sediments. The 130 target metals were $\mathrm{Cd}, \mathrm{Cr}, \mathrm{Cu}, \mathrm{Ni}, \mathrm{Pb}$ and $\mathrm{Zn}$ at relatively low concentrations with high non-mobile 131 fractions. Several conditioning agents $\left(\mathrm{HNO}_{3}, \mathrm{HCl}, \mathrm{H}_{2} \mathrm{SO}_{4}\right.$, citric acid, oxalic acid, ascorbic acid, 132 EDTA) were tested. The best result were obtained with strong acids, although EDTA was also found 133 to be effective for some of the investigated metals.

134 Ammami et al. (2015) performed electrokinetic treatments of dredged harbour sediments using a 135 mixture of citric acid and surfactants (Tween 20) and testing different operating conditions, including 136 the application of periodic voltage gradients. The best heavy metal removal was obtained with Tween 13720 with citric acid at the maximum concentration $(1 \mathrm{M})$ but only for some of the investigated metals. 138 The above mentioned studies on real contaminated sediments show that the identification of the best 139 enhancement strategy and operating conditions are still controversial and further investigations on the 140 application of the electrokinetic technology are still required, due to the complexity of the solid matrix 141 and the peculiar characteristics of marine sediments, such as the strong buffering capacity.

142 In this context, this study aims at evaluating the main factors affecting the electrokinetic remediation 143 for removing $\mathrm{Zn}, \mathrm{Pb}, \mathrm{V}, \mathrm{Ni}$ and $\mathrm{Cu}$ from dredged marine sediments characterized by high acid 144 buffering capacity, examining two possible electrolyte enhancement strategies. We particularly 145 focused on the effect of sediment $\mathrm{pH}$ on the speciation and mobility of heavy metals and their 146 interactions with the ligands, which affect the mechanisms of transport of contaminants. 


\section{Materials and methods}

\subsection{Sediment collection and analytical methods}

The marine sediments were collected during a survey campaign for dredging activities from the harbour of Isola Maddalena, located in northern Sardinia (Italy). The samples were manually collected by scuba divers from the sea-bottom top layer. Immediately after collection, the material was stored at ambient temperature in closed containers to ensure the stability of physicochemical properties. The whole collected material was then gathered in a single tank and manually homogenized. For the analyses, a subsample was taken from the homogenized sample and it was air-dried at a temperature of $\sim 20{ }^{\circ} \mathrm{C}$ and sieved to remove the fraction above $2 \mathrm{~mm}$ (mostly composed of shells). The particlesize distribution was determined by sieve analysis, up to $74 \mu \mathrm{m}$ fraction. $\mathrm{pH}$ was measured applying the ISO 10390:2005. The acid buffering capacity was determined by titration method using $0.1 \mathrm{M}$ $\mathrm{HCl}$, the base buffering capacity by titration with $0.1 \mathrm{M} \mathrm{NaOH}$. The elemental composition was determined by wavelength dispersive X-ray fluorescence spectrometer (WD-XRF Rigaku Primus II), while the heavy metal content was analysed by means of atomic emission spectrophotometer with inductively coupled plasma source (ICP Perkin Elmer Optima 2000 OES DV) after acid digestion. pH and heavy metal content analysis procedures were applied at least to 3 replicate samples.

\subsection{Experimental electrokinetic setup and test conditions}

The EKR experiments were carried out using an acrylic cell (Fig. 1) with rectangular cross-section, consisting of four principal parts: the sediment compartment, the electrode compartments, the electrolyte solution reservoirs and the power supply. The sediment compartment dimensions were 30 $\mathrm{cm} \times 15 \mathrm{~cm} \times 15 \mathrm{~cm}$, with a volume of $6.75 \mathrm{dm}^{3}$. The weight of the sediment employed in each experiment was about $14 \mathrm{~kg}$. In order to separate the sediments from the electrode compartments, a nylon grid (mesh size $2 \mathrm{~mm}$ ) and filter paper were used. The sediment sample was placed in the electrokinetic cell in layers and a static pressure of $40 \mathrm{~g} / \mathrm{cm}^{2}$ was applied for 24 hours to compact the material. Then it was left in the cell for at least 3 days before starting the tests. The anolyte and catholyte solutions were circulated into the electrolyte reservoirs $\left(4 \mathrm{dm}^{3}\right)$ by a peristaltic pump at a flow rate of $2000 \mathrm{ml} / \mathrm{h}$. The anolyte and catholyte chambers were with free surface and the electrolyte levels in the chambers were kept constant thanks to two respective overflows placed at a fixed height 
of $15 \mathrm{~cm}$ from the bottom of the cell. The sediment height was slightly higher than the electrolyte in 183 the compartments in order to avoid the flow of the electrolytes onto the surface of the sediment.

184 Reservoir solutions were replaced every 2 days. The anode and cathode electrodes were two graphite 185 plates $(15 \mathrm{~cm} \times 15 \mathrm{~cm} \times 0.4 \mathrm{~cm})$. They were connected to a power supply capable of operating under 186 constant voltage (800V, 1.8A max.). Six graphite rod electrodes (diameter $6 \mathrm{~mm}$ ) were placed along 187 the sediments to monitor the voltage drop between five sampling locations ( $S 1$ to $S 5$ ).

188 Four experiments (EXP1 to EXP4) were performed, with different applied voltages and conditioning 189 agents circulated at the electrode compartments. Tap water was used in the unenhanced test (EXP1). 190 To enhance metal removal, a 0.1M solution of citric acid was used in the test EXP2 and 0.1 EDTA 191 solution was used in runs EXP3 and EXP4.

192 The choice of the type and concentration of the enhancement agents was based on a literature review. 193 Kim et al. (2011) have shown that $0.1 \mathrm{M}$ citric acid was considerably effective as processing fluid 194 among other reagents for marine sediment remediation. Andreottola et al. (2010) observed significant 195 heavy metal extraction (up to 81\%, for As) during EKR with 0.2 M EDTA used a in both electrodic 196 chambers. Rozas and Castellote (2012) obtained up to 63\% (for Pb) with 0.1 EDTA dosed at the 197 catholyte and up to $58 \%$ for $\mathrm{Ni}$ and $48 \%$ for $\mathrm{Zn}$ with $0.3 \mathrm{M}$ citric acid dosed in both chambers.

198 The applied voltage gradients (constant DC) were $0.5 \mathrm{~V} / \mathrm{cm}$ (EXP1 to EXP3) and $0.8 \mathrm{~V} / \mathrm{cm}$ (EXP4). 199 The treatment duration was 10 days. A summary of the adopted treatment conditions is reported in 200 Table 1.

201 During the tests, the applied voltage, the electric current and the voltage drop across the monitoring 202 electrodes were recorded automatically by a data logger (Agilent 34970A) with a sampling interval of 2035 minutes. The recorded data was filtered and downsampled prior to representation.

204 The resistivity in each sampling section $S_{i}$ was determined using the following equation:

$$
\rho_{S_{i}}=\frac{V_{i}-V_{i+1}}{I} \frac{A}{d_{i, i+1}}, \quad i=1, \ldots, 5
$$

205 where $\rho_{\mathrm{Si}}(\Omega \mathrm{m})$ is the resistivity of the material in the i-th section, $V_{i}(\mathrm{~V})$ the measured voltage at the 206 i-th electrode, $I(\mathrm{~A})$ the electric current, $A\left(\mathrm{~m}^{2}\right)$ the cell cross section and $d_{\mathrm{i}, \mathrm{i}+1}(\mathrm{~m})$ the distance between 207 the i-th electrode and the next. In addition, the electroosmotic flow was calculated during the 208 experiments by measuring the volume change in the electrode reservoirs and calculating a mass 209 balance. At the end of each experiment, the material was sampled from five locations (S1 to S5) and 210 analysed for $\mathrm{pH}$ and total metal content. Metal concentrations were also measured in the anodic and 211 cathodic chambers. Electrodeposition was evaluated by analysing the electrodes for metal content. 


\subsection{Statistical analysis}

Heavy metal content and $\mathrm{pH}$ results are means of at least three replicates. A statistical evaluation of heavy metal removal was carried out by testing the differences among the means using one-way analysis of variance (ANOVA) test with $95 \%$ confidence interval. Means were compared by honest significant difference (HSD) Tukey's test $(\mathrm{p}<0.05)$. Significantly different values were represented in tables by different lowercase letters.

\section{Results and discussion}

\subsection{Sediment characterization}

The physicochemical characterization of the sediments is reported in Table 2. These results reveal the high acid buffering capacity of the sediment, due to high carbonate content. Additionally, the original $\mathrm{pH}$ was alkaline and the composition mainly sandy-silty.

The heavy metal contamination, although not particularly high, was above the Italian standards for sites intended to residential use, public parks and gardens (Legislative Decree 152/2006) for Zn and $\mathrm{Pb}$.

\subsection{Electrokinetic tests}

EXP1 was performed using tap water as the processing fluid. The applied voltage gradient was kept at a constant value of $0.5 \mathrm{~V} / \mathrm{cm}$ for the entire duration of the treatment (10 days). Fig. 2 shows the profiles of current density as a function of time. At the beginning of the test, current density raised to about $54 \mathrm{~A} / \mathrm{m}^{2}$, then it progressively decreased to a stable range of $9-10 \mathrm{~A} / \mathrm{m}^{2}$. The complementary behaviour with opposite trend was observed for the mean resistivity (Fig. 3). Current decrease (resistivity increase) is a phenomenon observed by many authors (Yuan and Weng 2006; Altaee et al. 2008; De Gioannis et al. 2009). It can be related to gradual depletion of salts (Yu and Neretnieks 1997) and precipitation of chemical species at the cathode in the form of non-soluble and nonconductive compounds (in particular carbonates, oxides and hydroxides) that blocked the pores of the material and prevented the transport of ions.

In fact, during EXP1, the production of $\mathrm{OH}^{-}$ions at the cathode, resulted in a high $\mathrm{pH}$ environment (Fig. 4). The acid front (i.e. the transport of $\mathrm{H}^{+}$ions) from the anode could not propagate due to the high acid buffering capacity of the sediments and the $\mathrm{pH}$ was lowered at $\mathrm{pH} \approx 6$ only in the first section of the sediment (S1). In all other sections the alkaline front (due to $\mathrm{OH}^{-}$produced at the 
cathode) prevailed over the acid front, because the sediment are characterized by a base buffering capacity much lower than the acid buffering capacity (Table 2). For this reason, the alkaline front from the cathode could easily propagate toward the anodic side.

As a consequence of the high $\mathrm{pH}$ developed in the sediments, the precipitation of species occurred in the catholyte and in the sections of the sediments near the cathode. The precipitates were visually detectable and they were collected from the cathode chamber and analysed by X-ray diffraction (Fig. 5). The analyses showed that they were composed by $\mathrm{CaCO}_{3}$ and some hydroxides such as $\mathrm{Ni}(\mathrm{OH})_{2}$ and $\mathrm{Mg}(\mathrm{OH})_{2}$.

253 The slight decrease of the $\mathrm{pH}$ near the cathode (section S5), compared to the other sections (S2 to S4) 254 at the end of EXP1 can be explained by the release of $\mathrm{H}^{+}$occurring during $\mathrm{CaCO}_{3}$ formation, as 255 shown in the following reaction:

$$
\mathrm{Ca}^{2+}+\mathrm{HCO}_{3}{ }^{-} \rightarrow \mathrm{CaCO}_{3}+\mathrm{H}^{+}
$$

257 The precipitation of these species also resulted in high resistivity zones near the cathode (Fig. 6). 258 Resistivity monitoring along the sediment during the experiments proved to be an effective tool for detecting such phenomena over time. As shown in Fig. 6, a sharp local increase in resistivity (sections $S 4$ and $S 5$ ) can be identified after 6 days of treatment and it corresponds to the instant of formation of precipitates.

To achieve acidic $\mathrm{pH}$ in the sediments and to prevent carbonate and hydroxide precipitation, a $0.1 \mathrm{M}$ citric acid solution was used as the processing fluid in EXP2. Citric acid, other than being a weak acid, is known to exhibit moderate chelating properties associated to a very low amount of environmental impact and negative side effects. The voltage gradient $(0.5 \mathrm{~V} / \mathrm{cm})$ and the treatment duration (10 days) were kept unchanged from the previous experiment. The current density (Fig. 2) followed the same trend as in the unenhanced test (EXP1) but no precipitates were detected and no sharp variation of local resistivity were observed. The mean resistivity (Fig. 3), in fact, smoothly raised during the experiment. The increase in resistivity is probably due to the salt depletion mechanism alone. The citric acid depolarized the cathode reaction, neutralizing $\mathrm{OH}^{-}$ions and preventing the formation of precipitates near the cathode. However, the $\mathrm{pH}$ values significantly changed from the initial value only near the electrodes (Fig. 4), due to the high buffering capacity of the sediments. The $\mathrm{pH}$ values through most of the sediments remained substantially higher $(\mathrm{pH}>6)$ than the $\mathrm{pH}$ values measured in the reservoir $(\mathrm{pH}<4)$. The sediment $\mathrm{pH}$ was not low enough to achieve the solubilisation of metal species and/or salt dissolution and the experiment resulted in no significant heavy metals removal. As a result of the $\mathrm{pH}$ decrease, a considerable reduction of the electroosmotic flow was observed during EXP2 compared to EXP1 (Fig. 7). A decrease in pH results in an alteration of the zeta potential of the sediment particles (i.e. a reduction of the magnitude of the 
electrical charge at the double layer) which causes a reduction of the electroosmotic flow (Vane and Zang 1997).

On the basis of the results of EXP1 (tap water) and EXP2 (citric acid), EDTA was used in runs EXP3 and EXP4 as conditioning agent with the purpose of solubilising the contaminants without attempting to reduce the $\mathrm{pH}$ of the sediments. EDTA is a strong chelating agent that promotes heavy metal removal by forming anionic EDTA-metal complexes, mainly in the form Me-EDTA ${ }^{2-}$ (De Gioannis et al. 2009). A solution of EDTA (pure acid) and sodium hydroxide at $\mathrm{pH} 8.0$ was prepared in order to promote the development of a basic environment, leading to an increase of thermodynamic stability of the metal complexes (Tsang et al. 2012) and of the electroosmotic flow. In EXP3 the applied voltage gradient was $0.5 \mathrm{~V} / \mathrm{cm}$, while in EXP4 it was raised to an average of $0.8 \mathrm{~V} / \mathrm{cm}$. During EXP4 in fact, the applied voltage gradient was initially set to $1 \mathrm{~V} / \mathrm{cm}$, but after about 5 days it was necessary to change it to about $0.7 \mathrm{~V} / \mathrm{cm}$ in order to avoid exceeding the instrumental limits for excessive electric current. Therefore, the (calculated) average voltage gradient during run EXP4 was $0.8 \mathrm{~V} / \mathrm{m}$. Compared to the previous tests, the electric current in the EDTA tests was more sustained (Fig. 2). This is related to the increase of the applied voltage and to the presence of $\mathrm{Na}^{+}$ions produced by the dissociation of sodium hydroxide during the preparation of the EDTA solution. The electroosmotic flow (Fig. 7) was considerably higher than in EXP1 and EXP2, as expected. Compared to the previous tests, the EDTA solution was effective to cause significant heavy metal migration (Fig. 8). Heavy metals moved toward the anode by electromigration, in the form of soluble EDTA-metal complexes 298 as they were found in solution in the anode compartment. In the anode compartment the presence of $299 \mathrm{H}^{+}$ions caused the EDTA to precipitate (in the form of $\mathrm{H}_{4}$-EDTA), with a reduced amount of chelate 300 available for heavy metal complexation, as detected by XRD analysis of the solid precipitates 301 collected from the anodic compartment.

302 For each experiment the metal distribution at the end of the experiments was determined and a mass 303 balance was calculated to check the error in the determination of the concentrations both in the 304 sediments and in the electrolyte. When precipitation occurred, the precipitates were also analysed and 305 included in the mass balance. Moreover, the electrodes were analysed for metal content and negligible 306 amount of metals was found on their surfaces. The highest metal content was detected at the end of 307 EXP1 and the results are reported in Table 3. However the metal masses on the electrodes are very 308 small compared to the mass measured in the sediment or found in the electrolytes (either in solution or 309 precipitated).

310 The calculated mass balance errors (values are reported in the last category "Error" in Fig. 8) ranged 311 from $1 \%$ to $10 \%$. In general, the results are consistent even when the mass balance error is significant. 
312 The removal efficiencies of the treatments were calculated and they are reported in Table 4 . The statistical differences between the treatments were analysed with one-way ANOVA and indicated by different letters in each row when the difference is significant (at 95\% confidence interval).

The run EXP1 resulted in no significant removal of heavy metals, except for Ni (20.8\%). The enhancement with citric acid did not produce any improvement in metal extraction. On the contrary, with EDTA the removal efficiencies were generally higher. In EXP4 a significant improvement compared to the other runs was observed, in fact the overall heavy metal removal ranged from $9.5 \%$ to $27 \%$ (Table 4).

To evaluate the possible speciation of the heavy metals as a function of the $\mathrm{pH}$ conditions, numerical simulations were carried out with PHREEQC-3 geochemical reaction code (Parkhurst and Appelo 2013). The graphical representations were realised with the free software PhreePlot, which automatically does multiple PHREEQC calculations for each $\mathrm{pH}$ value. In particular, two heavy metals $(\mathrm{Ni}$ and $\mathrm{Pb})$ were analysed, under the assumption that the concentration of metals in solution is $20 \%$ of the total metal concentration in the sediment. Three conditions were simulated for each metal. In the first condition, the speciation was obtained assuming that the electrolyte is composed only by $0.3 \mathrm{M} \mathrm{NaCl}$. This value was assumed as an estimation of the mean $\mathrm{NaCl}$ concentration in the electrolytes during the treatment. This simulation aims to reproduce the unenhanced experiment (EXP1). A second scenario was simulated adding 0.1M EDTA in the initial conditions for calculation (with the purpose to reproduce EXP2 and EXP3 conditions), with same $\mathrm{NaCl}$ content. In the third scenario the simulations were performed with $0.1 \mathrm{M}$ Citrate. All simulations were set up with $\mathrm{O}_{2}$ saturation conditions and $25^{\circ} \mathrm{C}$ temperature. The result of the calculations are reported in Fig. 9. Other minor complexes $(<5 \%)$ may form but they are not shown in the figures.

Speciation computations may be used to better interpret the observed removal rates. In general, Ni removal is higher than the other studied metals, with the exception of citric acid enhancement. The higher rate might be due to the distribution of metals among the bonding fractions of the sediment. In the case of $\mathrm{Ni}$, a possible higher exchangeable fraction may be present, which explains the higher removal compared to the other metal. The difference in the removal between the citric acid experiment (EXP2) and the other experiments can be attributed to the different mobility of the formed metal complexes. In fact, without any enhancement $\mathrm{Ni}^{2+}$ is predominant in the $\mathrm{pH}$ range 2-8 (Fig. 9a). This form of Ni is highly mobile and it moves toward the cathode, as observed during EXP1. Most of the $\mathrm{Ni}$ is found in the catholyte, though it was in precipitated $\mathrm{Ni}(\mathrm{OH})_{2}$ form (XRD analyses). The high mass balance error for $\mathrm{Ni}$ can be explained by possible experimental errors made during the sampling and determination of the amount of Ni precipitates. With EDTA, the main form at the observed $\mathrm{pH}$ range is Ni-EDTA ${ }^{2-}$ which has higher mobility than Ni-Citrate- because of the higher charge number. This can explain why the removal with citric acid is lower. The low removal can also be due to the 
347 low stability of the complexes formed with citric acid (Kim et al. 2011). Ni-Citrate ${ }^{-}$and $\mathrm{Ni}^{2+}$ may coexist and move in the opposite directions, causing possible alternating movements.

ANOVA analysis also shows that three groups exist for Ni results (Table 4). The first group, composed by EXP2 and EXP3 is characterized by low complex mobility due to low Ni-Citrate mobility and lower Ni-EDTA ${ }^{2-}$ mobility (compared to $\mathrm{Ni}^{2+}$ ), respectively. EXP3 is associated to EXP1 because $\mathrm{Ni}^{2+}$ has higher mobility but the removal is limited by the adverse $\mathrm{pH}$ environment which induce precipitation. Then, in EXP4 higher mobility is observed, due to the increase of the applied voltage gradient.

355 Concerning $\mathrm{Pb}$ and $\mathrm{Zn}$, the observed removal is lower than the other metals and ANOVA analysis 356 shows that there are not significant differences between the treatments (Table 4). For Pb, the lower 357 amount of metal found in the catholyte at the end of EXP1 compared to Ni may be explained by its 358 tendency to form mostly $\mathrm{PbCl}^{+}$instead of $\mathrm{Pb}^{2+}$ (Fig. 9d) which has lower mobility and $\mathrm{PbCl}_{2}$ which 359 can be transported only by the electroosmotic flow. In fact, from Fig. 8a it can be observed that during $360 \mathrm{EXP1} \mathrm{Pb}$ started to migrate toward the cathode but it remained mostly in the middle section of the 361 sediment (S3). The removal with EDTA is slightly higher but there is no significant improvement 362 when changing the conditions of treatment.

363 The $\mathrm{Cu}$ behaviour during EXP1 (very low removal) is the consequence of the high tendency of $\mathrm{Cu}$ to 364 precipitate at lower $\mathrm{pH}$ compared to the other analysed metals. In fact, it starts to precipitate as $365 \mathrm{Cu}_{2} \mathrm{Cl}(\mathrm{OH})_{3}$ at a $\mathrm{pH}$ lower than 6. Regarding the citric acid experiment, the observed low mobility of $366 \mathrm{Cu}$ cannot be explained by the simulated speciation and other factors may play a more important role. 367 The higher removal observed with EDTA instead can be justified by the high mobility of $368 \mathrm{CuOH}(\mathrm{EDTA})^{3-}$ at the working $\mathrm{pH}$, or by higher availability of $\mathrm{Cu}$ for chelation.

369 Overall, the best results were obtained for $\mathrm{Ni}, \mathrm{Cu}$ and $\mathrm{V}$ with EDTA and at $0.8 \mathrm{~V} / \mathrm{m}$, while no 370 significant differences between the treatments were observed for $\mathrm{Zn}$ and $\mathrm{Pb}$.

371 The unenhanced experiment showed that metal migration occur mostly toward the cathode, as some 372 amount of metal was found in the catholyte, but the $\mathrm{OH}^{-}$ions produced at the cathode had a strong 373 impact on the $\mathrm{pH}$ of the sediment and the high alkaline conditions caused the precipitation of the 374 species, e.g. $\mathrm{Ni}(\mathrm{OH})_{2}$, and prevented further metal extraction.

375 The use of citric acid resulted in very low metal removal, possibly because the amount of acid used 376 was not enough to form stable complexes.

377 It can be concluded that the use of EDTA resulted in a more favourable removal of metals. Under this 378 condition, electromigration was the main process responsible for the transport of metals in the form of 379 negatively charged EDTA-metal complexes from the cathode to the anode. Conversely, the transport 
by electroosmosis was less prominent, since very low concentrations of heavy metals were found in the catholyte.

\section{Conclusions}

Four laboratory scale electrokinetic experiments were carried out to extract heavy metals from 385 dredged marine sediments. The experimental study revealed that the electrokinetic remediation was 386 affected both by the intensity of the applied electric field and the type of conditioning agent used at 387 the electrode compartments. Tap water, $0.1 \mathrm{M}$ citric acid and $0.1 \mathrm{M}$ ethylenediaminetetraacetic acid 388 (EDTA) solutions were used, respectively, as processing fluids. The experiments were performed 389 under $0.5 \mathrm{~V} / \mathrm{cm}$ (EXP1 to EXP3) and $0.8 \mathrm{~V} / \mathrm{cm}$ (EXP4) constant voltage gradient (DC), respectively, 390 with treatment duration of 10 days. The unenhanced test (EXP1) and the citric acid enhanced test 391 (EXP2) did not result in an appreciable mobilization of the contaminants. The acidification of the 392 sediments was not achieved due to the high acid buffering capacity of the medium. During EXP1 the 393 alkaline front migrated faster than the acid front because of the greater sediment buffering capacity 394 towards acids rather than bases. As a consequence a high $\mathrm{pH}$ developed in the sediments causing the 395 precipitation of $\mathrm{CaCO}_{3}$ and metal hydroxides which hindered the transport processes. Sediment 396 resistivity monitoring during the experiments proved to be an effective tool for detecting such 397 phenomena, identified by a sharp local increase in resistivity over time. The use of EDTA (EXP3 and 398 EXP4) and the increase of voltage gradient to $0.8 \mathrm{~V} / \mathrm{cm}$ (EXP4) significantly improved heavy metal 399 removal. We found that with the addition of EDTA the dominant mechanism of removal was 400 electromigration, which promoted the transport of EDTA-metal complexes toward the anode. The 401 removal efficiencies were $9.5 \%$ for $\mathrm{Zn}, 9.8 \%$ for $\mathrm{Pb}, 17.4 \%$ for $\mathrm{V}, 24.3 \%$ for $\mathrm{Ni}$ and $27.3 \%$ for $\mathrm{Cu}$. 402 Therefore, EDTA-enhanced electrokinetic remediation can be used to remediate dredged marine 403 sediments with high acid buffering capacity. The removal performance can be further improved by 404 choosing appropriate electric field intensity and/or longer remediation time.

\section{Acknowledgements}

This work was financially supported by the Italian Ministry of Education, University and Research. 409 The authors are thankful to Sergio Lombardi of SGL Group for providing SIGRAFLEX® 410 graphite foils employed as electrodes. The authors are thankful to three anonymous reviewers, whose comments and suggestions helped us to significantly improve the quality of the manuscript. 
Acar YB, Alshawabkeh AN (1993) Principles of electrokinetic remediation. Environ Sci Technol 27:2638-2647. doi: 10.1021/es00049a002

Acar YB, Gale RJ, Alshawabkeh AN, et al (1995) Electrokinetic remediation: Basics and technology status. J Hazard Mater 40:117-137. doi: 10.1016/0304-3894(94)00066-P

Altaee A, Smith R, Mikhalovsky S (2008) The feasibility of decontamination of reduced saline sediments from copper using the electrokinetic process. J Environ Manage 88:1611-8. doi: 10.1016/j.jenvman.2007.08.008

Ammami MT, Portet-Koltalo F, Benamar A, et al (2015) Application of biosurfactants and periodic voltage gradient for enhanced electrokinetic remediation of metals and PAHs in dredged marine sediments. Chemosphere 125:1-8. doi: 10.1016/j.chemosphere.2014.12.087

Amrate S, Akretche DE (2005) Modeling EDTA enhanced electrokinetic remediation of lead contaminated soils. Chemosphere 60:1376-83. doi: 10.1016/j.chemosphere.2005.02.021

Andreottola G, Bonomo L, De Gioannis G, et al (2010) Lab-scale feasibility tests for sediment treatment using different physico-chemical techniques. J Soils Sediments 10:142-150. doi: 10.1007/s11368-009-0150-5

Colacicco A, De Gioannis G, Muntoni A, et al (2010) Enhanced electrokinetic treatment of marine sediments contaminated by heavy metals and PAHs. Chemosphere 81:46-56. doi: 10.1016/j.chemosphere.2010.07.004

De Gioannis G, Muntoni A, Polettini A, Pomi R (2009) Electrokinetic Treatment of Contaminated Marine Sediments. In: Electrochemical Remediation Technologies for Polluted Soils, Sediments and Groundwater, C. Cameselle and K. R. Reddy. John Wiley \& Sons, Inc., pp 149-177

Dubois V, Zentar R, Abriak N-E, Grégoire P (2011) Fine sediments as a granular source for civil engineering. Eur J Environ Civ Eng 15:137-166. doi: 10.1080/19648189.2011.9693315

Gidarakos E, Giannis A (2006) Chelate agents enhanced electrokinetic remediation for removal cadmium and zinc by conditioning catholyte pH. Water Air Soil Pollut 172:295-312. doi: 10.1007/s11270-006-9080-7

Grundl T, Reese C (1997) Laboratory study of electrokinetic effects in complex natural sediments. J Hazard Mater 55:187-201. doi: 10.1016/S0304-3894(97)00012-5

Hahladakis JN, Lekkas N, Smponias A, Gidarakos E (2014) Sequential application of chelating agents and innovative surfactants for the enhanced electroremediation of real sediments from toxic metals and PAHs. Chemosphere 105:44-52. doi: 10.1016/j.chemosphere.2013.11.022

Hansen HK, Rojo A, Ottosen LM (2005) Electrodialytic remediation of copper mine tailings. J Hazard Mater 117:179-83. doi: 10.1016/j.jhazmat.2004.09.014

Iannelli R, Masi M, Ceccarini A, et al (2015) Electrokinetic remediation of metal-polluted marine sediments: experimental investigation for plant design. Electrochim Acta. doi: 10.1016/j.electacta.2015.04.093 
Kim K-J, Kim D-H, Yoo J-C, Baek K (2011) Electrokinetic extraction of heavy metals from dredged marine sediment. Sep Purif Technol 79:164-169. doi: 10.1016/j.seppur.2011.02.010

Kim W-S, Kim S-O, Kim K-W (2005) Enhanced electrokinetic extraction of heavy metals from soils assisted by ion exchange membranes. J Hazard Mater 118:93-102. doi: 10.1016/j.jhazmat.2004.10.001

Lageman R (1993) Electroreclamation. Applications in the Netherlands. Environ Sci Technol 27:2648-2650. doi: 10.1021/es00049a003

Lestan D, Luo C, Li X (2008) The use of chelating agents in the remediation of metal-contaminated soils: a review. Environ Pollut 153:3-13. doi: 10.1016/j.envpol.2007.11.015

Mulligan CN, Yong RN, Gibbs BF (2001) Remediation technologies for metal-contaminated soils and groundwater: an evaluation. Eng Geol 60:193-207. doi: 10.1016/S0013-7952(00)00101-0

Parkhurst DL, Appelo C a. J (2013) Description of Input and Examples for PHREEQC Version 3 A Computer Program for Speciation , Batch-Reaction , One-Dimensional Transport , and Inverse Geochemical Calculations Chapter 43 of. In: U.S. Geological Survey Techniques and Methods, book 6. U.S. Geological Survey (USGS), p 497

Peng J-F, Song Y-H, Yuan P, et al (2009) The remediation of heavy metals contaminated sediment. J Hazard Mater 161:633-40. doi: 10.1016/j.jhazmat.2008.04.061

Pool W (1989) A process for electroreclamation of soil material, an electric current system for application of the process, and an electrode housing for use in the electric current system. European Patent EP0312174A1.

Pool W (1996) Process for electroeclamation of soil material. US Patent 5,589,056.

Probstein RF, Hicks RE (1993) Removal of Contaminants from Soils by Electric Fields. Sci 260 :498-503. doi: 10.1126/science.260.5107.498

Reddy K, Ala P (2006) Electrokinetic Remediation of Contaminated Dredged Sediment. J ASTM Int $3: 14$.

Reddy KR, Cameselle C (2009) Electrochemical Remediation Technologies for Polluted Soils, Sediments and Groundwater. Wiley

Rozas F, Castellote M (2012) Electrokinetic remediation of dredged sediments polluted with heavy metals with different enhancing electrolytes. Electrochim Acta 86:102-109. doi: 10.1016/j.electacta.2012.03.068

Sillanpää M, Oikari A (1996) Assessing the impact of complexation by EDTA and DTPA on heavy metal toxicity using microtox bioassay. Chemosphere 32:1485-1497. doi: 10.1016/00456535(96)00057-4

Tsang DCW, Lo IMC, Surampalli RY (2012) Chelating Agents for Land Decontamination Technologies. American Society of Civil Engineers

Vane LM, Zang GM (1997) Effect of aqueous phase properties on clay particle zeta potential and electro-osmotic permeability: Implications for electro-kinetic soil remediation processes. J Hazard Mater 55:1-22. doi: 10.1016/S0304-3894(97)00010-1 
Virkutyte J, Sillanpää M, Latostenmaa P (2002) Electrokinetic soil remediation — critical overview. Sci Total Environ 289:97-121. doi: 10.1016/S0048-9697(01)01027-0

Voglar D, Lestan D (2013) Pilot-scale washing of Pb, Zn and Cd contaminated soil using EDTA and process water recycling. Chemosphere 91:76-82. doi: 10.1016/j.chemosphere.2012.12.016

Wong JSH, Hicks RE, Probstein RF (1997) EDTA-enhanced electroremediation of metalcontaminated soils. J Hazard Mater 55:61-79. doi: 10.1016/S0304-3894(97)00008-3

Yeung AT (2011) Milestone developments, myths, and future directions of electrokinetic remediation. Sep Purif Technol 79:124-132. doi: 10.1016/j.seppur.2011.01.022

Yeung AT, Gu Y-Y (2011) A review on techniques to enhance electrochemical remediation of contaminated soils. J Hazard Mater 195:11-29. doi: 10.1016/j.jhazmat.2011.08.047

Yu J-W, Neretnieks I (1997) Theoretical evaluation of a technique for electrokinetic decontamination of soils. J Contam Hydrol 26:291-299. doi: 10.1016/S0169-7722(96)00076-9

Yuan C, Weng C-H (2006) Electrokinetic enhancement removal of heavy metals from industrial wastewater sludge. Chemosphere 65:88-96. doi: 10.1016/j.chemosphere.2006.02.050

Zhou D-M, Deng C-F, Cang L, Alshawabkeh AN (2005) Electrokinetic remediation of a Cu-Zn contaminated red soil by controlling the voltage and conditioning catholyte $\mathrm{pH}$. Chemosphere 61:519-27. doi: 10.1016/j.chemosphere.2005.02.055 


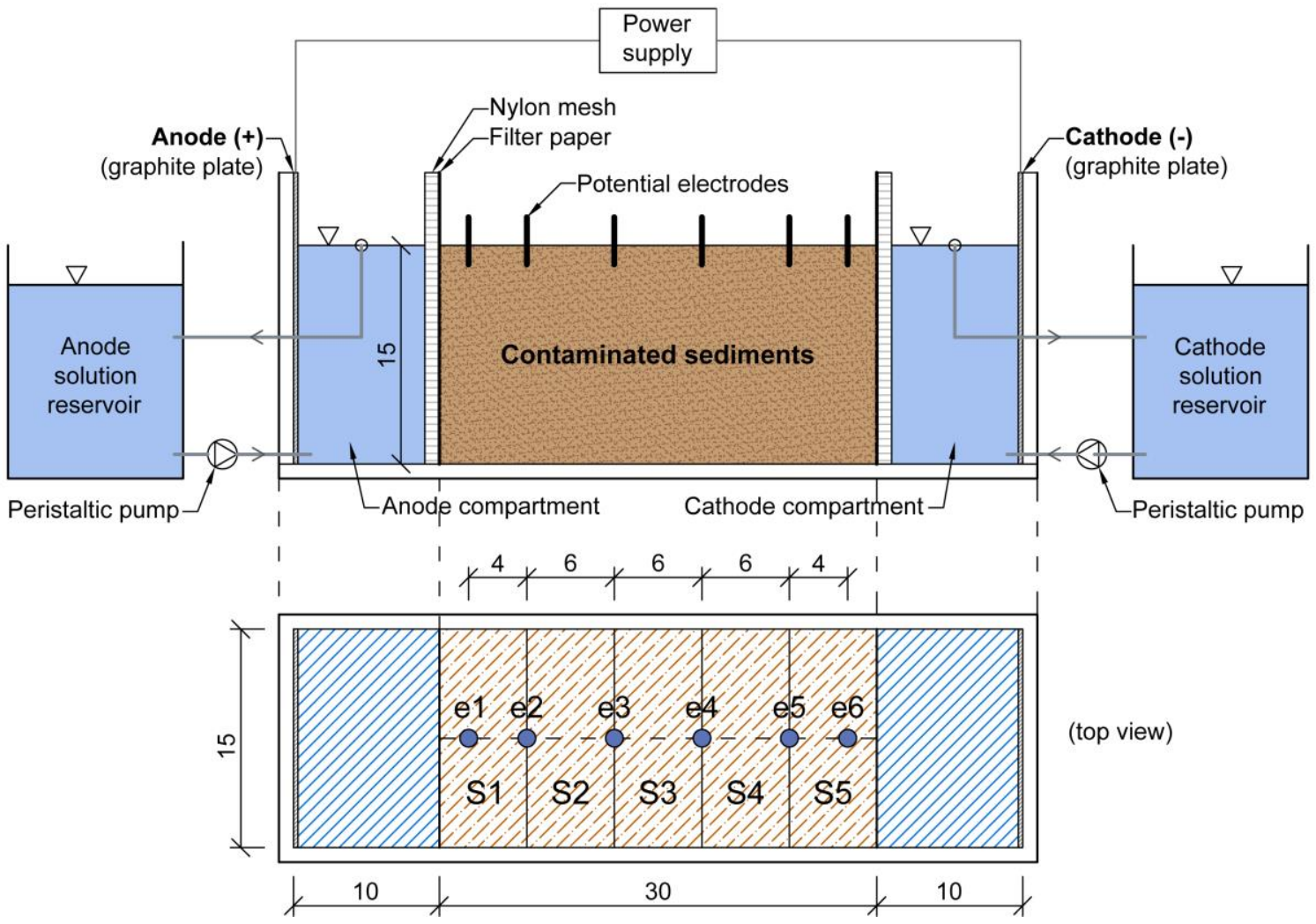

Fig. 1 Schematic diagram of the experimental electrokinetic cell. Dimensions are in cm. Monitoring (potential) electrodes are labelled from $e 1$ to $e 6$. The material is divided into five equal sections (sampling locations), from S1 to S5 


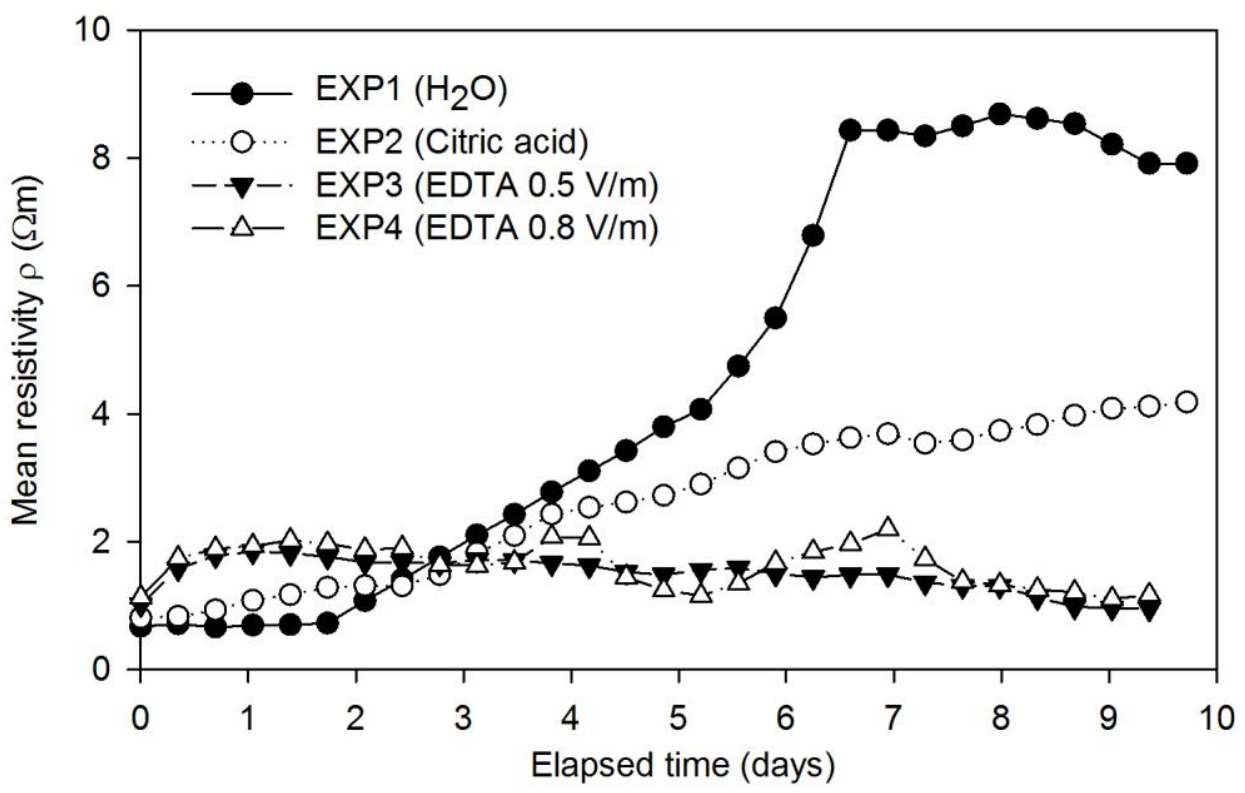

Fig. 3 Mean sediment resistivity change during the experiments 


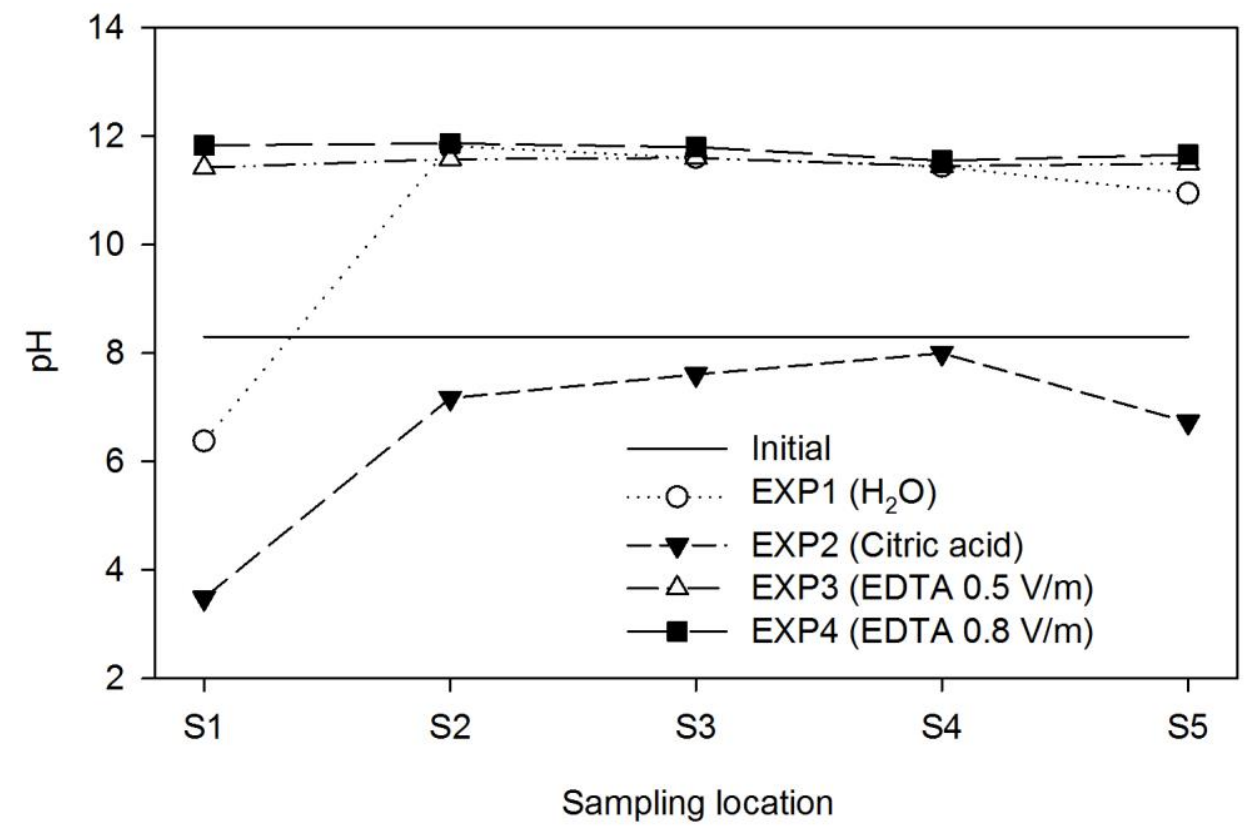

Fig. $4 \mathrm{pH}$ profiles along the cell at the beginning and at the end of the experiments. Maximum $\mathrm{pH}$ standard deviation over at least three replicate samples is \pm 0.1 (except for untreated sample \pm 0.2 )

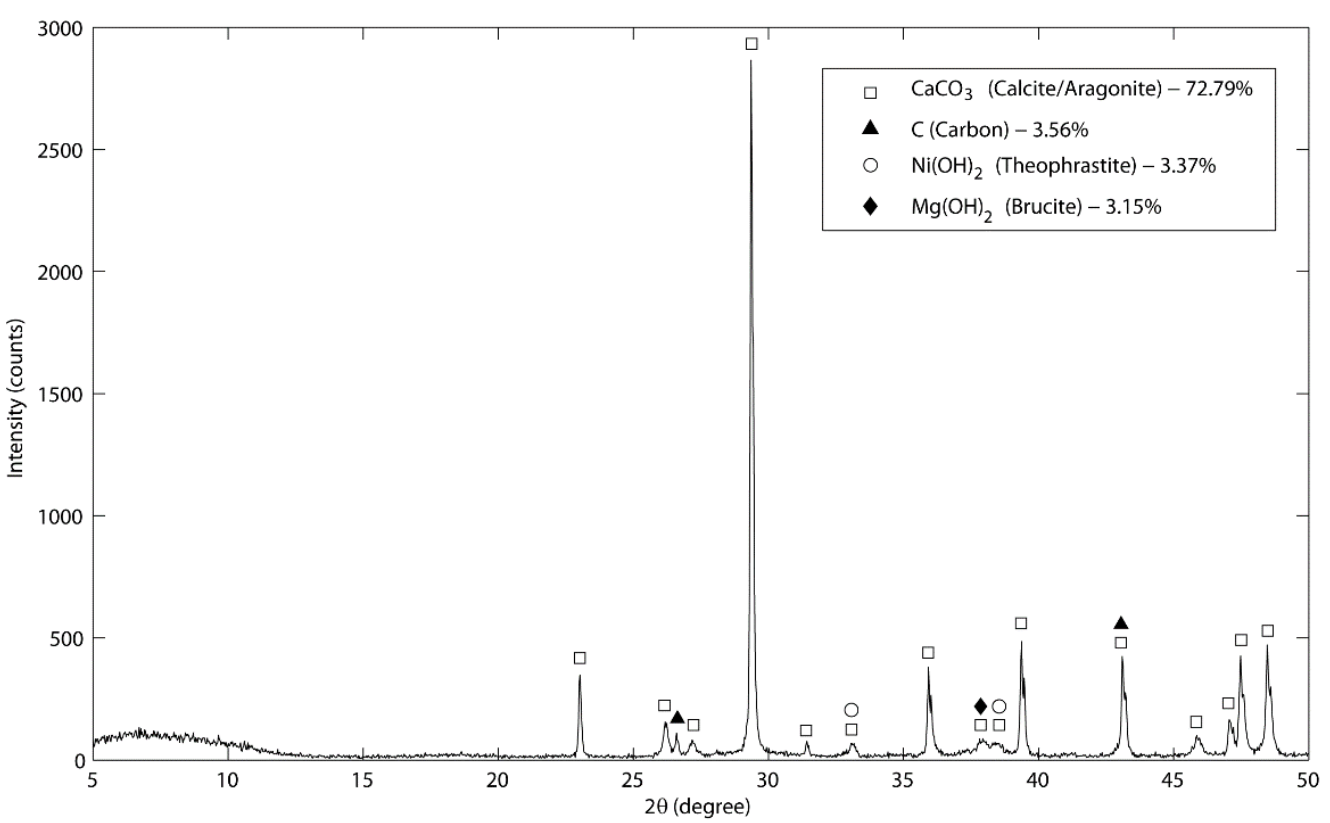

Fig. 5 X-Ray diffraction (XRD) analysis of the solid precipitates found in the cathode compartment at the end of experiment EXP1 


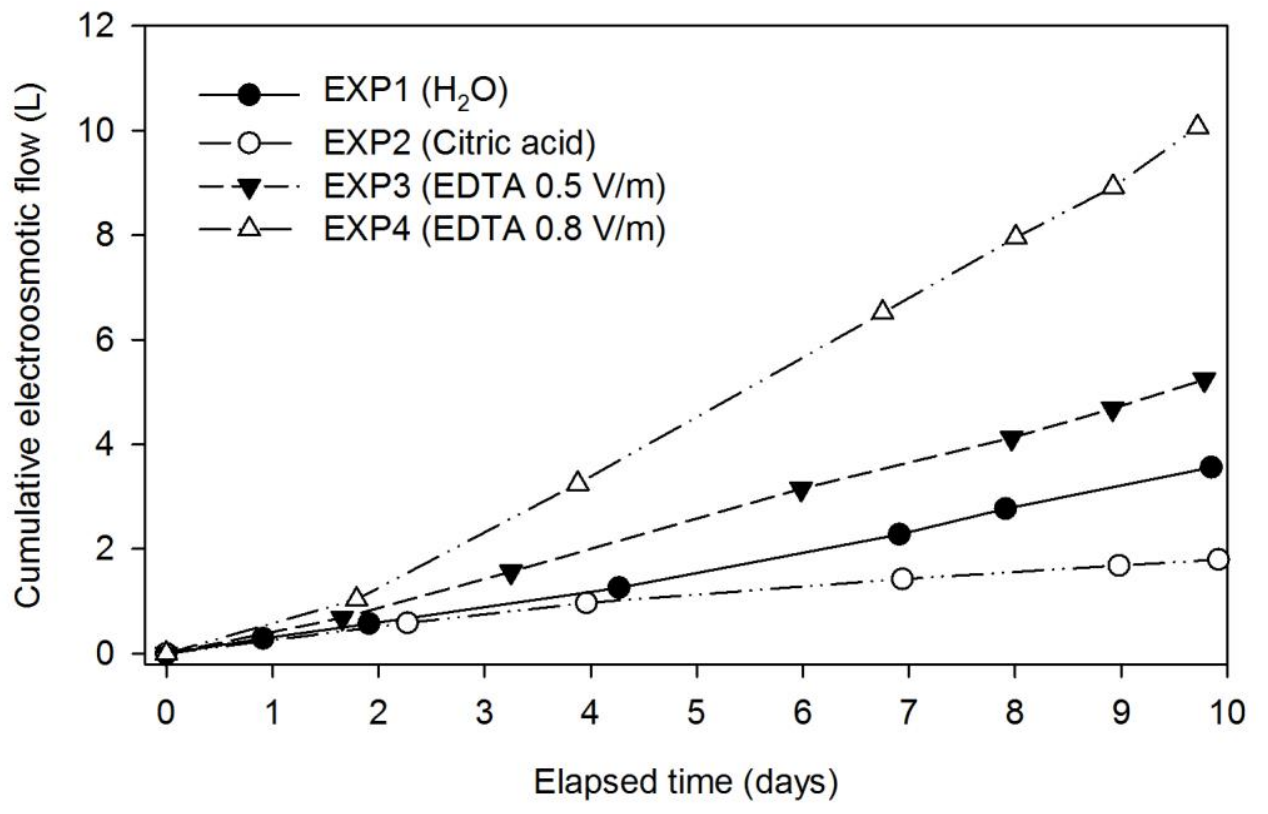

Fig. 7 Cumulative electroosmotic volume during the experiments 


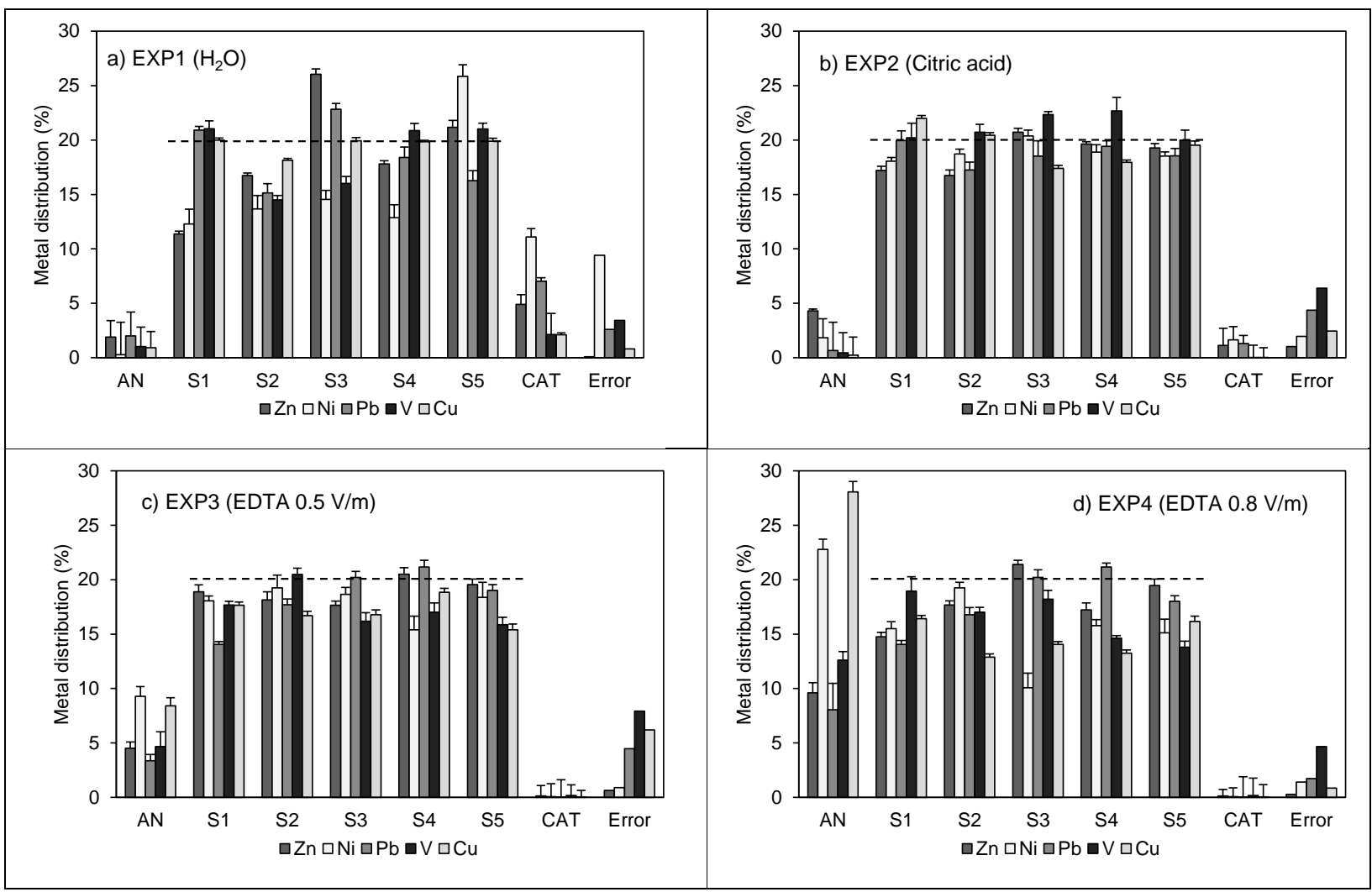

Fig. 8 Distribution of heavy metals (\% of the total mass) in the sediment and electrolytes at the beginning and at the end of the treatments. The dashed line indicates the initial distribution. Before treatment, heavy metals are equally distributed in five sections (20\% of the total metal mass in each section). Error bars represent the normalized standard deviation over 3 replicate samples. The last category "Error" refers to the mass balance error between the initial and final metal distribution 

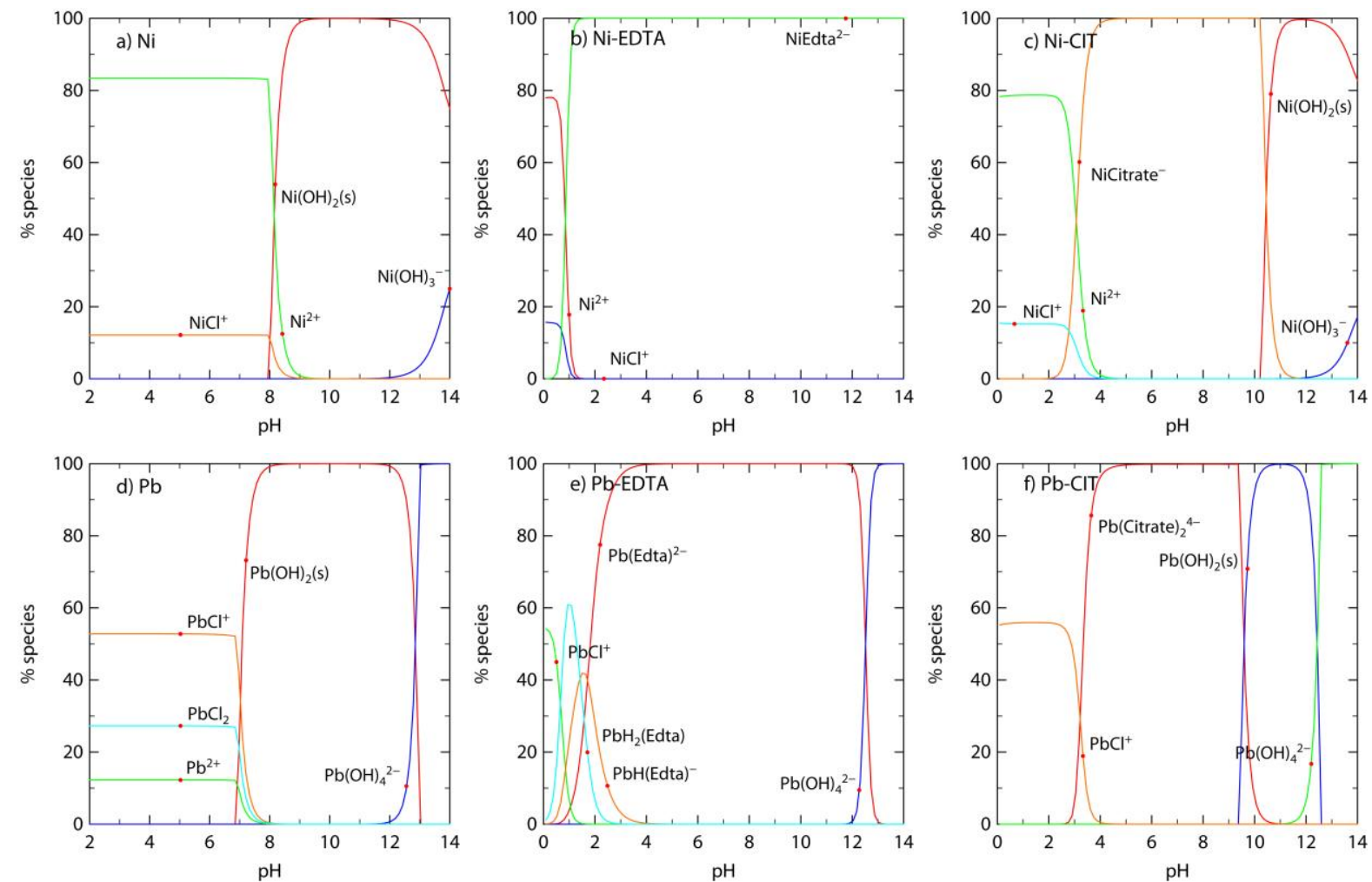

Fig. 9 Simulated metal speciation (aqueous and precipitates) as a function of $\mathrm{pH}$. a) Ni distribution in water, b) Ni distribution in presence of EDTA, c) Ni in presence of citric acid. d), e) and f) for $\mathrm{Pb}$.

Calculation were performed with USGS PHREEQC-3 and PhreePlot. Conditions: metal concentrations in solution assumed $20 \%$ of the total sediment metal content. $\mathrm{NaCl} 0.3 \mathrm{M}$, EDTA and Citrate $0.1 \mathrm{M}$ 
Table 1 Experimental conditions for the electrokinetic treatment

\begin{tabular}{lllll}
\hline Test & $\begin{array}{l}\text { Duration } \\
\text { (days) }\end{array}$ & $\begin{array}{l}\text { Applied voltage } \\
\text { gradient }(\mathrm{V} / \mathrm{cm})\end{array}$ & Anolyte & Catholyte \\
\hline EXP1 & 10 & 0.5 & Tap water & Tap water \\
EXP2 & 10 & 0.5 & Citric acid 0.1M & Citric acid 0.1M \\
EXP3 & 10 & 0.5 & EDTA 0.1M & EDTA 0.1M \\
EXP4 & 10 & 0.8 & EDTA 0.1M & EDTA 0.1M
\end{tabular}


Table 2 Physicochemical properties of the sediments. $\mathrm{pH}$ and metal content analysis were applied to 3 replicate samples (average value \pm standard deviation)

\begin{tabular}{|c|c|}
\hline \multicolumn{2}{|l|}{ Physicochemical properties } \\
\hline pH (ISO 10390:2005) & $8.3 \pm 0.2$ \\
\hline \multicolumn{2}{|l|}{ Buffering capacity } \\
\hline $\mathrm{pH}=3 \pm 0.2\left(\mathrm{~mol} \mathrm{H}^{+} / \mathrm{kg}\right)$ & 1.76 \\
\hline $\mathrm{pH}=13 \pm 0.2\left(\mathrm{~mol} \mathrm{OH}^{-} / \mathrm{kg}\right)$ & 0.74 \\
\hline Porosity $(\%)$ & 42 \\
\hline \multicolumn{2}{|l|}{ Particle size distribution } \\
\hline Diameter $(\mathrm{mm})$ & (\% d.w.) \\
\hline $2.0-1.0$ & 6.80 \\
\hline $1.0-0.5$ & 12.70 \\
\hline $0.5-0.25$ & 10.39 \\
\hline $0.25-0.125$ & 33.01 \\
\hline $0.125-0.074$ & 21.91 \\
\hline$<0.074$ & 15.19 \\
\hline Elemental composition & $(\%)$ \\
\hline $\mathrm{SiO}_{2}$ & 67.56 \\
\hline $\mathrm{CaO}$ & 15.27 \\
\hline $\mathrm{Al}_{2} \mathrm{O}_{3}$ & 5.13 \\
\hline $\mathrm{Fe}_{2} \mathrm{O}_{3}$ & 3.08 \\
\hline $\mathrm{K}_{2} \mathrm{O}$ & 2.55 \\
\hline $\mathrm{Cl}$ & 2.00 \\
\hline $\mathrm{Na}_{2} \mathrm{O}$ & 1.37 \\
\hline $\mathrm{MgO}$ & 0.96 \\
\hline S & 0.95 \\
\hline Metal content & $(\mathrm{mg} / \mathrm{kg})$ \\
\hline $\mathrm{Fe}$ & $5895 \pm 81.0$ \\
\hline $\mathrm{Zn}$ & $273.2 \pm 4.41$ \\
\hline $\mathrm{Ni}$ & $16.36 \pm 1.09$ \\
\hline $\mathrm{Cr}$ & $12.23 \pm 0.53$ \\
\hline $\mathrm{Pb}$ & $144.5 \pm 6.99$ \\
\hline Al & $2044 \pm 42.1$ \\
\hline $\mathrm{Cu}$ & $92.06 \pm 0.37$ \\
\hline V & $11.5 \pm 0.77$ \\
\hline
\end{tabular}


Table 3 Mass of metal found on the electrode surfaces at the end of EXP1

\begin{tabular}{lrr}
\hline & Anode & Cathode \\
\hline Zn (mg) & 0.05 & 0.21 \\
Ni (mg) & 0.01 & 0.04 \\
Pb (mg) & 0.09 & 0.15 \\
V (mg) & 0.01 & 0.05 \\
Cu (mg) & 0.04 & 0.58 \\
\hline
\end{tabular}

Table 4 Removal efficiencies of heavy metal after electrokinetic treatments. Values are the mean over 5703 replicate samples. Different letters in each row indicate significant differences (ANOVA) between $571 \quad$ the treatments $(\mathrm{p}<0.05, \mathrm{n}=3)$

\begin{tabular}{llllll}
\hline & \multicolumn{5}{c}{ Removal (\%) } \\
\cline { 2 - 6 } Test & $\mathrm{Zn}$ & $\mathrm{Ni}$ & $\mathrm{Pb}$ & $\mathrm{Cu}$ & $\mathrm{V}$ \\
\hline EXP1 & $6.9 \pm 1.9 \mathrm{a}$ & $20.8 \pm 5.7 \mathrm{bc}$ & $6.4 \pm 3.6 \mathrm{a}$ & $2.2 \pm 1.1 \mathrm{a}$ & $6.5 \pm 2.9 \mathrm{a}$ \\
EXP2 & $6.4 \pm 1.9 \mathrm{a}$ & $5.4 \pm 1.9 \mathrm{a}$ & $6.3 \pm 4.2 \mathrm{a}$ & $2.7 \pm 1.4 \mathrm{a}$ & $-5.9 \pm 4.5 \mathrm{c}$ \\
EXP3 & $5.3 \pm 2.9 \mathrm{a}$ & $10.3 \pm 4.9 \mathrm{ab}$ & $7.8 \pm 2.5 \mathrm{a}$ & $14.6 \pm 2.0 \mathrm{~b}$ & $12.8 \pm 3.2 \mathrm{ab}$ \\
EXP4 & $9.5 \pm 2.4 \mathrm{a}$ & $24.3 \pm 4.3 \mathrm{c}$ & $9.8 \pm 2.6 \mathrm{a}$ & $27.3 \pm 1.7 \mathrm{c}$ & $17.4 \pm 3.4 \mathrm{~b}$ \\
\hline
\end{tabular}


In the present document, a detailed list of responses to the questions and comments received from the reviewers is presented. The manuscript was thoroughly revised, by editing and adding several parts, particularly in the "Introduction" and "Results and discussion" sections.

Our answers to the comments/questions are reported in a "comment-response" format. The comments of the reviewers are reported in italic and the related responses are reported in plain text.

In addition to the revised manuscript, we uploaded an annotated version of the text with the "track changes" mode of MS Word activated, in order to highlight all the changes from the previous version.

We are sincerely thankful to the three anonymous reviewers, whose comments and suggestions helped us to significantly improve the quality of the manuscript.

We hope that the revisions have appropriately addressed the comments received and that the manuscript is now considered suitable for publication in the journal.

Note: In our responses below, when the line numbers are reported, they refer to the annotated version of the revised manuscript.

\begin{tabular}{|l|l|}
\hline Reviewer \#1 & $\begin{array}{l}\text { Reviewer \#1: Dear Renato and Matteo, nobody is ever giving us credit for the invention } \\
\text { of the electrolyte management system. The idea of putting the electrodes in separate } \\
\text { electrolytes and controlling pH was invented in 1987: You should include : Pool, } \\
\text { W.European patent 0312174, April 1989 and US patent 5, 433,829. July 1995. US } \\
\text { patent 5,589, 056, priority date Oct 1987. and our article Lageman, } \text {., W. Pool: } \\
\text { Electro-Reclamation, Applications in the Netherlands. Environmental Science and } \\
\text { Technology. Vol. 27, No. 13, pp. 2648-2650, December 1993. } \\
\text { Nowadays everybody takes it for granted but this invention made electrokinetic soil } \\
\text { treatment possible! }\end{array}$ \\
\hline Reply: & $\begin{array}{l}\text { Following the reviewer's suggestions, we included the above mentioned references in } \\
\text { the dedicated section, with appropriate citations in the "Introduction" section of the } \\
\text { manuscript. }\end{array}$ \\
\hline
\end{tabular}

\begin{tabular}{|l|l|}
\hline Reviewer \#2 & \\
\hline Comment: & $\begin{array}{l}\text { The manuscript titled "Ligand-enhanced electrokinetic remediation of metal- } \\
\text { contaminated marine sediments with high buffering capacity " describes an interesting } \\
\text { laboratory experiment about electrokinetic remediation of marine sediments. } \\
\text { The authors provided a full and clear description of the experiment and the } \\
\text { consequential results. } \\
\text { However, in my opinion, this paper requires an improvement of the presented data and }\end{array}$ \\
\hline
\end{tabular}




\begin{tabular}{|c|c|}
\hline & $\begin{array}{l}\text { discussion to be adequate as a full research paper. My suggestions for the required } \\
\text { enhancement are presented hereafter. } \\
\text { General comments: } \\
\text { The state-of-the-art of the adopted remediation technology presented in the introduction } \\
\text { is not up-to-date. Please enhance the presentation and cite more bibliographic } \\
\text { references, including some significant scientific papers published in recent years. } \\
\text { The performed experiments must be presented with more data: the targeted metals } \\
\text { should be detected not only in the sediment but also in the electrolytes. Additionally, a } \\
\text { deeper analysis is advisable for a proper evaluation of metal fate (possibly including } \\
\text { mass-balances and a discussion of the formed metal complexes as a function of } \\
\text { operative pH). The adopted voltages should be clarified and, if possible, made more } \\
\text { coherent as described in the specific comments. } \\
\text { The results need a deeper discussion with more bibliographic references and } \\
\text { comparisons with literature findings of similar cases. Moreover, a statistical revision of } \\
\text { the results has to be provided. }\end{array}$ \\
\hline Reply: & $\begin{array}{l}\text { Following the suggestion of the reviewer, we substantially improved the Introduction } \\
\text { reporting an updated state-of-the-art of the electrokinetic technology. More bibliographic } \\
\text { references were cited, including recent studies specifically focused on the remediation of } \\
\text { contaminated sediments. } \\
\text { The Discussion section of the manuscript was also deeply revised: more data were } \\
\text { included and a more rigorous evaluation of the fate of the metals and mass balances } \\
\text { errors was added. } \\
\text { The adopted operating conditions (voltage gradients and type and concentration of } \\
\text { conditioning agents) were clarified. Bibliographic references were added to justify the } \\
\text { choice of the adopted conditions. } \\
\text { Moreover, a statistical analysis of the results has been provided with ANOVA method. } \\
\text { We also presented a comparison of our results with literature findings of similar cases. }\end{array}$ \\
\hline & Page 4. Please re-write clearly the aim of the \\
\hline Reply: & $\begin{array}{l}\text { The aim of the paper was clarified and more logically connected to the literature context } \\
\text { previously introduced in the same section. }\end{array}$ \\
\hline Comment: & $\begin{array}{l}\text { Page 4. Please specify better the origin of the sample and the adopted method of } \\
\text { sampling. }\end{array}$ \\
\hline Reply: & $\begin{array}{l}\text { We provided more details about the origin of the sediments and about the methods used } \\
\text { for sampling. }\end{array}$ \\
\hline Comment: & $\begin{array}{l}\text { Page 6. How did the Authors select the concentration of citric acid and EDTA. Please } \\
\text { add bibliographic references }\end{array}$ \\
\hline Reply: & $\begin{array}{l}\text { We added bibliographic references to justify the choice of the concentrations of the } \\
\text { conditioning agents. }\end{array}$ \\
\hline Comment: & $\begin{array}{l}\text { Page 7. Please, add the statistical method used (ANOVA?) to determine the significance } \\
\text { of the data }\end{array}$ \\
\hline Reply: & $\begin{array}{l}\text { The statistical analysis was performed using one-way ANOVA. The description of the } \\
\text { method was reported in the Materials and Methods section. }\end{array}$ \\
\hline Comment: & $\begin{array}{l}\text { Page 9. Enhance the discussion of the presented current density data. How can these } \\
\text { data improve the understanding of the electrokinetic phenomenon? If possible, complete } \\
\text { the presented data with current density data of all experiments. }\end{array}$ \\
\hline Reply: & $\begin{array}{l}\text { We improved the whole Discussion section also enhancing the discussion about current } \\
\text { density and resistivity. We presented all the current density data and we also included a } \\
\text { figure showing the mean resistivity evolution during the treatments. }\end{array}$ \\
\hline & ne for each parameter? Triplicate? \\
\hline
\end{tabular}




\begin{tabular}{|c|c|}
\hline Reply: & $\begin{array}{l}\text { For the determination of } \mathrm{pH} \text { and metal content we carried out at least } 3 \text { measures. } \\
\text { Current density and resistivity were recorded by an automated datalogger with a } \\
\text { sampling interval of } 5 \text { minute. The data recorded by datalogger was first filtered and } \\
\text { downsampled and finally plotted with much higher sampling interval. These } \\
\text { considerations were added in the Materials and methods section. }\end{array}$ \\
\hline Comment: & $\begin{array}{l}\text { Page 12-13. Complete the discussion as indicated in the general comments: add data of } \\
\text { metal masses in the electrolytes and on the electrodes, make an analysis of possible } \\
\text { formed metal complexes as a function of operative pH and state a hypothesis of how they } \\
\text { migrated so as to reach the detected situation at the end of each experiment. }\end{array}$ \\
\hline Reply: & $\begin{array}{l}\text { We presented all the collected data in new graphs (Fig. 8) which were not shown in the } \\
\text { previous version of the manuscript. Fig. } 8 \text { reports all the residual concentrations in the } \\
\text { sediment after the treatments along with errors, the amount of metals detected in the } \\
\text { anolyte and catholyte and the mass balance error between the initial and final metal } \\
\text { distribution. } \\
\text { The metal masses found on the electrodes were also reported (Table 3). }\end{array}$ \\
\hline Comment: & $\begin{array}{l}\text { Page 13. Are there significant differences (ANOVA) between EXP } 1 \text { and EXP } 3 \text { about } Z n \\
\text { and Ni content? It seems that the EDTA is suitable only for } P b, C u \text { and } V \text { removal. }\end{array}$ \\
\hline Reply: & $\begin{array}{l}\text { We carried out a deeper analysis of the differences between the various experiments, } \\
\text { both by discussing the results of the ANOVA study and by performing simulations of } \\
\text { the possible metal speciation as a function of the } \mathrm{pH} \text {. }\end{array}$ \\
\hline Comment: & Page14. Please, rewrite the conclusions more clearly \\
\hline Reply: & The Conclusion section was improved. \\
\hline Comment: & $\begin{array}{l}\text { Table } 1 . \text { Why just in EXP3 a higher voltage has been applied. Please, explain in the } \\
\text { experimental layout. If possible, complete the presented data with an EDTA experiment } \\
\text { at the same voltage as EXP1 and EXP2. }\end{array}$ \\
\hline Reply: & $\begin{array}{l}\text { A more clear presentation of the data was included. We reviewed and added all available } \\
\text { data, including an intermediate experiment with EDTA but with lower voltage }(0.5 \mathrm{~V} / \mathrm{m}) \\
\text { than the one already presented in the previous version of the manuscript }(0.8 \mathrm{~V} / \mathrm{m}) . \mathrm{We} \\
\text { hope that the new presented data is able to make the obtained results and relative } \\
\text { discussion more straightforward. }\end{array}$ \\
\hline
\end{tabular}

\begin{tabular}{|l|l|}
\hline Reviewer \#3 & $\begin{array}{l}\text { The topic of the research presented in the paper is the evaluation of the suitability of } \\
\text { applying enhanced electrokinetics for the removal of heavy metals form sea harbor } \\
\text { sediments. } \\
\text { The topic is for sure worth the interest the journal readers, and I appreciated the way } \\
\text { the experimental data were presented and discussed. } \\
\text { That being said, in the following some more specific suggestions to be submitted to the } \\
\text { Authors in order to further improve the paper. }\end{array}$ \\
\hline Reply: & $\begin{array}{l}\text { We would like to thank the reviewer for the valuable suggestions and comments which } \\
\text { contributed to improve the manuscript }\end{array}$ \\
\hline Comment: & $\begin{array}{l}\text { Pg 3, lines 40-4l: I would add more comments aimed at explaining why unenhanced EK } \\
\text { is usually not effective in removing heavy metals, in particular from sea sediments, so to } \\
\text { better introduce the following statements on the use of pH-based enhancing strategies. } \\
\text { In particular I would better explain here that pH may be a problem either due to the } \\
\text { alkaline conditions caused by the reactions at the cathode, and/or, as for sea sediments, }\end{array}$ \\
\hline
\end{tabular}




\begin{tabular}{|c|c|}
\hline & due to the strong buffer capacity of the material to be treated. \\
\hline Reply: & $\begin{array}{l}\text { Following the reviewer's suggestion, we thoroughly revised the introduction section in } \\
\text { order to present a more up-to-date state of art of the electrokinetic remediation } \\
\text { technology. } \\
\text { More bibliographic references were cited, including recent studies specifically focused } \\
\text { on the remediation of contaminated sediments. }\end{array}$ \\
\hline Comment: & $\begin{array}{l}\text { Pg.3, lines 57-60. I do not find useful mentioning here the combination of EK and } \\
\text { phytoremediation. The discussion is focusing on the pH control and related strategies, } \\
\text { among all the possible combinations of EK and other processes the one mentioned here } \\
\text { is not relevant to this regard. }\end{array}$ \\
\hline Reply: & $\begin{array}{l}\text { In the revision of the introduction section, we removed the reference to the combination } \\
\text { of EK with phytoremediation }\end{array}$ \\
\hline Comment: & $\begin{array}{l}\text { Pg. } 4 \text {, lines } 1 . \text { I would move up this sentence. The sequence of citations may be more } \\
\text { logical. Authors may discuss first the pH problems (deriving from electrode reactions or } \\
\text { material buffer capacity), discuss about zeta potential, EDTA, EO flow etc. }\end{array}$ \\
\hline Reply: & $\begin{array}{l}\text { We hope that in the revised introduction the sequence of citation appears now more } \\
\text { logical. }\end{array}$ \\
\hline Comment: & $\begin{array}{l}\text { Pg. 4, lines 12-15. The Authors state that promoting the EO flow would be beneficial } \\
\text { when EK is enhanced using EDTA. Please explain better why. The EDTA-metal complex } \\
\text { move towards the anode, while the EO flow is usually directed towards the cathode, } \\
\text { unless the pH of the system is very acidic, that is not the case when EDTA is used. Or do } \\
\text { you mean that the EO flow may help transport of EDTA from anode to cathode? }\end{array}$ \\
\hline Reply: & $\begin{array}{l}\text { We meant that the electroosmotic flow could improve the transport of EDTA from the } \\
\text { anode to the cathode. However, we removed the sentence from the manuscript since we } \\
\text { verified that the transport by electroosmosis is much lower than the transport by } \\
\text { electromigration. Thus, the EDTA is mainly transported from the cathode to the anode. }\end{array}$ \\
\hline Comment: & $\begin{array}{l}\text { Pg 5, lines 17-18. Were the layers horizontal ones? Placing the sediment according } \\
\text { horizontal layers may result in preferential flow pathways }\end{array}$ \\
\hline Reply: & $\begin{array}{l}\text { The layers were horizontal ones. } \\
\text { However, we believe that we were able to achieve a reasonable grade of homogeneity, } \\
\text { since the observed electroosmotic flow data was consistent (with observed } \mathrm{pH} \text { and with } \\
\text { the type of conditioning agent) and the mass balances errors were quite low even if the } \\
\text { sediments are real dredged sediment and they can show a certain heterogeneity. We } \\
\text { think that the possible heterogeneities were minimized also because the material } \\
\text { employed in each experiment was rather high (about } 14 \text { kg each experiment). }\end{array}$ \\
\hline Comment: & $\begin{array}{l}\text { Pg 5, lines 19-21. Was there any system for avoiding or controlling building up of } \\
\text { hydraulic gradients? }\end{array}$ \\
\hline Reply: & $\begin{array}{l}\text { The anolyte and catholyte chambers are free surface and the electrolyte levels in the } \\
\text { chambers are kept constant thanks to an overflow placed at a fixed height. The } \\
\text { electrolyte from the solution reservoirs is pumped into the electrodic chambers, then it } \\
\text { outflows from the overflow. } \\
\text { Since the levels in the two chambers remain always constant, no hydraulic gradients } \\
\text { should have been generated. } \\
\text { These details were reported in the Materials and method section. }\end{array}$ \\
\hline Comment: & Table 2: is "frequency" the right label? \\
\hline Reply: & $\begin{array}{l}\text { We changed the label for the particle size distribution in Table } 2 \text { from "Frequency (\%)" } \\
\text { to (\% d.w.). }\end{array}$ \\
\hline Comment: & Figure 3. Please explain better why in EXP1 and EXP3 the final $p H$ was so higher than \\
\hline
\end{tabular}




\begin{tabular}{|c|c|}
\hline & $\begin{array}{l}\text { the beginning one. This can not be due to the sediment buffer capacity. Was so } \\
\text { significant the cathodic OH-front? }\end{array}$ \\
\hline Reply: & $\begin{array}{l}\text { In the unenhanced experiment (EXP1) the development of the alkaline } \mathrm{pH} \text { in the } \\
\text { sediment is due only to the } \mathrm{OH}^{-} \text {front generated at the cathode. The alkaline front } \\
\text { prevails over the acid front because the base buffering capacity is much lower than the } \\
\text { acid buffering capacity. } \\
\text { To clarify this point we added the base buffering capacity (obtained by titration with } \\
\mathrm{NaOH} \text { ) in Table } 2 \text {. We also added specific comment in the Results and discussion } \\
\text { section. } \\
\text { Concerning the EDTA enhanced experiments, the conditioning solutions were prepared } \\
\text { with EDTA (pure acid) and NaOH at a pH around } 8 \text {. The solution buffered the } \mathrm{H}^{+} \text {at the } \\
\text { anode (also in order to a keep basic environment to avoid EDTA precipitation) and much } \\
\text { less } \mathrm{H}^{+} \text {entered into the sediment. For this reason, the pH was not decreased in any } \\
\text { section, not even in the section closer to the anode, while the alkaline front could easily } \\
\text { propagate toward the anodic side. }\end{array}$ \\
\hline Comment: & $\begin{array}{l}\text { Pg 13, lines 15-17. Please explain better why in EXP3 it was necessary to increase the } \\
\text { voltage. I understood that the electric I was increasing beyond the maximum set value of } \\
\text { the generator. In order to keep I at lower values you should decrease the V. May be that } \\
\text { I am missing something. }\end{array}$ \\
\hline Reply: & $\begin{array}{l}\text { We agree that the explanation about voltage variation was confusing. In fact the voltage } \\
\text { was decreased in order to keep the current to lower levels. We changed the sentence in } \\
\text { the manuscript accordingly. }\end{array}$ \\
\hline Comment: & $\begin{array}{l}\text { Pg } 13 \text {, lines 26-27. The removal efficiency in EXP3 can not be seen from Figure 7, but } \\
\text { only understood from the statement that metals were found in the anodic chamber. May } \\
\text { be useful to add some more data in Table } 3 .\end{array}$ \\
\hline Reply: & $\begin{array}{l}\text { We agree with the reviewer that the presented data were not exhaustive. } \\
\text { We added new data of an intermediate experiment with EDTA with lower voltage ( } 0.5 \\
\mathrm{~V} / \mathrm{m}) \text { in addition to the one already presented in the previous version of the manuscript } \\
(0.8 \mathrm{~V} / \mathrm{m}) \text {. } \\
\text { We also reviewed and added all available data. In particular we added detailed graphs } \\
\text { for all the experiments (Fig. 8). The figure reports all the residual concentrations in the } \\
\text { sediment after the treatments along with errors, the amount of metals detected in the } \\
\text { anolyte and catholyte and the mass balance error between the initial and final metal } \\
\text { distribution. } \\
\text { Moreover, we presented the analysis of the electrode surfaces at the end of one of the } \\
\text { experiments (EXP1). } \\
\text { Concerning the table with removal efficiencies (Table } 4) \text {, we performed a statistical } \\
\text { analysis of the results with one-way ANOVA technique, in order to identify the } \\
\text { significant difference between the treatments (in statistical terms). }\end{array}$ \\
\hline
\end{tabular}




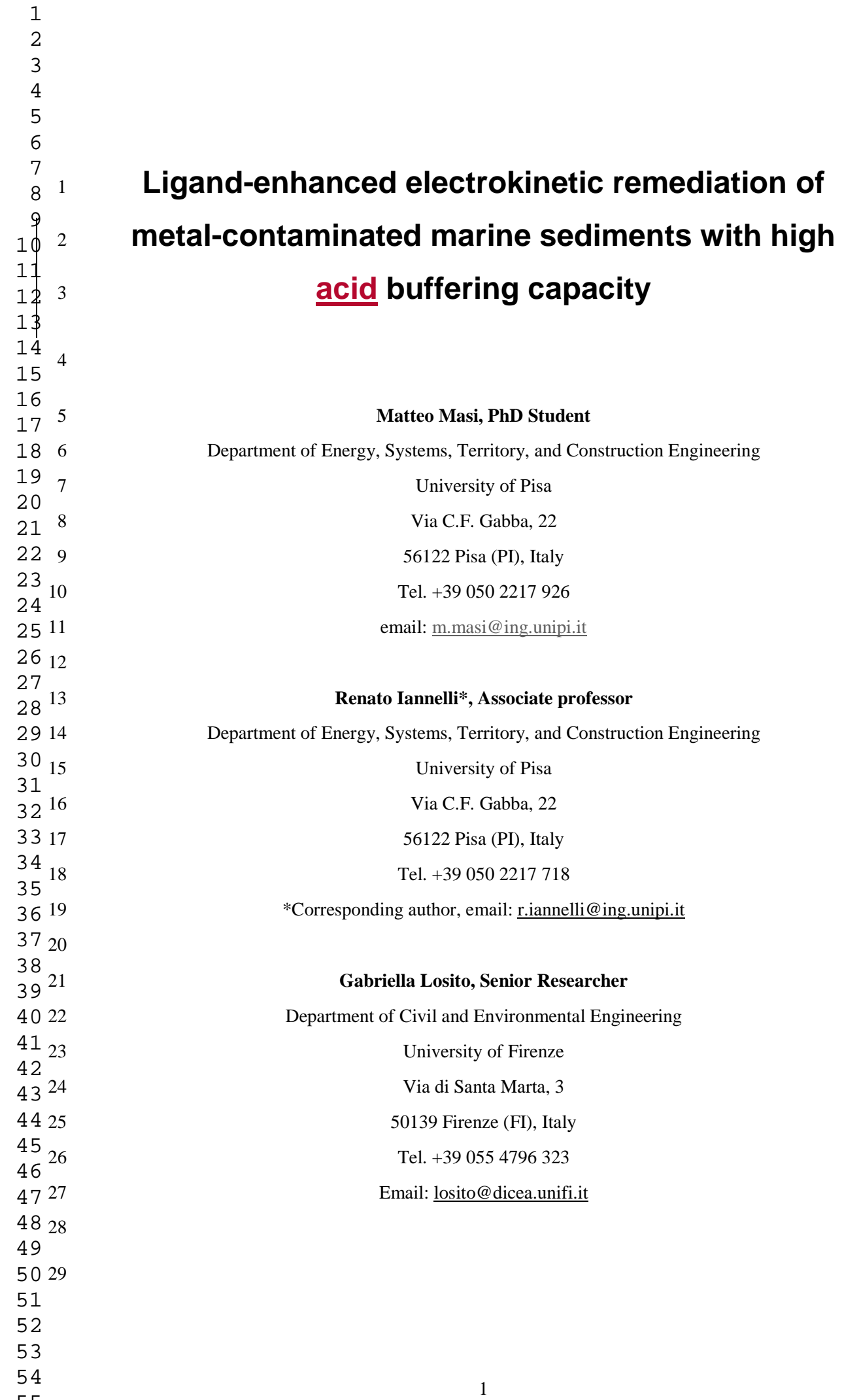

\section{Ligand-enhanced electrokinetic remediation of metal-contaminated marine sediments with high acid buffering capacity}




\section{Abstract}

9

The suitability of electrokinetic remediation for removing heavy metals from dredged marine sediments with high acid buffering capacity was investigated. Laboratory scale electrokinetic remediation experiments were carried out by applying two different voltage gradients to the sediment $(0.5$ and $0.8 \mathrm{~V} / \mathrm{cm})$ while circulating water or two different chelating agents at the electrode compartments. Tap water, $0.1 \mathrm{M}$ citric acid and $0.1 \mathrm{M}$ ethylenediaminetetraacetic acid (EDTA) solutions were used respectively. The investigated metals were $\mathrm{Zn}, \mathrm{Pb}, \mathrm{V}, \mathrm{Ni}$ and $\mathrm{Cu}$. In the unenhanced experiment the acid front could not propagate due to the high-acid buffering capacity of the sediments; the production of $\mathrm{OH}^{-}$ions at the cathode resulted in a high-pH environment causing the precipitation of $\mathrm{CaCO}_{3}$ and metal hydroxides. The use of citric acid prevented the formation of precipitates but solubilisation and mobilisation of metal species were not sufficiently achieved. Metal removal was relevant when EDTA was used as the conditioning agent and the electric potential was raised up to $0.8 \mathrm{~V} / \mathrm{cm}$. EDTA led to the formation of negatively charged complexes with metals which migrated toward the anode compartment by electromigration. This result shows that metal removal from sediments with high acid buffering capacity may be achieved by enhancing the electrokinetic process by EDTA addition when the acidification of the medium is not economically and/or environmentally sustainable.

Keywords: Electroremediation; heavy metals; dredged sediments; enhanced electrokinetics; buffering capacity; EDTA; citric acid 


\section{Introduction}

MarineThe management of contaminated sediments is of great concern particularly in harbours and adjacent areas where dredging is essential for the maintenance of harbour waterways. Dredged sediments are often severely contaminated by a variety of hazardous pollutants, mostly heavy metals and hydrocarbons, originated from different sources such as ships, harbour activities, industry, municipal sewage and other upstream sources_(Mulligan et al. 2001). When no contamination is found or the contamination levels comply with regulatory standards, traditional management strategies include alternatives such as dumping at open sea or disposal in longshore confined disposal facilities. Beneficial reuse of sediments, e.g. for construction materials in civil engineering (Dubois et al. 2011), also represents a viable solution, as long as the sediments do not pose a risk. When the regulatory standards are not met, disposal in landfill is a widespread solution. However, storage on disposal sites is not sustainable because of the large amount of sediments to be disposed and because of the risk of contaminant to be transferred to the environment (Ammami et al. 2015).Contaminated sediments have become a remarkable problem particularly in harbours and adjacent areas where dredging is essential for maintaining adequate navigation depths. In such case large amount of potentially contaminated material need to be treated before reuse or final disposal (Mulligan et al. 2001). Consequently, sediment treatment is required.

Heay In marine sediment remediation, heavy metal pollution is a major issue-in marine sediment remediation because most sediments consist of clay minerals and organic matter. Metals can be bound to clay surfaces or complexed with organic matter thus reducing their mobility through the porous matrix (Peng et al. 2009)(Peng al. 2009).. Furthermore, marine sediments are frequently characterized by low hydraulic permeability and high buffering capacity (Reddy and Ala 2006). These conditions pose severe threatslimitations to remediation efficiency as traditional decontamination techniques available for treating high permeability soils are not effective for finegrained matrices. In this context, electrokinetic remediation (EKR) is widely recognised as an efficient technique for removing a broad range of organic and inorganic contaminants from lowpermeability materials (Probstein and Hicks 1993; Lageman 1993; Virkutyte et al. 2002; Reddy and Cameselle 2009; Yeung 2011)(Probstein et al. 1993; Mattson and Lindgren 1994; Acar et al. 1995; Virkutyte et al. 2009; Yeung 2011; Pamukeu and Wittle 1992; Reddy and Cameselle 2009).. EKR technology is based on the application of a low-intensity electric field which induces the mobilization of charged species through the porous media toward the electrodes, due to three main transport mechanisms (Acar and Alshawabkeh 1993)(Aear and Alshawabkeh 1993):: electromigration (movement of eharged ions and charged molecules), electroosmosis (movement of fluid), and electrophoresis (eharged particle-movement)-of colloids). The application of an electric field to a 
porous matrix also results in water electrolysis reactions at the electrodes, producing $\mathrm{H}^{+}$ions at the anode and $\mathrm{OH}^{-}$at the cathode, which, if not buffered with external chemical agents, generate a pH gradient along the material under treatment.

In general, pollutant speciation is $\mathrm{pH}$-dependent and it is often required to adjust the sediment $\mathrm{pH}$ to (e.g. carbonates or hydroxides) which can hinder the transport processes. This is usually carried out by acid/base addition at the electrode compartments (Acar et al. 1995; Zhou et al. 2005; Kim et al. 2011). This approach was also one of the first to be implemented in full scale in-situ EKR systems (Pool 1989; Pool 1996). However, when the material under treatment is characterized by a high acid/base buffering capacity, particularly marine sediments, more energy expenditure and greater amount of reagents are required in order to reach the $\mathrm{pH}$ target levels and the costs and effectiveness of the treatment can be strongly affected (Altaee et al. 2008). In most cases, the buffer capacity is due to the presence of calcite which buffers the system, as observed by Grundl and Reese (1997)The.

In case of high buffering capacity, the mobility of metals can be improved by severatother possible enhancement strategies for increasing removal rates and reducingin order to reduce remediation time and costs (Yeung and $\mathrm{Gu} 2011$ ). Most enhancement methods are primarily aimed at controlling $\mathrm{pH}$ to prevent precipitation of metal hydroxides. Reddy and Chinthamreddy (2004) found that precipitation phenomena under high $\mathrm{pH}$ conditions resulted in negligible removal of cationic contaminants. A similar result was also found by Nystrøm et al. (2005) for harbour sediments. pH control can be achieved by controlling anolyte and catholyte $\mathrm{pH}$ via acidic or basic solution addition in the electrode compartments (Zhow et al. 2005; Baek et al. 2009; Kim et al. 2011). Another strategy. Among these strategies, one involves the use of chelating agents for improving metal solubility (Gidarakes and Giannis 2006; Wong et al. 1997; Amrate and Akretche 2005; Colaciceo et al. 2010). Finally, someto achieve the solubilisation of metals. Other authors proposed the use of ion-exchange membranes to isolate reactions occurring at the electrodes and remediation phenomena occurring inside the porous matrix (Hansen et al. 2005; Kim et al. 2005)in the soil (Hansen al. 2005; Kim al. 2005), while other authors proposed to use EKR in combination with other techniques such as phytoremediation (O'Connor et al. 2003; Cang et al. 2011).

The use of chelating agents has been shown to be effective for improving metal solubility and removal rates in high acid buffering capacity soils and sediments (Wong et al. 1997; Amrate and Akretche 2005; Gidarakos and Giannis 2006; Colacicco et al. 2010). When the natural pH of the material is in the alkaline range, the use of chelating agents, such as EDTA, may be advantageous as they are found to be more efficient at alkaline $\mathrm{pH}$ (Lestan et al. 2008). However, in many situations the use of EDTA is not recommended because of the potential toxicity and poor biodegradability (Sillanpää and Oikari 1996). Conversely, Voglar and Lestan (2013) have demonstrated that it is 
possible to implement a method for EDTA recycling, with lower generation of wastewater or other toxic wastes and with technical and economical feasibility. The economic value of chelant-enhanced electrokinetic remediation would greatly be increased by the development of more efficient recycling methods.

Many recent studies have examined the effects of the different enhancing agents on the electrokinetic remediation of marine sediments, showing that the remediation of real contaminated sediments is particularly dependent on the characteristics of the solid matrix and on the specific interactions between the pollutants and the constituents of the sediment constituents (Hahladakis et al. 2014). Therefore, the selection of the operating parameters and conditioning agents must be carefully evaluated in order to choose the best remediation strategy.

Kim et al. (2011) investigated the suitability of various processing fluids (EDTA, citric acid, $\mathrm{HCl}$ and $\mathrm{NO}_{3}$ ) for the enhancement of the electrokinetic remediation of dredged marine sediments contaminated by $\mathrm{Ni}, \mathrm{Cu}, \mathrm{Zn}$ and $\mathrm{Pb}$. Tap water was used as anolyte and the processing fluids were circulated at the cathode at $0.1 \mathrm{M}$ concentration. The experiments were performed under a constant voltage gradient of $1 \mathrm{~V} / \mathrm{cm}$ for 15 days. They obtained the best removal rates with citric acid and $\mathrm{HCl}$, showing extraction efficiencies up to about $70 \%$.

Rozas and Castellote (2012) carried out electrokinetic removal of $\mathrm{Cu}, \mathrm{Zn}, \mathrm{Cd}, \mathrm{Cr}, \mathrm{Pb}$ and $\mathrm{Ni}$ from contaminated dredged material testing the effectiveness of different enhancing solutions (distilled water, citric acid, acetic acid, humic acid and EDTA). They performed a multiple regression analysis on the measured parameters and they found that the main factors affecting the efficiency of the treatments were the $\mathrm{pH}$ of the cathodic solution, chelating ability of the conditioning agent and the zeta potential of the sediment.

Iannelli et al. (2015) performed an extensive set of laboratory experiments aimed teat designing a pilot-scale demonstrative electrokinetic plant for extracting heavy metals from marine sediments. The target metals were $\mathrm{Cd}, \mathrm{Cr}, \mathrm{Cu}, \mathrm{Ni}, \mathrm{Pb}$ and $\mathrm{Zn}$ at relatively low concentrations with high non-mobile fractions. Several conditioning agents $\left(\mathrm{HNO}_{3}, \mathrm{HCl}, \mathrm{H}_{2} \mathrm{SO}_{4}\right.$, citric acid, oxalic acid, ascorbic acid, EDTA) were tested. The best result were obtained with strong acids, although EDTA was also found to be effective for some of the investigated metals.

Ammami et al. (2015)In marine sediment treatment, the efficiency of metal removal can be strongly affected by sediment buffer capacity 8 Altae et al. 2008). Grundl and Reese (1997) observed that the presence of calcite buffers the system, thus preventing $\mathrm{pH}$ from shifting to the acidic range. Rozas and Castellote (2012) reported that enhancement agents alter sediment zeta potential, which is considered among the most relevant factors in process efficiency. Zeta potential depends on $\mathrm{pH}$ and affects electroesmotic flow velocity. Cameselle and Reddy (2012) found that electroesmotic flow is the key transport phenomenon in organic contaminant removal when solubilizing agents such as surfactants, 
bio-surfactants, co-solvents or cyclodextrins are used. When chelating agents are used to remediate metals, electroosmotic flow development and enhancement can also be necessary to improve chelation process and chelate transport trough the porous matrix.

The above mentioned studies on real contaminated sediments show that the identification of the best application of the electrokinetic technology are still required, due to the complexity of the solid matrix and the peculiar characteristics of marine sediments, such as the strong buffering capacity.

In this context, this study aims at: 1 . investigating the feasibility of evaluating the main factors affecting the electrokinetic remediation for removing $\mathrm{Zn}, \mathrm{Pb}, \mathrm{V}, \mathrm{Ni}$ and $\mathrm{Cu}$ from dredged marine sediments, and 2. evaluating the influence of some experimental treatment parameters on process efficiency, with a special focus on the role of sediment $\mathrm{pH}$ and the evaluation of characterized by high acid buffering capacity, examining two possible electrolyte enhancement strategies. We particularly focused on the effect of sediment $\mathrm{pH}$ on the speciation and mobility of heavy metals and their interactions with the ligands, which affect the mechanisms of transport of the-contaminants.

\section{Materials and methods}

\subsection{Sediment collection and analytical methods}

The marine sediments were collected during a survey campaign for dredging activities from athe harbour of Isola Maddalena, located in northern Sardinia (Italy). The samples were manually collected by scuba divers from the sea--bottom top layer. Immediately after dredgingcollection, the material was stored at ambient temperature in closed containers to ensure the stability of physicochemical properties. After three days The whole collected material was then gathered in a single tank and manually homogenized. For the analyses, a subsample was taken from the homogenized sample and it was air-dried at a temperature of $\sim 20^{\circ} \mathrm{C}$ and sieved to remove the fraction above $2 \mathrm{~mm}$ (mostly composed of shells). The particle-size distribution was determined by sieve analysis, up to $74 \mu \mathrm{m}$ fraction. pH was measured applying the ISO 10390:2005. The acid buffering capacity was determined by titration method using $0.1 \mathrm{M} \mathrm{HCl}_{-}$, the base buffering capacity by titration with $0.1 \mathrm{M} \mathrm{NaOH}$. The elemental composition was determined by wavelength dispersive X-ray fluorescence spectrometer (WD-XRF Rigaku Primus II), while the heavy metal content was analysed by means of atomic 

OES DV) after acid digestion. ThepH and heavy metal content analysis procedures were applied at

\subsection{Experimental electrokinetic setup and test conditions}

The EKR experiments were carried out using an acrylic cell (FigureFig. 1) with rectangular crosssection, consisting of four principal parts: the sediment compartment, the electrode compartments, the electrolyte solution reservoirs and the power supply. The sediment compartment dimensions were 30 $\mathrm{cm} \times 15 \mathrm{~cm} \times 15 \mathrm{~cm}$, with a volume of $6.75 \mathrm{dm}^{3}$. The weight of the sediment employed in each experiment was about $14 \mathrm{~kg}$. In order to separate the sediments from the electrode compartments, a nylon grid (mesh size $2 \mathrm{~mm}$ ) and filter paper were used. The sediment sample was placed in the electrokinetic cell in layers and a static pressure of $40 \mathrm{~g} / \mathrm{cm}^{2}$ was applied for 24 hours to compact the material. Then it was left in the cell for at least 3 days before starting the tests. The anolyte and catholyte solutions were circulated into the electrolyte reservoirs $\left(4 \mathrm{dm}^{3}\right)$ by a peristaltic pump at a flow rate of $2000 \mathrm{ml} / \mathrm{h}$. The anolyte and catholyte chambers were with free surface and the electrolyte levels in the chambers were kept constant thanks to two respective overflows placed at a fixed height of $15 \mathrm{~cm}$ from the bottom of the cell. The sediment height was slightly higher than the electrolyte in the compartments in order to avoid the flow of the electrolytes onto the surface of the sediment. Reservoir solutions were replaced every 2 days. The anode and cathode electrodes were two graphite plates $(15 \mathrm{~cm} \times 15 \mathrm{~cm} \times 0.4 \mathrm{~cm})$. They were connected to a power supply capable of operating under constant voltage ( $800 \mathrm{~V}, 1.8 \mathrm{~A}$ max.). Six graphite rod electrodes (diameter $6 \mathrm{~mm}$ ) were placed along the sediments to monitor the voltage drop between five sampling locations ( $S 1$ to $S 5$ ).

The choice of the type and concentration of the enhancement agents was based on a literature review. Kim et al. (2011) have shown that $0.1 \mathrm{M}$ citric acid was considerably effective as processing fluid among other reagents for marine sediment remediation. Andreottola et al. (2010) observed significant heavy metal extraction (up to $81 \%$, for As) during EKR with 0.2 M EDTA used a in both electrodic chambers. Rozas and Castellote (2012), respectively. obtained up to $63 \%$ (for Pb) with 0.1 EDTA dosed at the catholyte and up to $58 \%$ for $\mathrm{Ni}$ and $48 \%$ for $\mathrm{Zn}$ with $0.3 \mathrm{M}$ citric acid dosed in both chambers. 
The applied voltage gradients (constant DC) were $0.5 \mathrm{~V} / \mathrm{cm}$ (EXP1 and EXP2to EXP3) and $0.8 \mathrm{~V} / \mathrm{cm}$ The treatment duration was 10 days. A summary of the adopted treatment conditions is reported in Table 21 .

The resistivity in each sampling section $S_{i}$ was determined using the following equation:

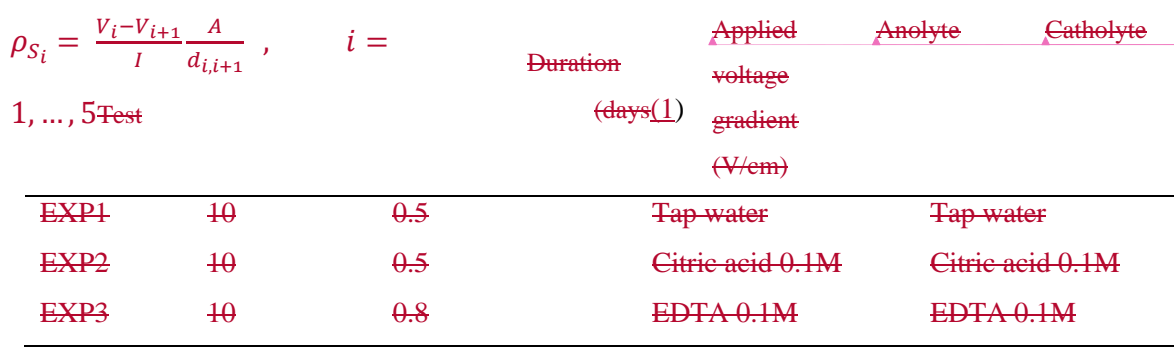

During the tests, the applied voltage, the current and the voltage drop across the sediment were recorded by a data logger. Referring to Figure 1, the resistivity in each sampling section $S_{i}$ was determined using the following equation:

$\rho_{S i}=\frac{V_{i}-V_{i+1}}{I} \frac{A}{d_{i+i+1}}, \quad i=1, \ldots, 5$

where $\rho_{\mathrm{Si}}(\Omega \mathrm{m})$ is the resistivity of the material in the i-th section, $V_{i}(\mathrm{~V})$ the measured voltage at the i-th electrode, $I$ (A) the electric current, $A\left(\mathrm{~m}^{2}\right)$ the cell cross section and $d_{\mathrm{i}, \mathrm{i}+1}(\mathrm{~m})$ the distance between the i-th electrode and the next. In addition, the electroosmotic flow was calculated during the experiments by measuring the volume change in the electrode reservoirs and calculating a mass balance. At the end of each experiment, the material was sampled from five locations ( $S 1$ to $S 5$ ) and analysed for $\mathrm{pH}$ and total metal content. Metal concentrations were also measured in the anodic and cathodic -chambers. Electrodeposition was evaluated by analysing the electrodes for metal content.

\subsection{Statistical analysis}

Heavy metal content and $\mathrm{pH}$ results are means of at least three replicates. A statistical evaluation of heavy metal removal was carried out by testing the differences among the means using one-way

\begin{tabular}{|l|}
\hline Deleted Cells \\
\hline Deleted Cells \\
\hline Deleted Cells \\
\hline
\end{tabular}


analysis of variance (ANOVA) test with 95\% confidence interval. Means were compared by honest significant difference (HSD) Tukey's test $(\mathrm{p}<0.05)$. Significantly different values were represented in tables by different lowercase letters.

\section{Results and discussion}

The heavy metal contamination, although not particularly high, was everabove the Italian standards for sites intended to residential use, public parks and gardens (Legislative Decree 152/2006) for $\mathrm{Zn}$ and $\mathrm{Pb}$.

\begin{tabular}{|c|c|}
\hline \multicolumn{2}{|l|}{ Phy p o } \\
\hline $\mathrm{pH}($ ISO 10390:2005) & $8.3 \pm 0.2$ \\
\hline Buffer capacity $\mathrm{pH}=3\left(\mathrm{~mol} \mathrm{H}^{+} \mathrm{Akg}\right)$ & 1.76 \\
\hline Poresity $(\%)$ & 47 \\
\hline \multicolumn{2}{|l|}{ Particle size distribution } \\
\hline Diameter (mm) & Frequency $(\%)$ \\
\hline $20-10$ & 6 \\
\hline $10-0.5$ & 12.70 \\
\hline $0.5-0.25$ & 10.39 \\
\hline $0.25-0.125$ & 33.01 \\
\hline $0.125-0.074$ & 21.91 \\
\hline$\$ 074$ & 15.19 \\
\hline E & 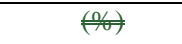 \\
\hline $\mathrm{SiO}_{\underline{\underline{z}}}$ & 67.56 \\
\hline $\mathrm{EaO}$ & 15.27 \\
\hline $\mathrm{AH}_{2} \theta_{3}$ & 5.13 \\
\hline $\mathrm{Fe}_{2} \theta_{3}$ & 3.08 \\
\hline$K_{2} \theta$ & 2.55 \\
\hline$\Leftrightarrow$ & 200 \\
\hline $\mathrm{Na}_{2} \mathrm{O}$ & 1.37 \\
\hline
\end{tabular}




\begin{tabular}{|c|c|}
\hline$\theta$ & 896 \\
\hline s & 0.95 \\
\hline Metal content & $(\mathrm{mg} / \mathrm{kg})$ \\
\hline $\mathrm{Fe}$ & $5895 \pm 810$ \\
\hline 如 & $273.2 \pm 4.41$ \\
\hline $\mathrm{Ni}$ & $16.36 \pm 1.09$ \\
\hline$\epsilon$ & $12.23=0.53$ \\
\hline $\mathrm{Pb}$ & $144.5 \pm 6.99$ \\
\hline A & $2044 \pm 42.1$ \\
\hline$€$ & $92.06 \pm 0.37$ \\
\hline$¥$ & $11.5 \pm 0.77$ \\
\hline
\end{tabular}

\subsection{Electrokinetic tests}

EXP1 was performed using tap water as the processing fluid. The applied voltage gradient was kept at thea constant value of $0.5 \mathrm{~V} / \mathrm{cm}$ along for the entire duration of the whole treatment duration of $\_10$ days-Figure). Fig. 2 shows the profileprofiles of current density as a function of time. At the beginning of the test, current density raised to about $54 \mathrm{~A} / \mathrm{m}^{2}$, then it progressively decreased to a stable range of $9-10 \mathrm{~A} / \mathrm{m}^{2}$. The complementary behaviour with opposite trend was observed for the mean resistivity (Fig. 3). Current decrease (resistivity increase) is a phenomenon observed by many authors (Yuan and Weng 2006; Altaee et al. 2008; De Gioannis et al. 2009)(Altae et al. 2008; Yuan and Weng 2006; De Gioannis et al. 2009).. It can be related to gradual depletion of salts (Yu and Neretnieks 1997)(Yu and Neretnieks 1997) and precipitation of chemical species at the cathode in the form of non-soluble and non-conductive compounds (in particular carbonates, oxides and hydroxides) that blocked the pores of the material and prevented the transport of electric charge-ions.

In fact, during EXP1, the production of $\mathrm{OH}^{-}$ions at the cathode, resultingresulted in a high $\underline{\mathrm{pH}}$ environment $\mathrm{pH}$ (Figure 3), caused(Fig. 4). The acid front (i.e. the transport of $\mathrm{H}^{+}$ions) from the anode could not propagate due to the high acid buffering capacity of the sediments and the $\mathrm{pH}$ was lowered at $\mathrm{pH} \approx 6$ only in the first section of the sediment (S1). In all other sections the alkaline front (due to $\mathrm{OH}^{-}$produced at the cathode) prevailed over the acid front, because the sediment are characterized by a base buffering capacity much lower than the acid buffering capacity (Table 2). For this reason, the alkaline front from the cathode could easily propagate toward the anodic side.

As a consequence of the high $\mathrm{pH}$ developed in the sediments, the precipitation of species occurred in

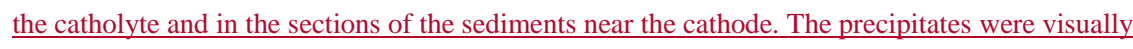
detectable and they were collected from the cathode chamber and analysed by X-ray diffraction (Fig. 
5). The analyses showed that they were composed by $\mathrm{CaCO}_{3}$ and some hydroxides $\underline{(\text { such as }} \mathrm{Ni}(\mathrm{OH})_{2}$ and $\mathrm{Mg}(\mathrm{OH})_{2}$ ), as detected by $\mathrm{X}$ ray diffraction analysis of the solid precipitates found in the cathode compartment (Figure 4). The-

The slight decrease of the $\mathrm{pH}$ near the cathode (section S5), compared to the other sections (S2 to S4 as shown in the following reaction:

$$
\mathrm{Ca}^{2+}+\mathrm{HCO}_{3}{ }^{-} \rightarrow \mathrm{CaCO}_{3}+\mathrm{H}^{+}
$$

The precipitation of these species also resulted in high resistivity zones near the cathode (Figure 5Fig. 6). Resistivity monitoring acrossalong the eellsediment during the experiments proved to be an effective tool for detecting such phenomena over time. As shown in Figure 5, an abruptFig. 6, a sharp local increase in resistivity (sections $S 4$ and $S 5$ ) can be identified after 6 days of treatment and it corresponds to the instant of formation of precipitates. Buring EXP1 (tap water) the acid front (i.e. the transport of $\mathrm{H}^{+}$ions) could not propagate due to the high buffering capacity of the sediments, which decreased the dissolution and desorption rates of adsorbed and/or complexed species. The experiment resulted in no significant removal of heavy metals, except for $\mathrm{Ni}$.

citric acid solution was used as the processing fluid in experiment 2 (runEXP2).. Citric acid, other than being a weak acid, is known to exhibit moderate chelating properties associated to a very low amount of environmental impact and negative side effects. The voltage gradient $(0.5 \mathrm{~V} / \mathrm{cm})$ and the treatment duration (10 days) were kept unchanged from the previous experiment. The current density (FigureFig. 2) followed the same trend as in the unenhanced test (EXP1) but no precipitates were detected and no sharp variation of local resistivity were observed. The decrease in current density $\underline{\text { The }}$ mean resistivity (Fig. 3), in fact, smoothly raised during the experiment. The increase in resistivity is probably due to the salt depletion mechanism alone. The citric acid depolarized the cathode reaction, neutralizing $\mathrm{OH}^{-}$ions and preventing the formation of precipitates near the cathode. However, the $\mathrm{pH}$ values significantly changed from the initial value only near the electrodes (Figure 3 Fig. 4), due to the 
For each experiment the metal distribution at the end of the experiments was determined and a mass balance was calculated to check the error in the determination of the concentrations both in the sediments and in the electrolyte. When precipitation occurred, the precipitates were also analysed and amount of metals was found on their surfaces. The highest metal content was detected at the end of EXP1 and the results are reported in Table 3. However the metal masses on the electrodes are very small compared to the mass measured in the sediment or found in the electrolytes (either in solution or precipitated).

The calculated mass balance errors (values are reported in the last category "Error" in Fig. 8) ranged from $1 \%$ to $10 \%$. In general, the results are consistent even when the mass balance error is significant.

The removal efficiencies of the treatments were calculated and they are reported in Table 4. The statistical differences between the treatments were analysed with one-way ANOVA and indicated by different letters in each row when the difference is significant (at 95\% confidence interval).

The run EXP1 resulted in no significant removal of heavy metals, except for $\mathrm{Ni}(20.8 \%)$. The enhancement with citric acid did not produce any improvement in metal extraction. On the contrary, with EDTA the removal efficiencies were generally higher. In EXP4 a significant improvement compared to the other runs was observed, in fact the overall heavy metal removal ranged from $9.5 \%$ to $27 \%$ (Table 4).

To evaluate the possible speciation of the heavy metals as a function of the $\mathrm{pH}$ conditions, numerical simulations were carried out with PHREEQC-3 geochemical reaction code (Parkhurst and Appelo 2013). The graphical representations were realised with the free software PhreePlot, which automatically does multiple PHREEQC calculations for each $\mathrm{pH}$ value. In particular, two heavy metals $(\mathrm{Ni}$ and $\mathrm{Pb}$ ) were analysed, under the assumption that the concentration of metals in solution is $20 \%$ of the total metal concentration in the sediment. Three conditions were simulated for each metal. In the first condition, the speciation was obtained assuming that the electrolyte is composed only by $\underline{0.3 \mathrm{M} \mathrm{NaCl}}$. This value was assumed as an estimation of the mean $\mathrm{NaCl}$ concentration in the electrolytes during the treatment. This simulation aims to reproduce the unenhanced experiment (EXP1). A second scenario was simulated adding 0.1M EDTA in the initial conditions for calculation (with the purpose to reproduce EXP2 and EXP3 conditions), with same $\mathrm{NaCl}$ content. In the third $\underline{\text { scenario the simulations were performed with } 0.1 \mathrm{M} \text { Citrate. All simulations were set up with } \mathrm{O}_{2}}$ saturation conditions and $25^{\circ} \mathrm{C}$ temperature. The result of the calculations are reported in Fig. 9. Other minor complexes $(<5 \%)$ may form but they are not shown in the figures.

Speciation computations may be used to better interpret the observed removal rates. In general, $\mathrm{Ni}$ removal is higher than the other studied metals, with the exception of citric acid enhancement. The higher rate might be due to the distribution of metals among the bonding fractions of the sediment. In 
$\underline{\text { the case of } \mathrm{Ni} \text {, a possible higher exchangeable fraction may be present, which explains the higher }}$

removal compared to the other metal. The difference in the removal between the citric acid experiment (EXP2) and the other experiments can be attributed to the different mobility of the formed metal complexes. In fact, without any enhancement $\mathrm{Ni}^{2+}$ is predominant in the $\mathrm{pH}$ range 2-8 (Fig. 9a). This form of Ni is highly mobile and it moves toward the cathode, as observed during EXP1. Most of the $\mathrm{Ni}$ is found in the catholyte, though it was in precipitated $\mathrm{Ni}(\mathrm{OH})_{2}$ form (XRD analyses). The high mass balance error for $\mathrm{Ni}$ can be explained by possible experimental errors made during the sampling and determination of the amount of Ni precipitates. With EDTA, the main form at the observed $\mathrm{pH}$ range is Ni-EDTA ${ }^{2-}$ which has higher mobility than Ni-Citrate-, because of the higher charge number. This can explain why the removal with citric acid is lower. The low removal can also be due to the low stability of the complexes formed with citric acid (Kim et al. 2011)

. Ni-Citrate ${ }^{-}$and $\mathrm{Ni}^{2+}$ may coexist and move in the opposite directions, causing possible alternating movements.

ANOVA analysis also shows that three groups exist for Ni results (Table 4). The first group, composed by EXP2 and EXP3 is characterized by low complex mobility due to low Ni-Citratemobility and lower Ni-EDTA ${ }^{2-}$ mobility (compared to $\mathrm{Ni}^{2+}$ ), respectively. EXP3 is associated to EXP1 because $\mathrm{Ni}^{2+}$ has higher mobility but the removal is limited by the adverse $\mathrm{pH}$ environment which induce precipitation. Then, in EXP4 higher mobility is observed, due to the increase of the applied voltage gradient.

Concerning $\mathrm{Pb}$ and $\mathrm{Zn}$, the observed removal is lower than the other metals and ANOVA analysis shows that there are not significant differences between the treatments (Table 4). For $\mathrm{Pb}$, the lower amount of metal found in the catholyte at the end of EXP1 compared to Ni may be explained by its tendency to form mostly $\mathrm{PbCl}^{+}$instead of $\mathrm{Pb}^{2+}$ (Fig. 9d) which has lower mobility and $\mathrm{PbCl}_{2}$ which can be transported only by the electroosmotic flow. In fact, from Fig. 8a it can be observed that during EXP1 Pb started to migrate toward the cathode but it remained mostly in the middle section of the sediment (S3). The removal with EDTA is slightly higher but there is no significant improvement when changing the conditions of treatment.

The $\mathrm{Cu}$ behaviour during EXP1 (very low removal) is the consequence of the high tendency of $\mathrm{Cu}$ to precipitate at lower $\mathrm{pH}$ compared to the other analysed metals. In fact, it starts to precipitate as $\underline{\mathrm{Cu}}_{2} \underline{\mathrm{Cl}(\mathrm{OH})_{3}}$ at a pH lower than 6. Regarding the citric acid experiment, the observed low mobility of $\mathrm{Cu}$ cannot be explained by the simulated speciation and other factors may play a more important role. The higher removal observed with EDTA instead can be justified by the high mobility of

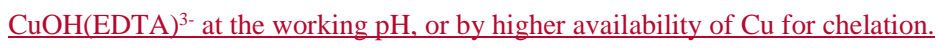

Overall, the best results were obtained for $\mathrm{Ni}, \mathrm{Cu}$ and $\mathrm{V}$ with EDTA and at $0.8 \mathrm{~V} / \mathrm{m}$, while no significant differences between the treatments were observed for $\mathrm{Zn}$ and $\mathrm{Pb}$. 
The unenhanced experiment showed that metal migration occur mostly toward the cathode, as some amount of metal was found in the catholyte, but the $\mathrm{OH}^{-}$ions produced at the cathode had a strong impact on the $\mathrm{pH}$ of the sediment and the high alkaline conditions caused the precipitation of the species, e.g. $\mathrm{Ni}(\mathrm{OH})_{2}$, and prevented further metal extraction.

The use of citric acid resulted in very low metal removal, possibly because the amount of acid used was not enough to form stable complexes.

\begin{tabular}{llllll}
\cline { 2 - 6 } It & Zn & Pf & Pb & $\theta$ & $\#$ \\
\hline EXP1 & $6.9 \pm 1.9$ & $20.8 \pm 5.7$ & $\theta$ & $\theta$ & $\theta$ \\
EXP2 & $\theta$ & $\theta$ & $\theta$ & $\sim \theta$ & $\sim \theta$ \\
EXP3 & $9.5 \pm 2.4$ & $24.3 \pm 4.3$ & $9.8 \pm 2.6$ & $27.3 \pm 1.7$ & $17.4 \pm 3.4$ \\
\hline
\end{tabular}

Overall, it can be concluded that the use of EDTA resulted in a more favourable removal of metals. Under this condition, electromigration was the main process responsible for the transport of metals in the form of negatively charged EDTA-metal complexes from the cathode to the anode. Conversely, electrosmotic the transport by electroosmosis was less prominent, since very low concentrations of heavy metals were found in the catholyte.

\section{Conclusions}

ThreeFour laboratory scale electrokinetic experiments(EXP1, EXP2 and EXP3) were carried out to extract heavy metals from dredged marine sediments. The experimental study revealed that the electrokinetic remediation was affected both by the intensity of the applied electric field and the type of conditioning agent used at the electrode compartments. Tap water, $0.1 \mathrm{M}$ citric acid and $0.1 \mathrm{M}$ ethylenediaminetetraacetic acid (EDTA) solutions were used, respectively, as processing fluids. The experiments were performed under $0.5 \mathrm{~V} / \mathrm{cm}$ (EXP1 and EXP2to EXP3) and $0.8 \mathrm{~V} / \mathrm{cm}$ (EXP3EXP4) constant voltage gradient (DC), respectively, with treatment duration of 10 days. The unenhanced test (EXP1) and the citric acid enhanced test (EXP2) did not result in an appreciable mobilization of the contaminants. The acidification of the sediments was not achieved due to the high acid buffering capacity of the medium. Monitoring During EXP1 the alkaline front migrated faster than the acid front because of the greater sediment buffering capacity towards acids rather than bases. As a consequence a high $\mathrm{pH}$ developed in the sediments causing the precipitation of $\mathrm{CaCO}_{3}$ and metal hydroxides which hindered the transport processes. Sediment resistivity profile across the eleetrokinetic cell was performedmonitoring during the experiments and it demenstrated that proved 


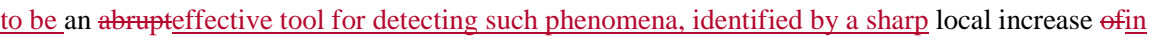
over time-corresponded to carbonate and metal hydroxide precipitation phenomena, which should be (EXP4) significantly improved heavy metal removal(EXP3).. We found that with the addition of dominant mechanism of removal was electromigration, which promoted the transport of EDTA-metal complexes which migrated toward the anode. The removal percentagesefficiencies were $9.5 \%$ for $\mathrm{Zn}$, 9.8\% for $\mathrm{Pb}, 17.4 \%$ for $\mathrm{V}, 24.3 \%$ for $\mathrm{Ni}$ and $27.3 \%$ for $\mathrm{Cu}$. Therefore, EDTA-enhanced electrokinetic

Acar YB, Alshawabkeh AN (1993) Principles of electrokinetic remediation. Environ Sci Technol 27:2638-2647. doi: 10.1021/es00049a002

Acar YB, Gale RJ, Alshawabkeh AN, et al (1995) Electrokinetic remediation: Basics and technology status. J Hazard Mater 40:117-137. doi: 10.1016/0304-3894(94)00066-P

Altaee A, Smith R, Mikhalovsky S (2008) The feasibility of decontamination of reduced saline sediments from copper using the electrokinetic process. J Environ Manage 88:1611-8. doi: 10.1016/j.jenvman.2007.08.008

Ammami MT, Portet-Koltalo F, Benamar A, et al (2015) Application of biosurfactants and periodic voltage gradient for enhanced electrokinetic remediation of metals and PAHs in dredged marine sediments. Chemosphere 125:1-8. doi: 10.1016/j.chemosphere.2014.12.087

Amrate S, Akretche DE (2005) Modeling EDTA enhanced electrokinetic remediation of lead contaminated soils. Chemosphere 60:1376-83. doi: 10.1016/j.chemosphere.2005.02.021

Andreottola G, Bonomo L, De Gioannis G, et al (2010) Lab-scale feasibility tests for sediment treatment using different physico-chemical techniques. J Soils Sediments 10:142-150. doi: 10.1007/s11368-009-0150-5 
Colacicco A, De Gioannis G, Muntoni A, et al (2010) Enhanced electrokinetic treatment of marine sediments contaminated by heavy metals and PAHs. Chemosphere 81:46-56. doi: 10.1016/j.chemosphere.2010.07.004

De Gioannis G, Muntoni A, Polettini A, Pomi R (2009) Electrokinetic Treatment of Contaminated Marine Sediments. In: Electrochemical Remediation Technologies for Polluted Soils, Sediments and Groundwater, C. Cameselle and K. R. Reddy. John Wiley \& Sons, Inc., pp 149-177

Dubois V, Zentar R, Abriak N-E, Grégoire P (2011) Fine sediments as a granular source for civil engineering. Eur J Environ Civ Eng 15:137-166. doi: 10.1080/19648189.2011.9693315

Gidarakos E, Giannis A (2006) Chelate agents enhanced electrokinetic remediation for removal cadmium and zinc by conditioning catholyte $\mathrm{pH}$. Water Air Soil Pollut 172:295-312. doi: $10.1007 / \mathrm{s} 11270-006-9080-7$

Grundl T, Reese C (1997) Laboratory study of electrokinetic effects in complex natural sediments. J Hazard Mater 55:187-201. doi: 10.1016/S0304-3894(97)00012-5

Hahladakis JN, Lekkas N, Smponias A, Gidarakos E (2014) Sequential application of chelating agents and innovative surfactants for the enhanced electroremediation of real sediments from toxic metals and PAHs. Chemosphere 105:44-52. doi: 10.1016/j.chemosphere.2013.11.022

Hansen HK, Rojo A, Ottosen LM (2005) Electrodialytic remediation of copper mine tailings. J Hazard Mater 117:179-83. doi: 10.1016/j.jhazmat.2004.09.014

Iannelli R, Masi M, Ceccarini A, et al (2015) Electrokinetic remediation of metal-polluted marine sediments: experimental investigation for plant design. Electrochim Acta. doi: 10.1016/j.electacta.2015.04.093

Kim K-J, Kim D-H, Yoo J-C, Baek K (2011) Electrokinetic extraction of heavy metals from dredged marine sediment. Sep Purif Technol 79:164-169. doi: 10.1016/j.seppur.2011.02.010

Kim W-S, Kim S-O, Kim K-W (2005) Enhanced electrokinetic extraction of heavy metals from soils assisted by ion exchange membranes. J Hazard Mater 118:93-102. doi: 10.1016/j.jhazmat.2004.10.001

Lageman R (1993) Electroreclamation. Applications in the Netherlands. Environ Sci Technol 27:2648-2650. doi: 10.1021/es00049a003

Lestan D, Luo C, Li X (2008) The use of chelating agents in the remediation of metal-contaminated soils: a review. Environ Pollut 153:3-13. doi: 10.1016/j.envpol.2007.11.015

Mulligan CN, Yong RN, Gibbs BF (2001) Remediation technologies for metal-contaminated soils and groundwater: an evaluation. Eng Geol 60:193-207. doi: 10.1016/S0013-7952(00)00101-0

Parkhurst DL, Appelo C a. J (2013) Description of Input and Examples for PHREEQC Version 3 A Computer Program for Speciation , Batch-Reaction, One-Dimensional Transport , and Inverse Geochemical Calculations Chapter 43 of. In: U.S. Geological Survey Techniques and Methods, book 6. U.S. Geological Survey (USGS), p 497

Peng J-F, Song Y-H, Yuan P, et al (2009) The remediation of heavy metals contaminated sediment. J Hazard Mater 161:633-40. doi: 10.1016/j.jhazmat.2008.04.061 
Pool W (1989) A process for electroreclamation of soil material, an electric current system for application of the process, and an electrode housing for use in the electric current system. European Patent EP0312174A1.

Pool W (1996) Process for electroeclamation of soil material. US Patent 5,589,056.

Probstein RF, Hicks RE (1993) Removal of Contaminants from Soils by Electric Fields. Sci 260 :498-503. doi: 10.1126/science.260.5107.498

Reddy K, Ala P (2006) Electrokinetic Remediation of Contaminated Dredged Sediment. J ASTM Int 3:14.

Reddy KR, Cameselle C (2009) Electrochemical Remediation Technologies for Polluted Soils, Sediments and Groundwater. Wiley

Rozas F, Castellote M (2012) Electrokinetic remediation of dredged sediments polluted with heavy metals with different enhancing electrolytes. Electrochim Acta 86:102-109. doi: 10.1016/j.electacta.2012.03.068

Sillanpää M, Oikari A (1996) Assessing the impact of complexation by EDTA and DTPA on heavy metal toxicity using microtox bioassay. Chemosphere 32:1485-1497. doi: 10.1016/00456535(96)00057-4

Tsang DCW, Lo IMC, Surampalli RY (2012) Chelating Agents for Land Decontamination Technologies. American Society of Civil Engineers

Vane LM, Zang GM (1997) Effect of aqueous phase properties on clay particle zeta potential and electro-osmotic permeability: Implications for electro-kinetic soil remediation processes. J Hazard Mater 55:1-22. doi: 10.1016/S0304-3894(97)00010-1

Virkutyte J, Sillanpää M, Latostenmaa P (2002) Electrokinetic soil remediation - critical overview. Sci Total Environ 289:97-121. doi: 10.1016/S0048-9697(01)01027-0

Voglar D, Lestan D (2013) Pilot-scale washing of $\mathrm{Pb}, \mathrm{Zn}$ and Cd contaminated soil using EDTA and process water recycling. Chemosphere 91:76-82. doi: 10.1016/j.chemosphere.2012.12.016

Wong JSH, Hicks RE, Probstein RF (1997) EDTA-enhanced electroremediation of metalcontaminated soils. J Hazard Mater 55:61-79. doi: 10.1016/S0304-3894(97)00008-3

Yeung AT (2011) Milestone developments, myths, and future directions of electrokinetic remediation. Sep Purif Technol 79:124-132. doi: 10.1016/j.seppur.2011.01.022

Yeung AT, Gu Y-Y (2011) A review on techniques to enhance electrochemical remediation of contaminated soils. J Hazard Mater 195:11-29. doi: 10.1016/j.jhazmat.2011.08.047

Yu J-W, Neretnieks I (1997) Theoretical evaluation of a technique for electrokinetic decontamination of soils. J Contam Hydrol 26:291-299. doi: 10.1016/S0169-7722(96)00076-9

Yuan C, Weng C-H (2006) Electrokinetic enhancement removal of heavy metals from industrial wastewater sludge. Chemosphere 65:88-96. doi: 10.1016/j.chemosphere.2006.02.050 
1

2

3

4

5

$7_{52}$ 852 9522 10

$1\}^{523}$

12

$13^{52}$

$14_{525}$

15

$1 \phi 526$

17

18

19

20

21

22

23

24

25

26

27

28

29

30

31

32

33

34

35

36

37

38

39

40

41

42

43

44

45

46

47

48

49

50

51

52

53

54

55

56

57

58

59

60

61

62

63

64

65

Zhou D-M, Deng C-F, Cang L, Alshawabkeh AN (2005) Electrokinetic remediation of a Cu-Zn contaminated red soil by controlling the voltage and conditioning catholyte $\mathrm{pH}$. Chemosphere 61:519-27. doi: 10.1016/j.chemosphere.2005.02.055 
1

2

3

4

5

$\$$

10

11

12

13

14

15

16

17

18

19

20

21

22

23

24

25

$2 \phi_{527}$

27

$2 \$_{528}$

$2 \$ 529$

30530

31531

$33_{532}$

34

$3 \$ 533$

36

37

38

39

40

41

42

43

44

45

46

47

48

49

50

51

52

53

54

55

56

57

58

59

60

61

62

63

64

65

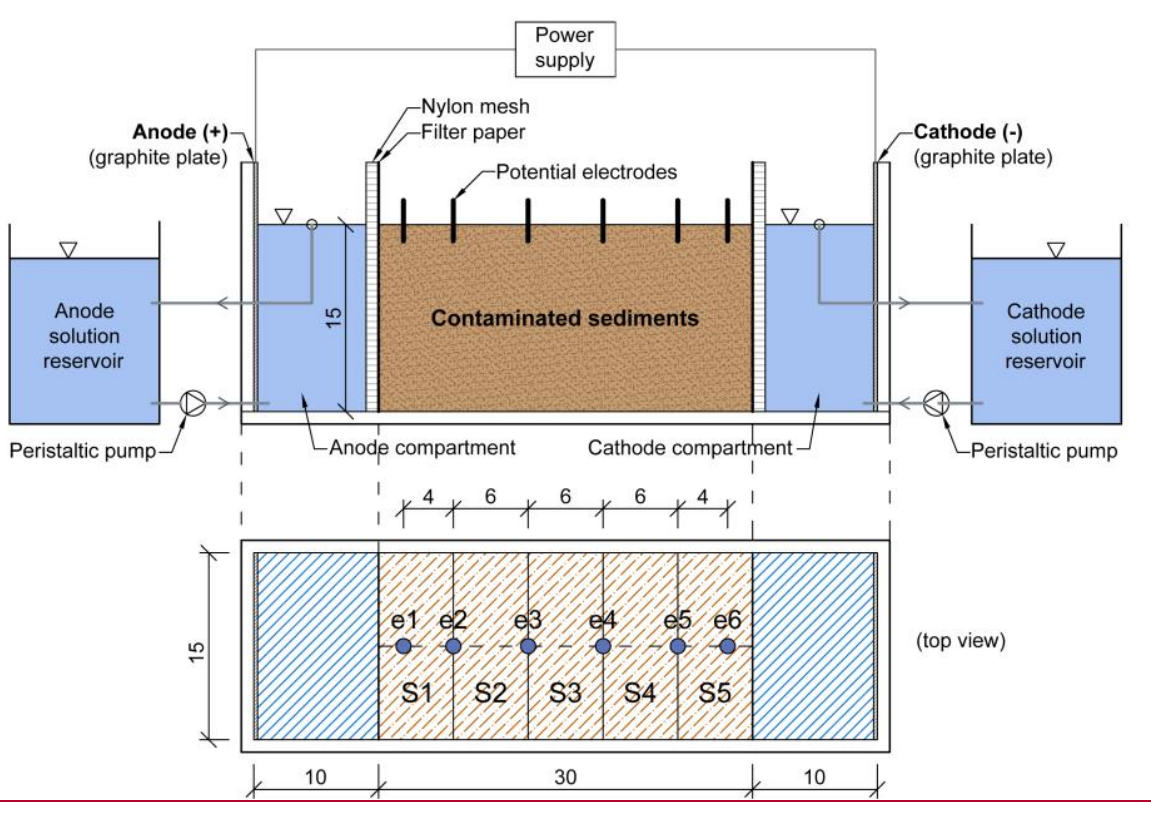

Fig. 1 Schematic diagram of the experimental electrokinetic cell. Dimensions are in $\mathrm{cm}$. Monitoring (potential) electrodes are labelled from $e 1$ to $e 6$. The material is divided into five equal sections (sampling locations), from $S 1$ to $S 5$ 


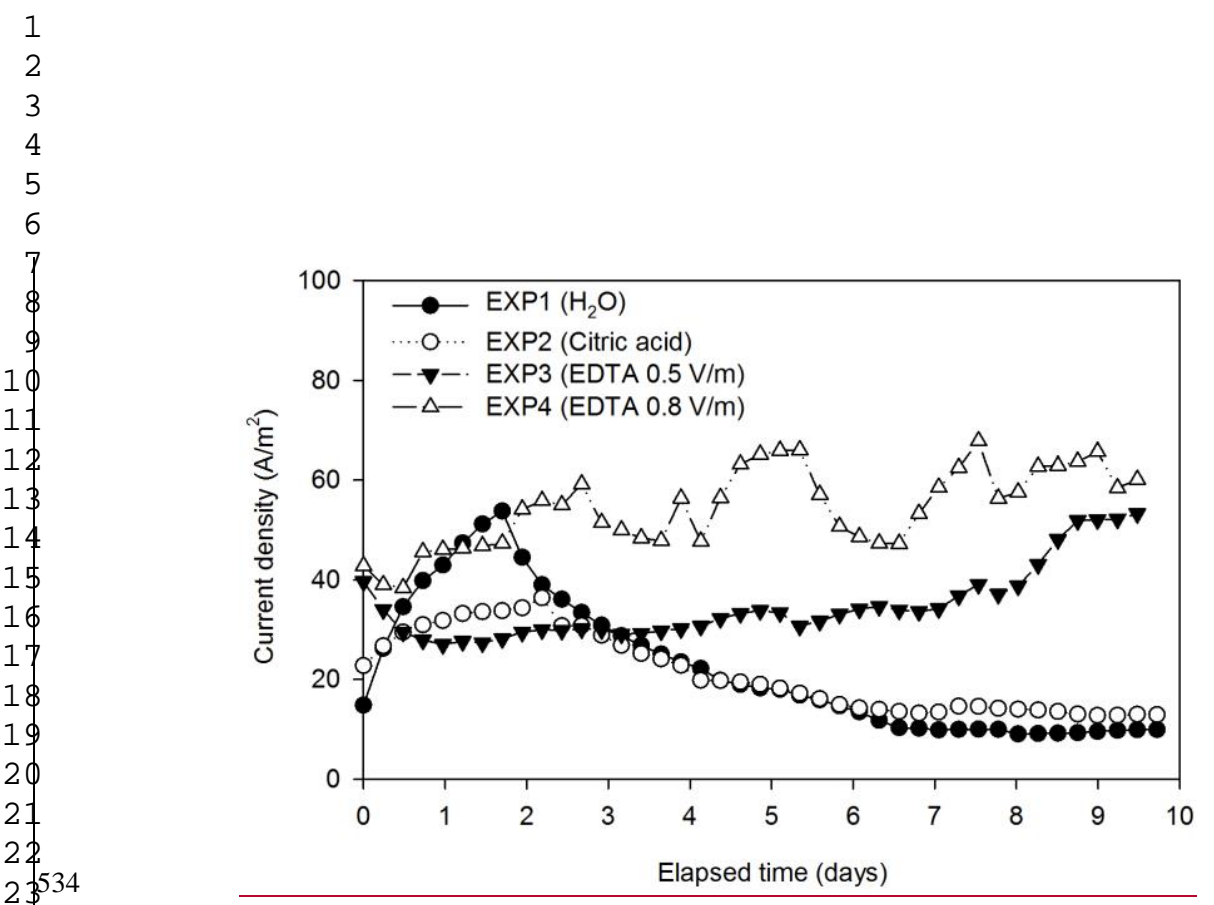

Fig. 2 Electric current density evolution during the electrokinetic experiments

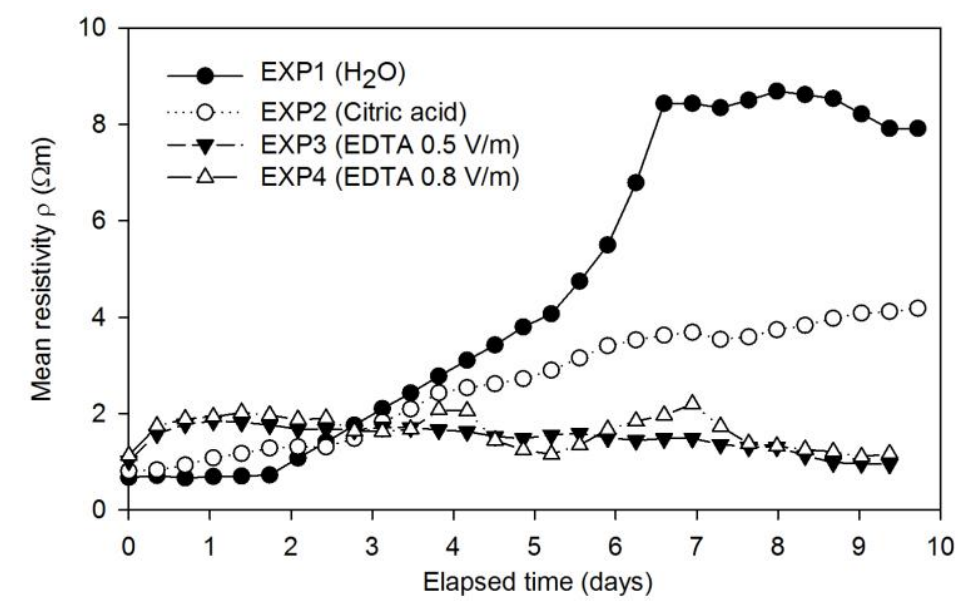

Fig. 3 Mean sediment resistivity change during the experiments 


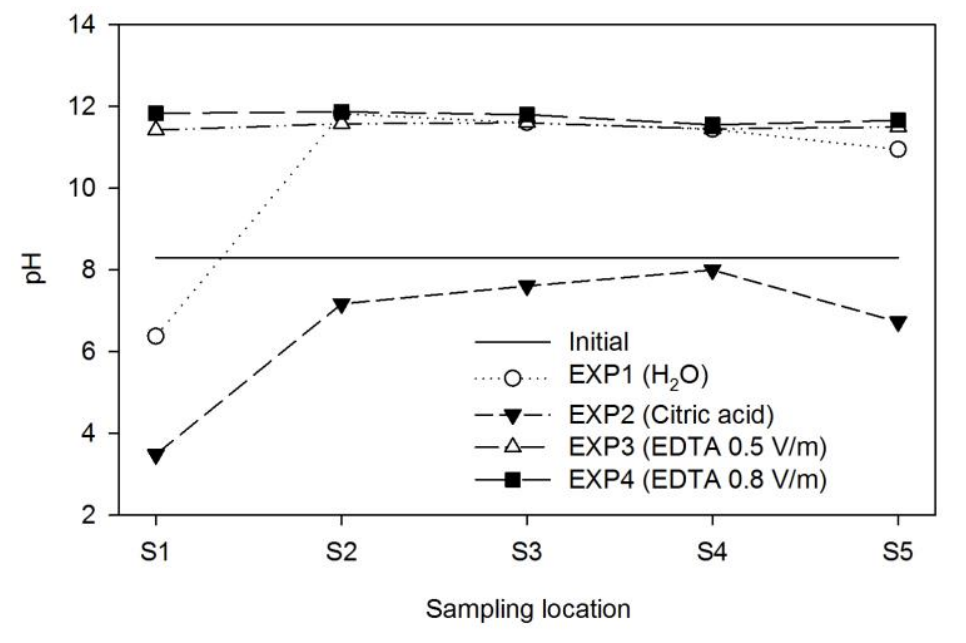

Fig. $4 \mathrm{pH}$ profiles along the cell at the beginning and at the end of the experiments. Maximum $\mathrm{pH}$ $\underline{\text { standard deviation over at least three replicate samples is } \pm 0.1 \text { (except for untreated sample } \pm 0.2 \text { ) }}$

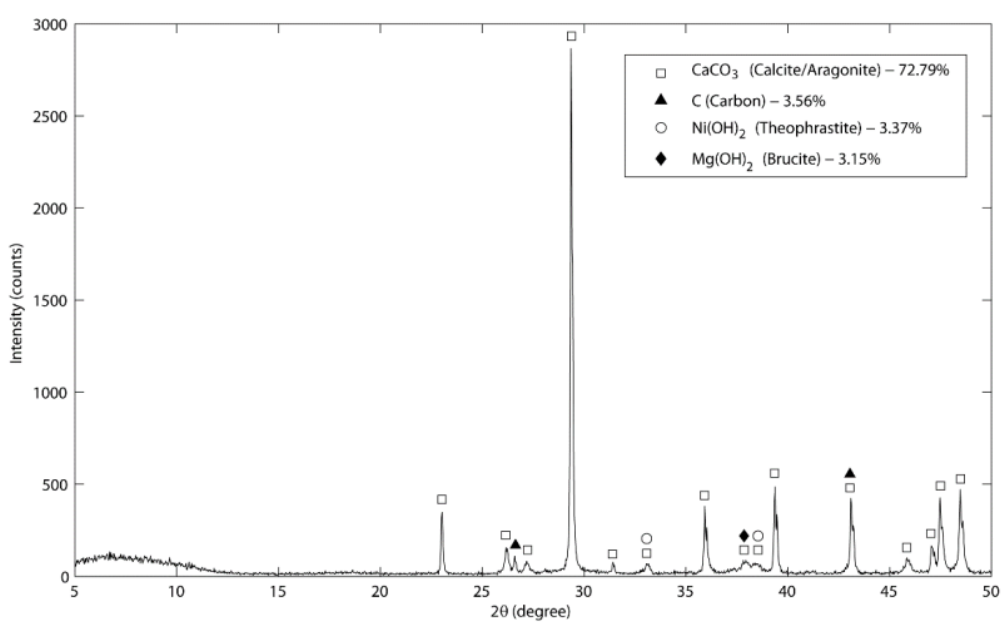

Fig. 5 X-Ray diffraction (XRD) analysis of the solid precipitates found in the cathode compartment at the end of experiment EXP1 

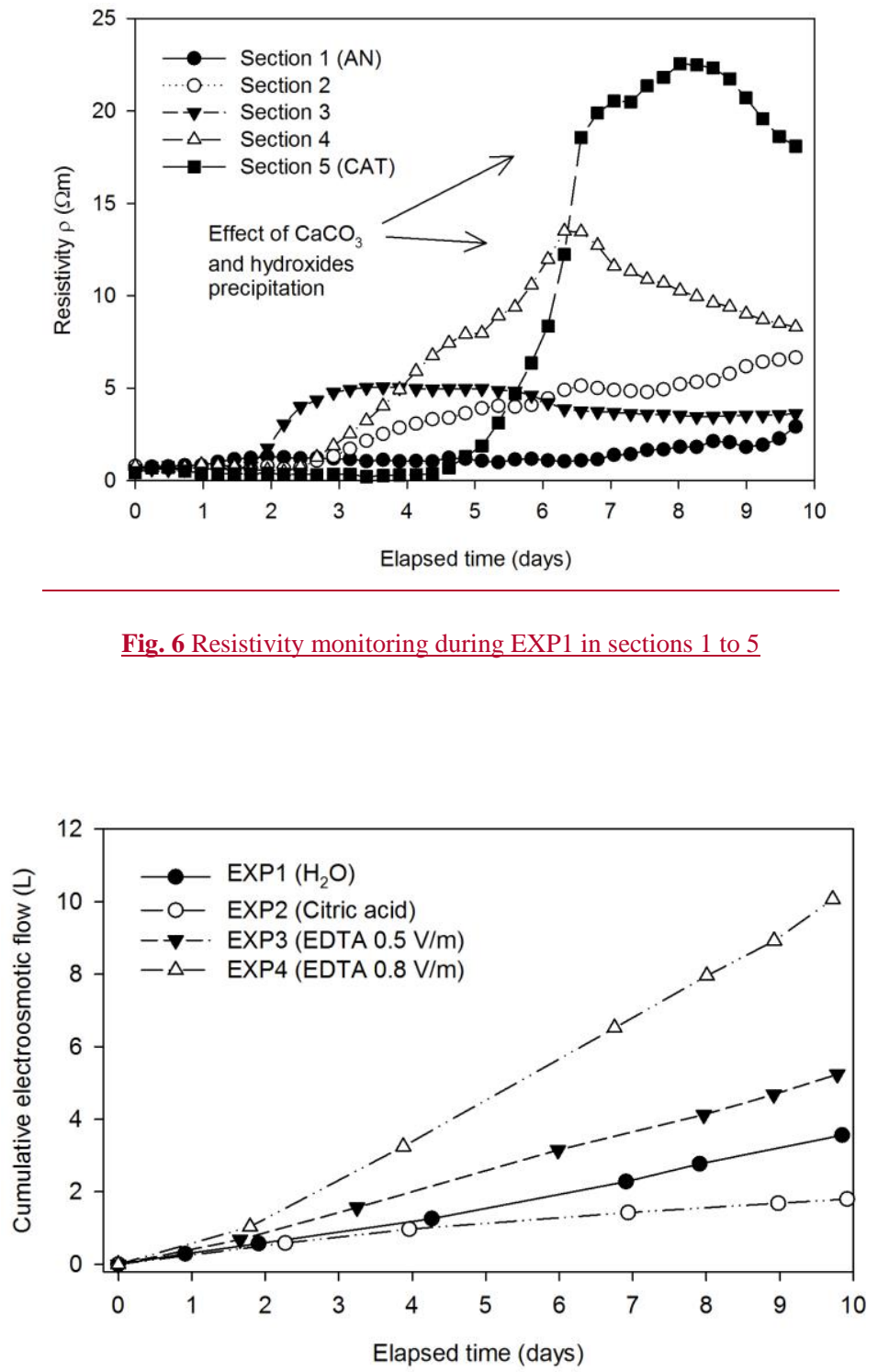

Fig. 7 Cumulative electroosmotic volume during the experiments 

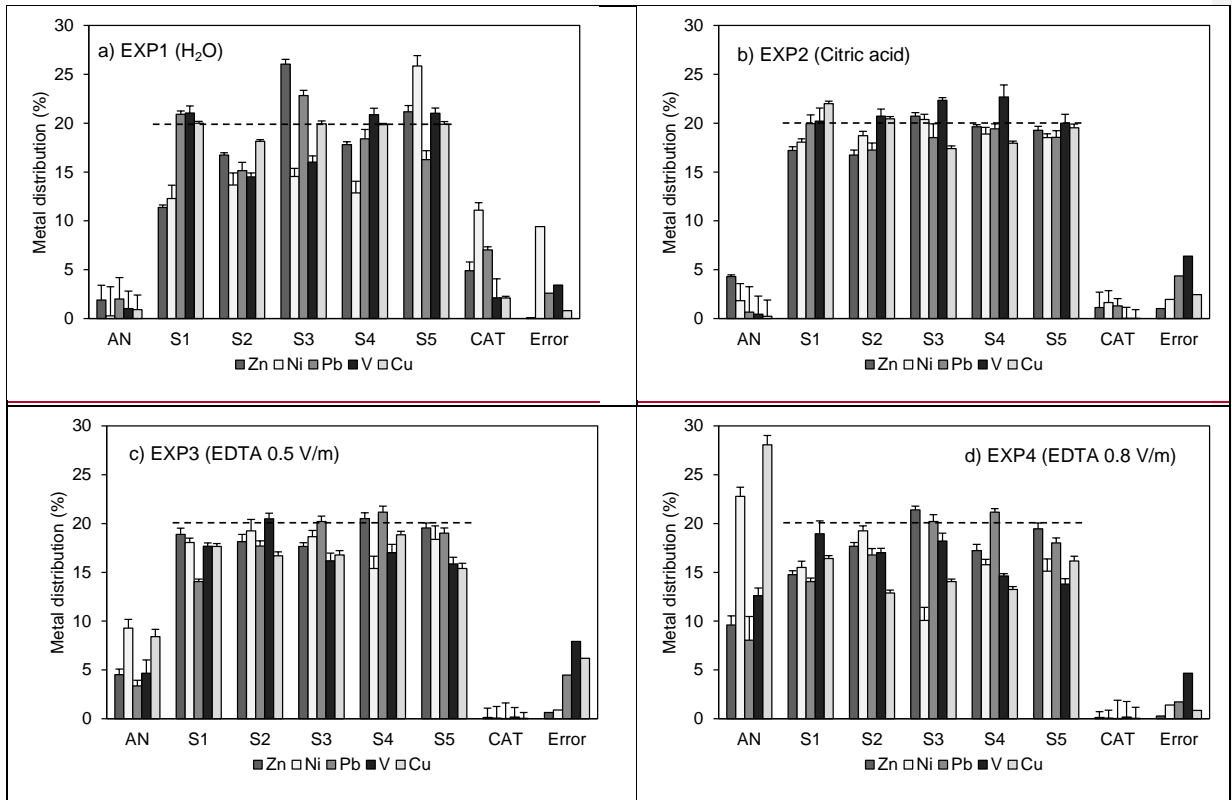

Fig. 8 Distribution of heavy metals (\% of the total mass) in the sediment and electrolytes at the beginning and at the end of the treatments. The dashed line indicates the initial distribution. Before treatment, heavy metals are equally distributed in five sections (20\% of the total metal mass in each section). Error bars represent the normalized standard deviation over 3 replicate samples. The last category "Error" refers to the mass balance error between the initial and final metal distribution 
1

2

4

5

7568

$\$$

10

11

12

13

14

15

16

17

18

19

20

21

22

23

24

25

$2 \phi$

27

28

29

30

31570

32571

33572

34573

3574

$36^{575}$

37576

$3 \$$

$3 \$ 577$

40

41

42

43

44

45

46

47

48

49

50

51

52

53

54

55

56

57

58

59

60

61

62

63

64

65
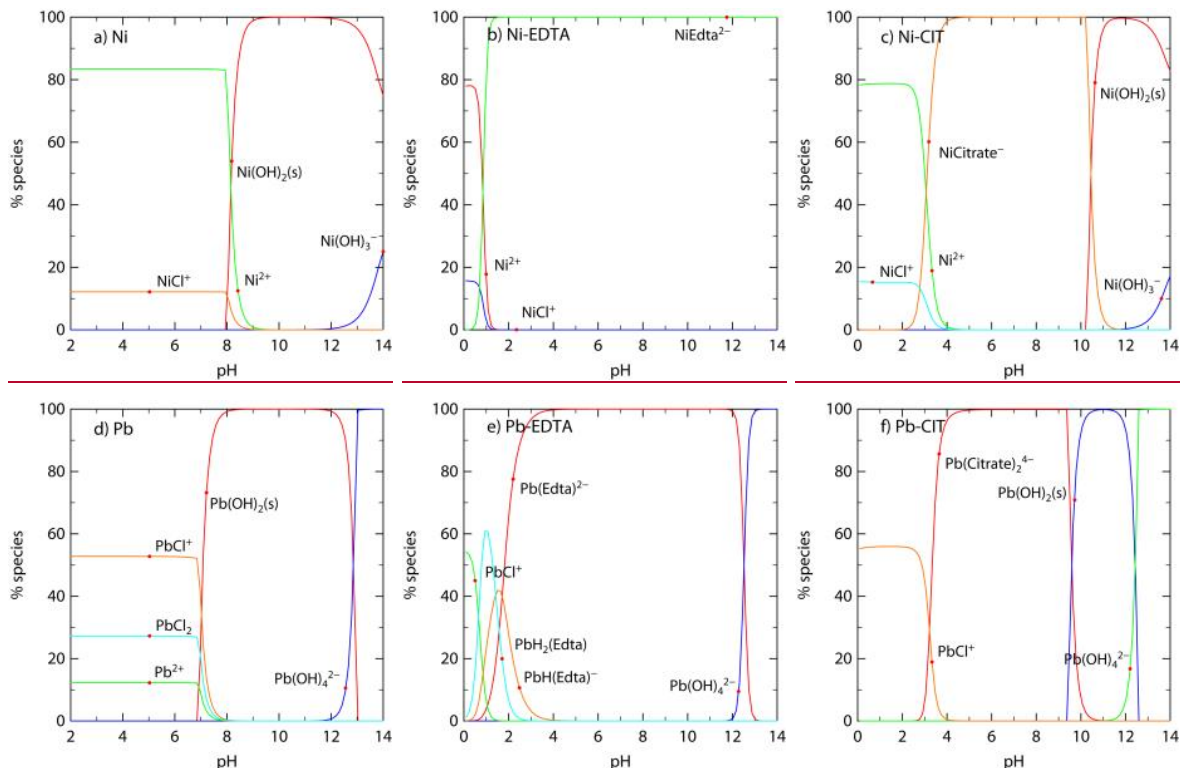

Fig. 9 Simulated metal speciation (aqueous and precipitates) as a function of $\mathrm{pH}$. a) Ni distribution in water, b) Ni distribution in presence of EDTA, c) Ni in presence of citric acid. d), e) and f) for $\mathrm{Pb}$.

Calculation were performed with USGS PHREEQC- 3 and PhreePlot. Conditions: metal concentrations in solution assumed $20 \%$ of the total sediment metal content. $\mathrm{NaCl} 0.3 \mathrm{M}$, EDTA and Citrate $0.1 \mathrm{M}$ 
1

2

3

4

5

6

7578

$\$ 579$ 10

11

12

13

14

15

$1 \oint$

17

$1 \$_{580}$

19

20581

21

22

23

24

25

26

27

28

29

30

31

32

33

34

35

36

37

38

39

40

41

42

43

44

45

46

47

48

49

50

51

52

53

54

55

56

57

58

59

60

61

62

63

64

65

$\underline{\text { Table } 1 \text { Experimental conditions for the electrokinetic treatment }}$

\begin{tabular}{|c|c|c|c|c|}
\hline Test & $\begin{array}{l}\text { Duration } \\
\text { (days) }\end{array}$ & $\begin{array}{l}\text { Applied voltage } \\
\text { gradient }(V / \mathrm{cm})\end{array}$ & Anolyte & Catholyte \\
\hline EXP1 & $\underline{10}$ & $\underline{0.5}$ & Tap water & Tap water \\
\hline EXP2 & $\underline{10}$ & $\underline{0.5}$ & Citric acid $0.1 \mathrm{M}$ & Citric acid $0.1 \mathrm{M}$ \\
\hline EXP3 & $\underline{10}$ & $\underline{0.5}$ & EDTA $0.1 \mathrm{M}$ & EDTA $0.1 \mathrm{M}$ \\
\hline EXP4 & 10 & $\underline{0.8}$ & EDTA $0.1 \mathrm{M}$ & EDTA $0.1 \mathrm{M}$ \\
\hline
\end{tabular}


Table 2 Physicochemical properties of the sediments. $\mathrm{pH}$ and metal content analysis were applied to 3 replicate samples (average value \pm standard deviation)

\begin{tabular}{|c|c|}
\hline \multicolumn{2}{|l|}{ Physicochemical properties } \\
\hline $\mathrm{pH}(\mathrm{ISO} 10390: 2005)$ & $8.3 \pm 0.2$ \\
\hline \multicolumn{2}{|l|}{ Buffering capacity } \\
\hline $\mathrm{pH}=3 \pm 0.2\left(\mathrm{~mol} \mathrm{H}^{+} / \mathrm{kg}\right)$ & 1.76 \\
\hline $\mathrm{pH}=13 \pm 0.2(\mathrm{~mol} \mathrm{OH} / \mathrm{kg})$ & $\underline{0.74}$ \\
\hline Porosity (\%) & $\underline{\underline{42}}$ \\
\hline \multicolumn{2}{|l|}{ Particle size distribution } \\
\hline Diameter $(\mathrm{mm})$ & (\% d.w.) \\
\hline$\underline{\underline{2.0-1.0}}$ & $\underline{\underline{6.80}}$ \\
\hline$\underline{\underline{1.0-0.5}}$ & $\underline{\underline{12.70}}$ \\
\hline$\underline{0.5-0.25}$ & 10.39 \\
\hline$\underline{\underline{0.25-0.125}}$ & $\underline{\underline{33.01}}$ \\
\hline$\underline{\underline{0.125-0.074}}$ & $\underline{\underline{21.91}}$ \\
\hline$\leq 0.074$ & $\underline{\underline{15.19}}$ \\
\hline Elemental composition & $\underline{\underline{(\%)}}$ \\
\hline$\underline{\underline{\mathrm{SiO}_{2}}}$ & $\underline{\underline{67.56}}$ \\
\hline$\underline{\underline{\mathrm{CaO}}}$ & $\underline{\underline{15.27}}$ \\
\hline$\underline{\underline{\mathrm{A}}} \underline{\underline{1}}_{\underline{\underline{\mathrm{O}_{3}}}} \underline{\underline{\underline{3}}}$ & $\underline{\underline{5.13}}$ \\
\hline$\underline{\underline{\mathrm{Fe}_{2}}} \underline{\underline{\underline{\mathrm{O}_{3}}}}$ & $\underline{\underline{3.08}}$ \\
\hline$\underline{\underline{\mathrm{K}_{2}}} \underline{\underline{\underline{\mathrm{O}}}}$ & $\underline{\underline{2.55}}$ \\
\hline$\underline{\underline{\mathrm{Cl}}}$ & $\underline{\underline{2.00}}$ \\
\hline$\underline{\underline{\mathrm{Na}_{2}}} \underline{\underline{O}}$ & $\underline{\underline{1.37}}$ \\
\hline$\underline{\underline{\mathrm{MgO}}}$ & $\underline{\underline{0.96}}$ \\
\hline$\underline{\underline{S}}$ & $\underline{\underline{0.95}}$ \\
\hline Metal content & $\underline{\underline{(\mathrm{mg} / \mathrm{kg})}}$ \\
\hline$\underline{\underline{\mathrm{Fe}}}$ & $\underline{\underline{5895 \pm 81.0}}$ \\
\hline$\underline{\underline{\mathrm{Zn}}}$ & $\underline{\underline{273.2 \pm 4.41}}$ \\
\hline$\underline{\underline{\mathrm{Ni}}}$ & $\underline{\underline{16.36 \pm 1.09}}$ \\
\hline$\underline{\underline{\mathrm{Cr}}}$ & $\underline{\underline{12.23 \pm 0.53}}$ \\
\hline$\underline{\underline{\mathrm{Pb}}}$ & $\underline{\underline{144.5 \pm 6.99}}$ \\
\hline$\underline{\underline{\mathrm{Al}}}$ & $\underline{\underline{2044}} \underline{\underline{42.1}}$ \\
\hline$\underline{\underline{\mathrm{Cu}}}$ & $\underline{\underline{92.06 \pm 0.37}}$ \\
\hline$\underline{\underline{\mathrm{V}}}$ & $\underline{11.5 \pm 0.77}$ \\
\hline
\end{tabular}




\section{Table 3 Mass of metal found on the electrode surfaces at the end of EXP1}

\begin{tabular}{lrr}
\hline & Anode & Cathode \\
\hline$\underline{\mathbf{Z n}(\mathbf{m g})}$ & $\underline{0.05}$ & $\underline{0.21}$ \\
$\underline{\mathbf{N i}(\mathbf{m g})}$ & $\underline{0.01}$ & $\underline{0.04}$ \\
$\underline{\mathbf{P b}(\mathbf{m g})}$ & $\underline{0.09}$ & $\underline{0.15}$ \\
$\underline{\mathbf{V ~ ( m g )}}$ & $\underline{0.01}$ & $\underline{0.05}$ \\
$\underline{\mathbf{C u}(\mathbf{m g})}$ & $\underline{0.04}$ & $\underline{0.58}$ \\
\hline
\end{tabular}

Table 4 Removal efficiencies of heavy metal after electrokinetic treatments. Values are the mean over $\underline{3 \text { replicate samples. Different letters in each row indicate significant differences (ANOVA) between }}$ the treatments $(p<0.05, n=3)$

\begin{tabular}{|c|c|c|c|c|c|}
\hline \multirow[b]{2}{*}{$\underline{\underline{T e s t}}$} & \multicolumn{5}{|c|}{ Removal (\%) } \\
\hline & $\underline{\underline{\mathrm{Zn}}}$ & $\underline{\underline{\mathrm{Ni}}}$ & $\underline{\underline{\mathrm{Pb}}}$ & $\underline{\underline{\mathrm{Cu}}}$ & $\underline{\underline{V}}$ \\
\hline$\underline{E X P 1}$ & $\underline{6.9 \pm 1.9 a}$ & $\underline{20.8 \pm 5.7 \mathrm{bc}}$ & $\underline{6.4 \pm 3.6 \mathrm{a}}$ & $2.2 \pm 1.1 \mathrm{a}$ & $\underline{6.5 \pm 2.9 \mathrm{a}}$ \\
\hline$\underline{\mathrm{EXP} 2}$ & $\underline{6.4 \pm 1.9 a}$ & $\underline{5.4 \pm 1.9 \mathrm{a}}$ & $\underline{6.3 \pm 4.2 \mathrm{a}}$ & $\underline{2.7 \pm 1.4 \mathrm{a}}$ & $-5.9 \pm 4.5 c$ \\
\hline EXP3 & $5.3 \pm 2.9 \mathrm{a}$ & $\underline{10.3 \pm 4.9 \mathrm{ab}}$ & $7.8 \pm 2.5 \mathrm{a}$ & $\underline{14.6 \pm 2.0 \mathrm{~b}}$ & $\underline{12.8 \pm 3.2 \mathrm{ab}}$ \\
\hline$\underline{\text { EXP4 }}$ & $9.5 \pm 2.4 \mathrm{a}$ & $\underline{24.3 \pm 4.3 \mathrm{c}}$ & $9.8 \pm 2.6 \mathrm{a}$ & $\underline{27.3 \pm 1.7 \mathrm{c}}$ & $\underline{17.4 \pm 3.4 \mathrm{~b}}$ \\
\hline
\end{tabular}




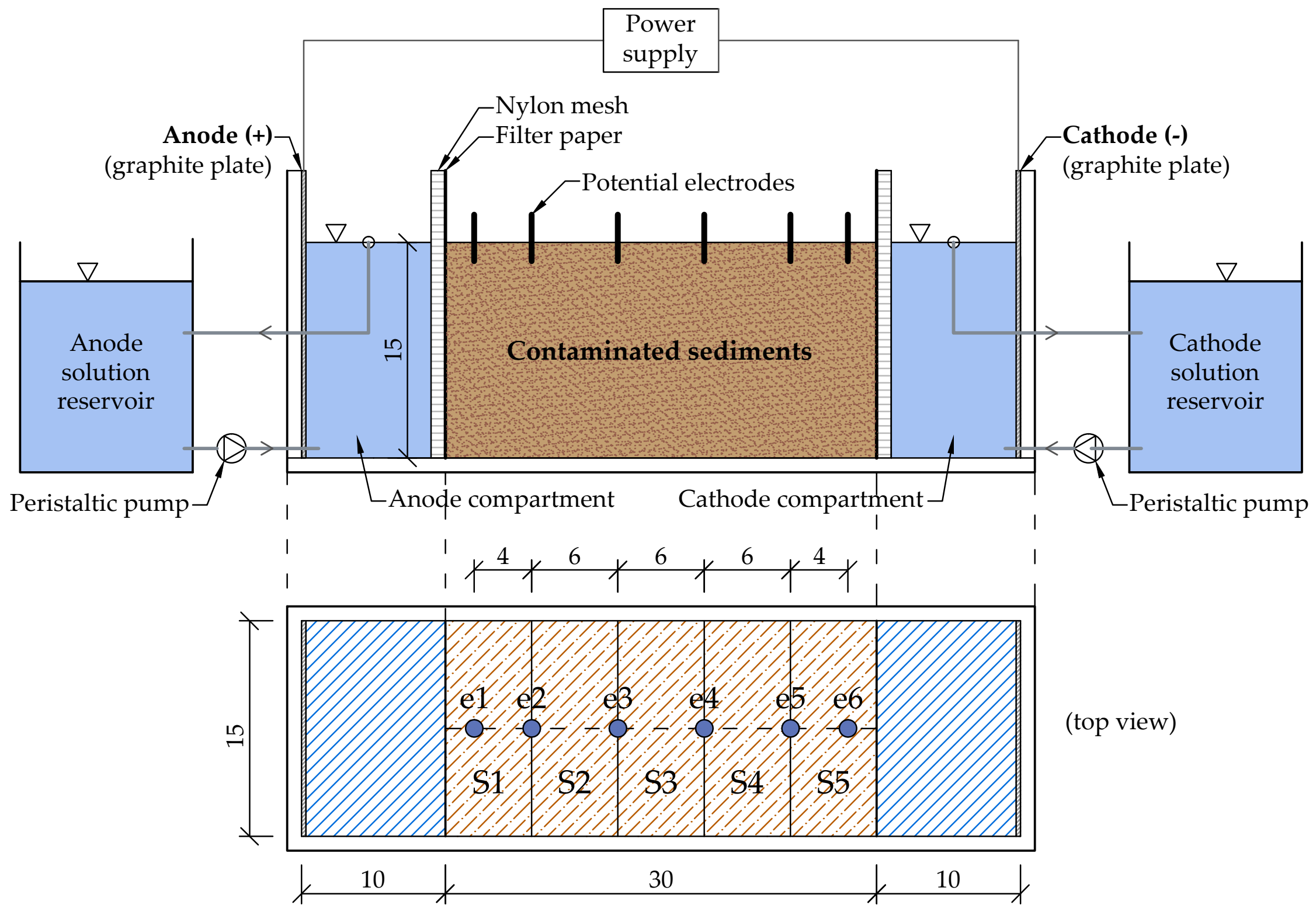




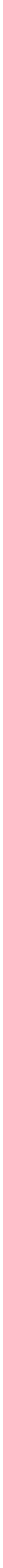




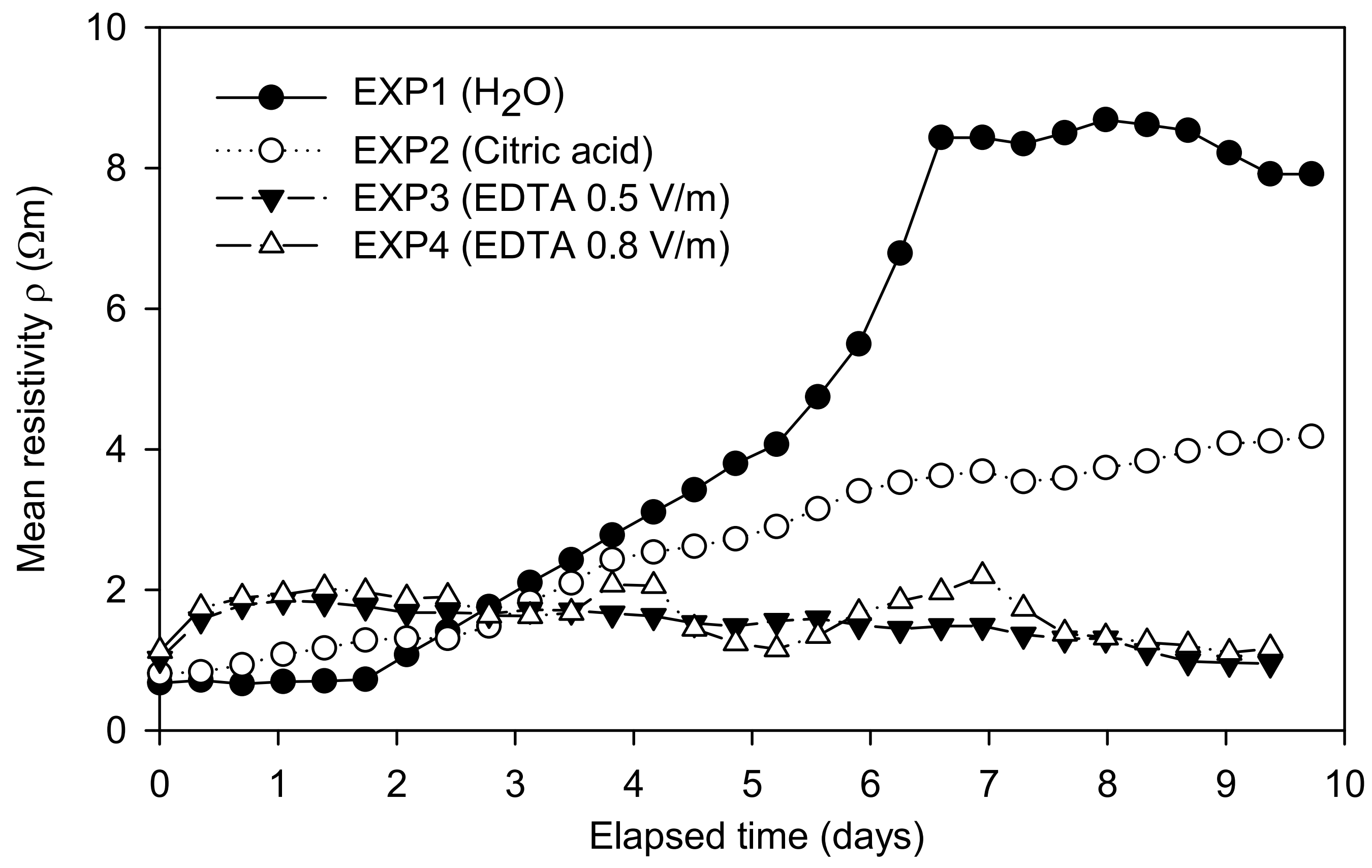


Figure 5

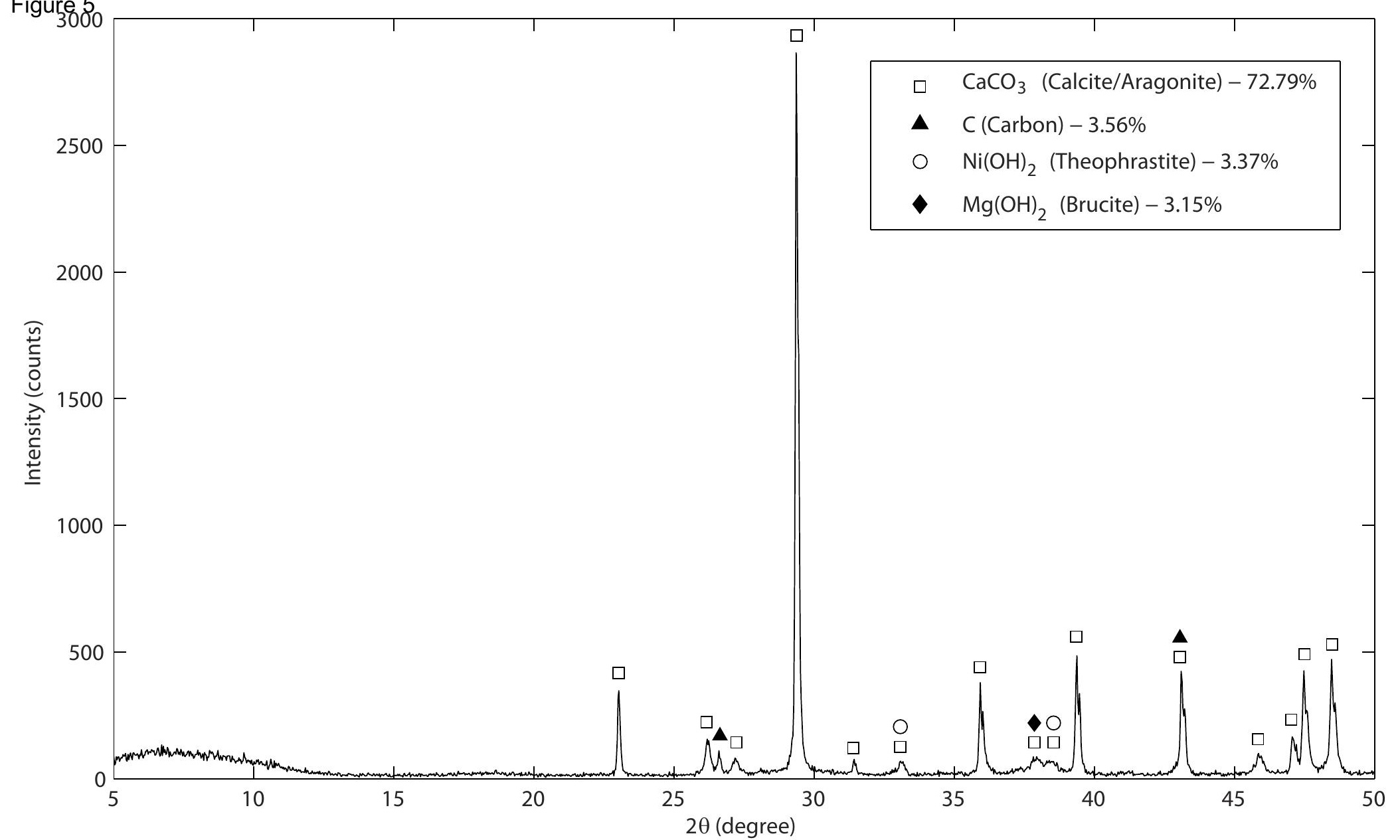




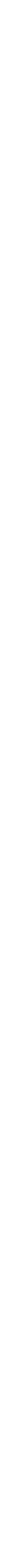




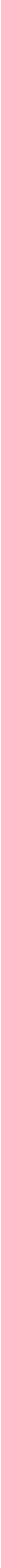



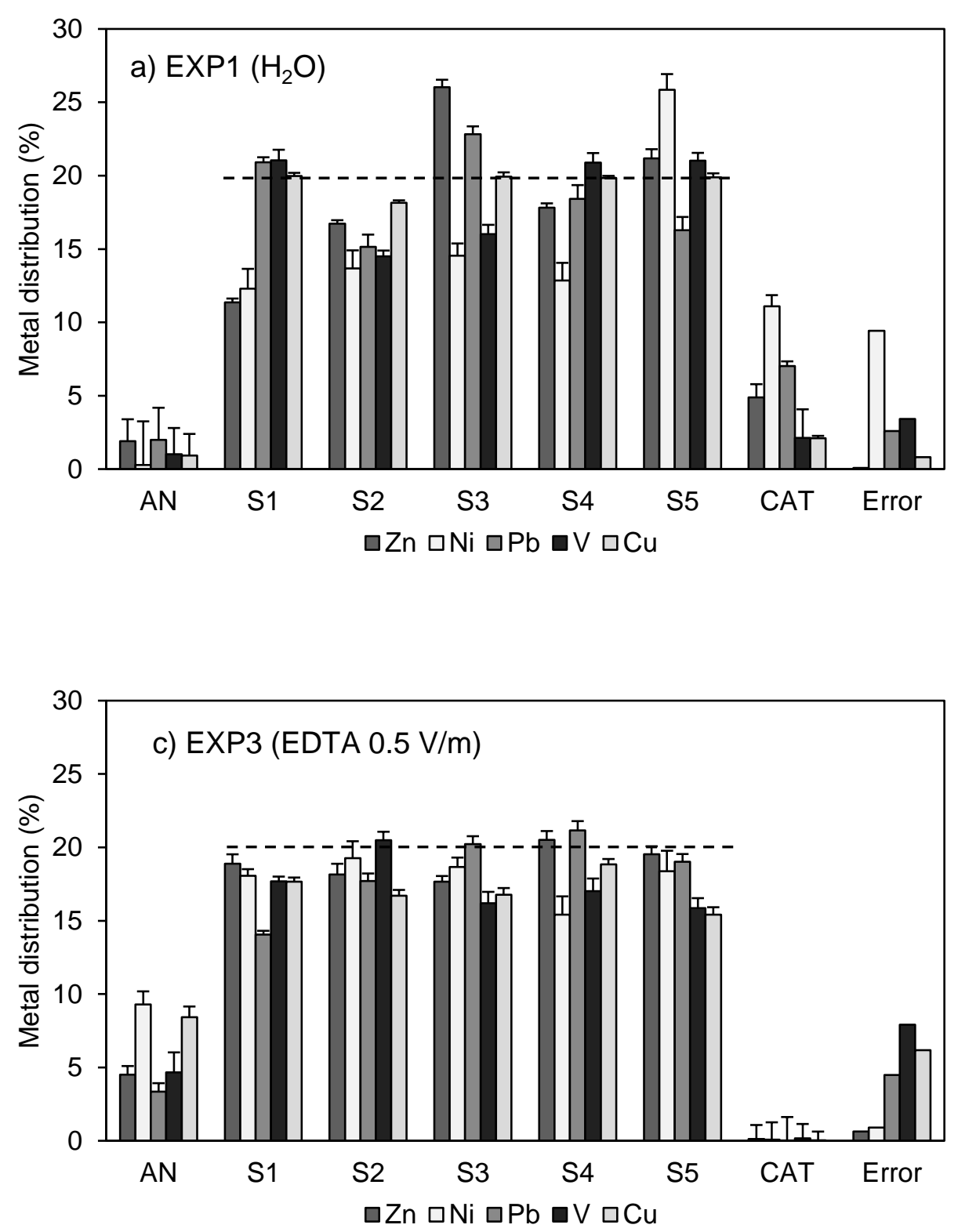

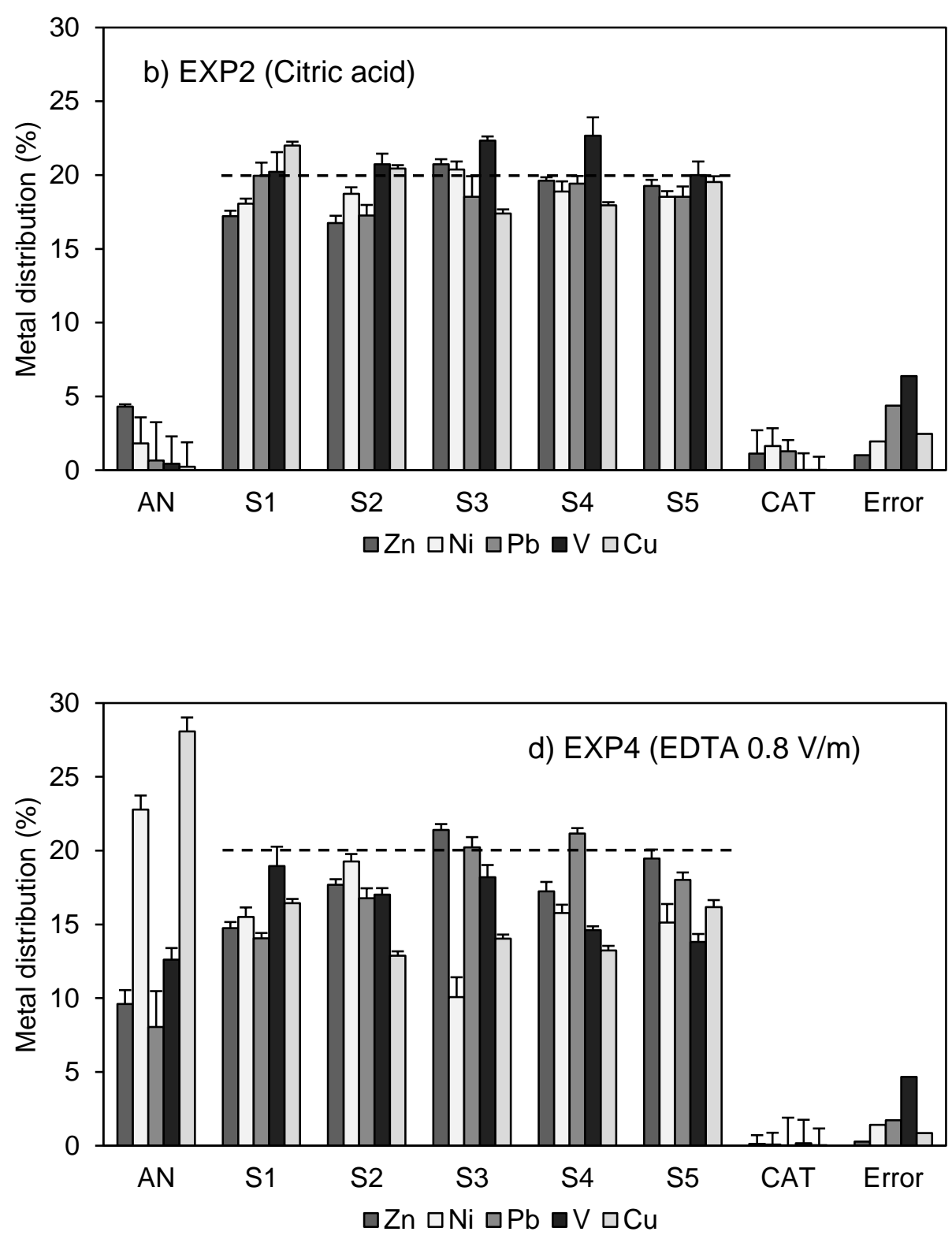
FigurbCOA

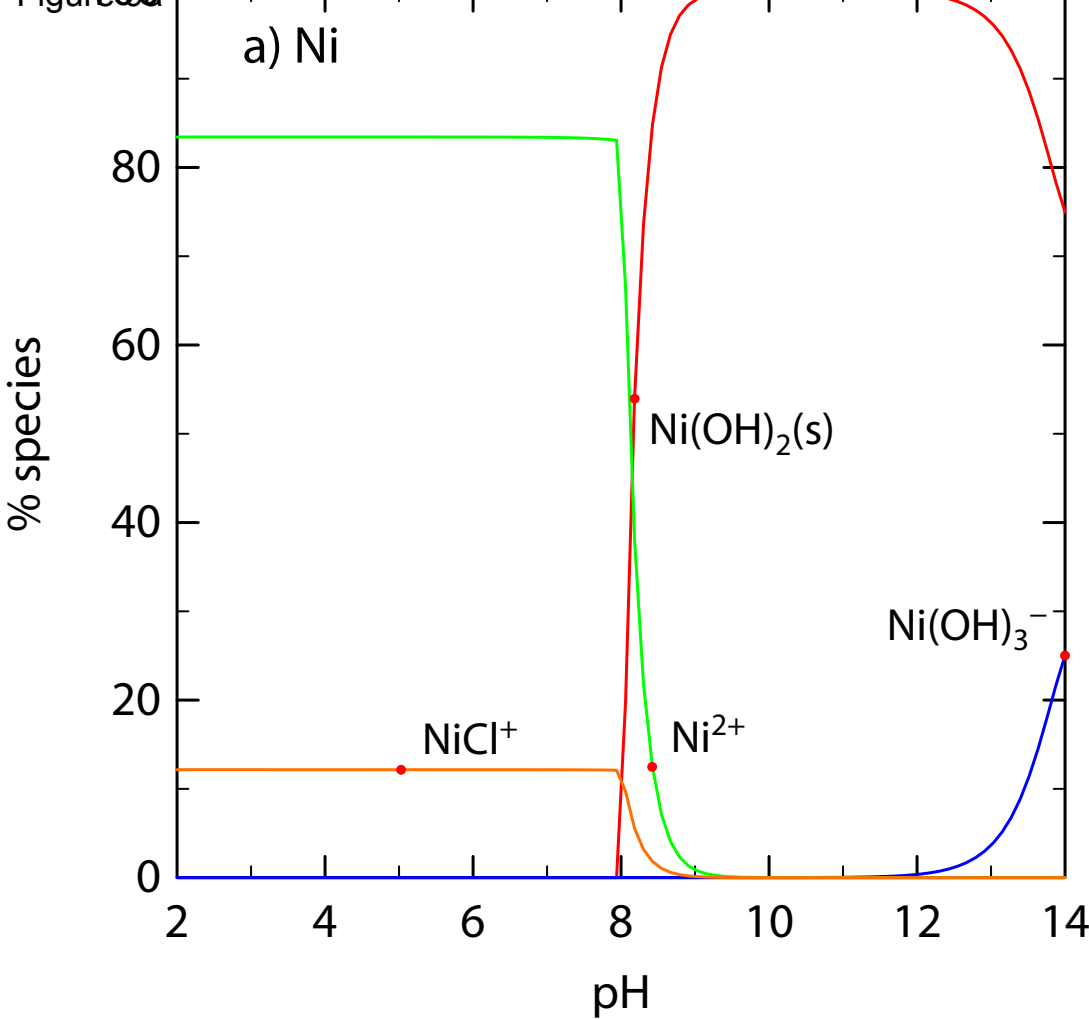




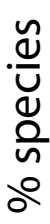

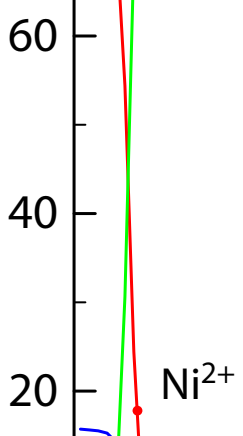

0

80

$20-\sqrt{\mathrm{Ni}^{2+}}$

$\mathrm{NiCl}^{+}$

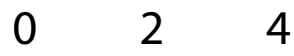

46

$\mathrm{pH}$ 


\section{Figurece}

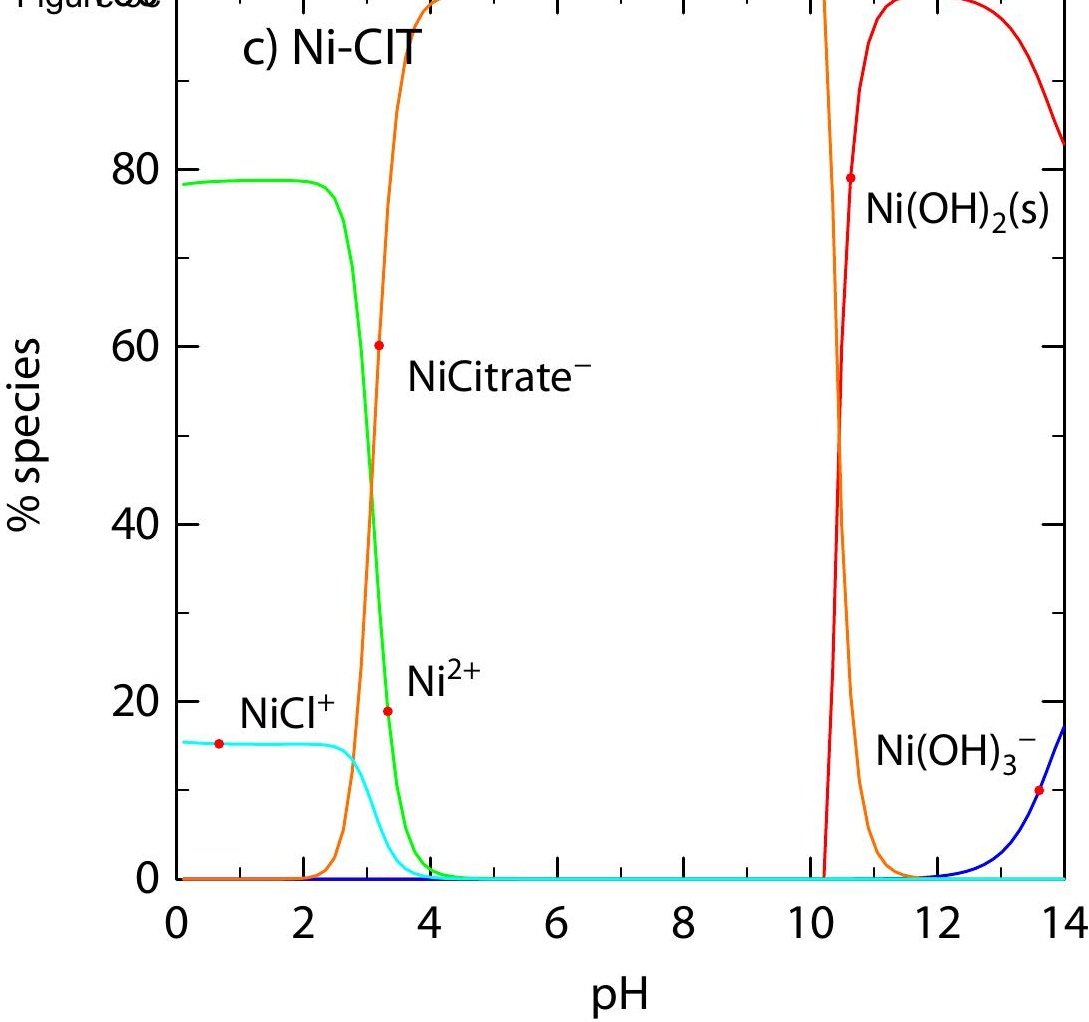


FigureQda

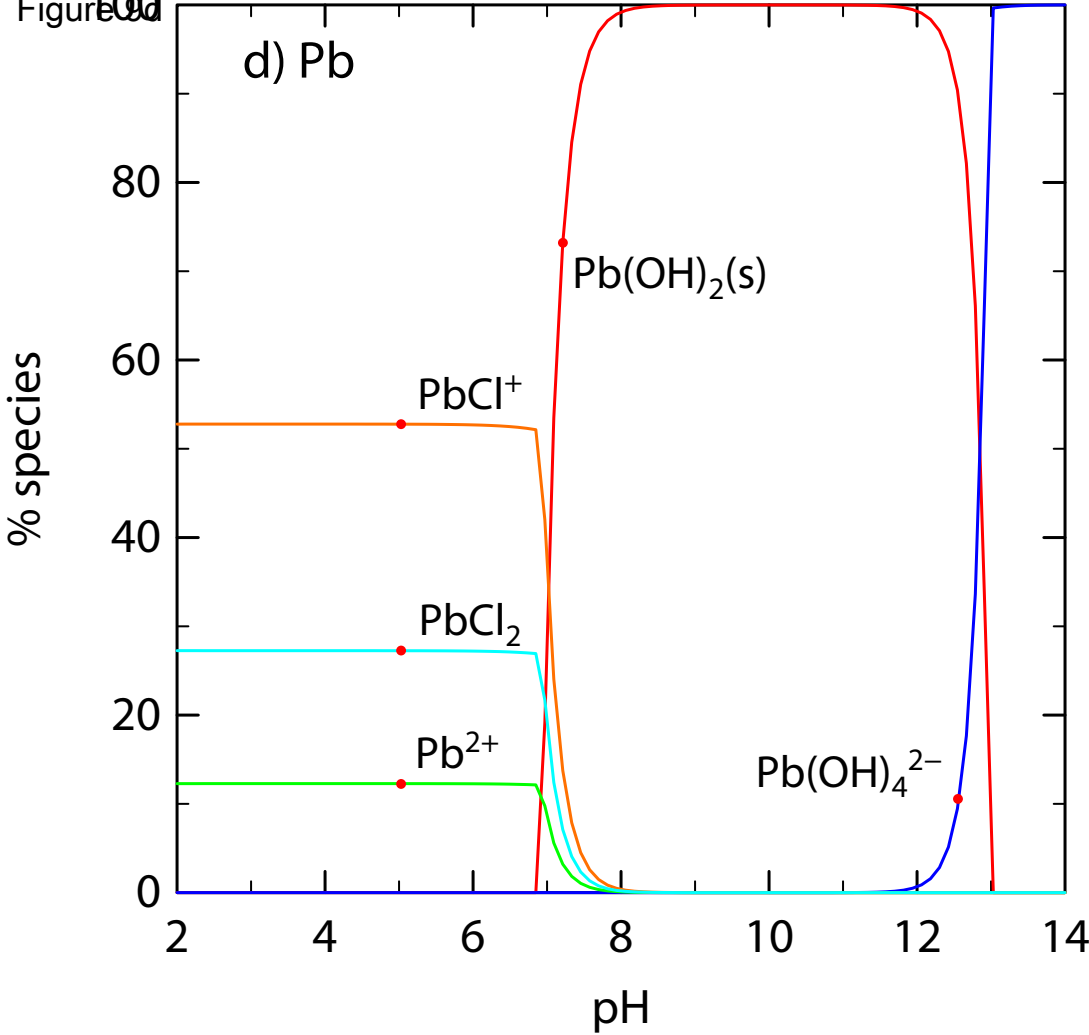




\section{FigureQ}

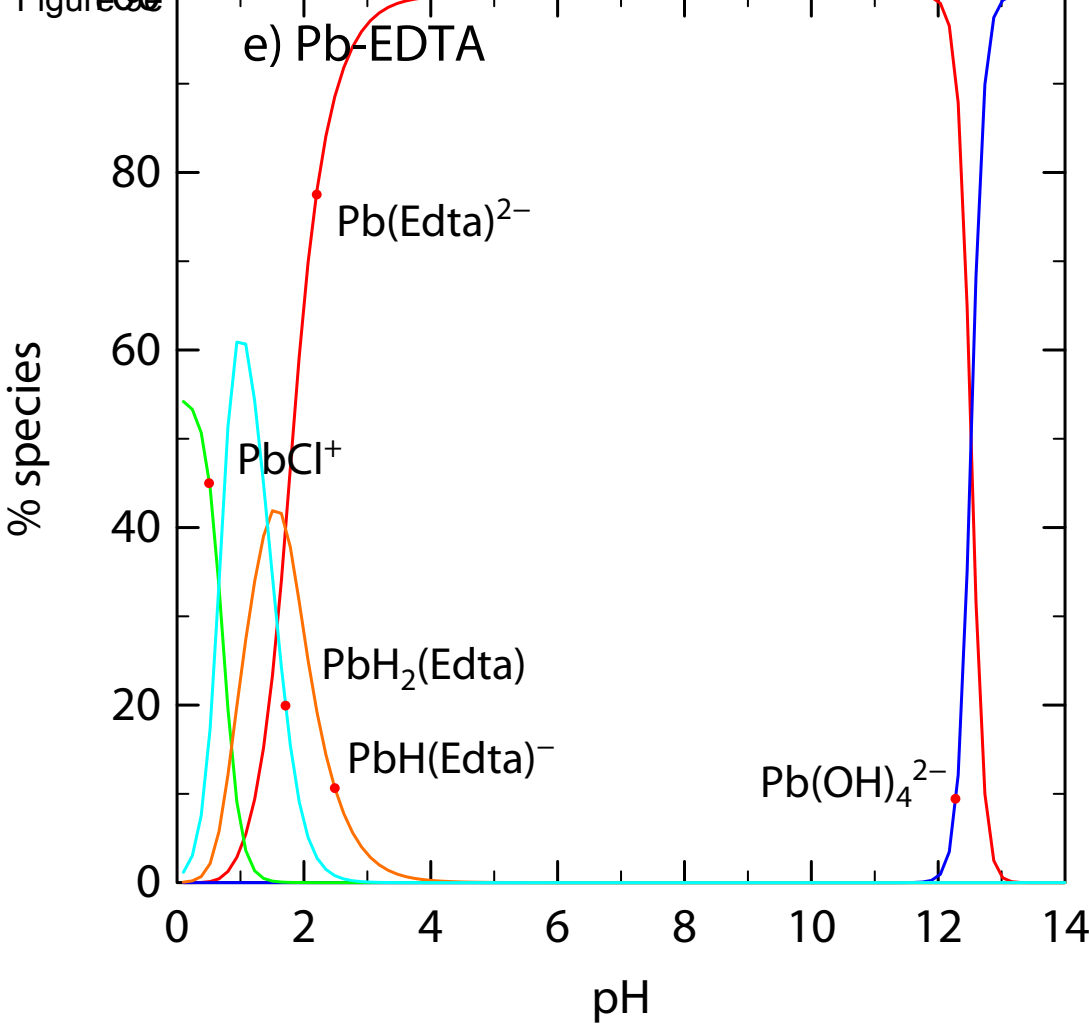




\section{FigureCef}

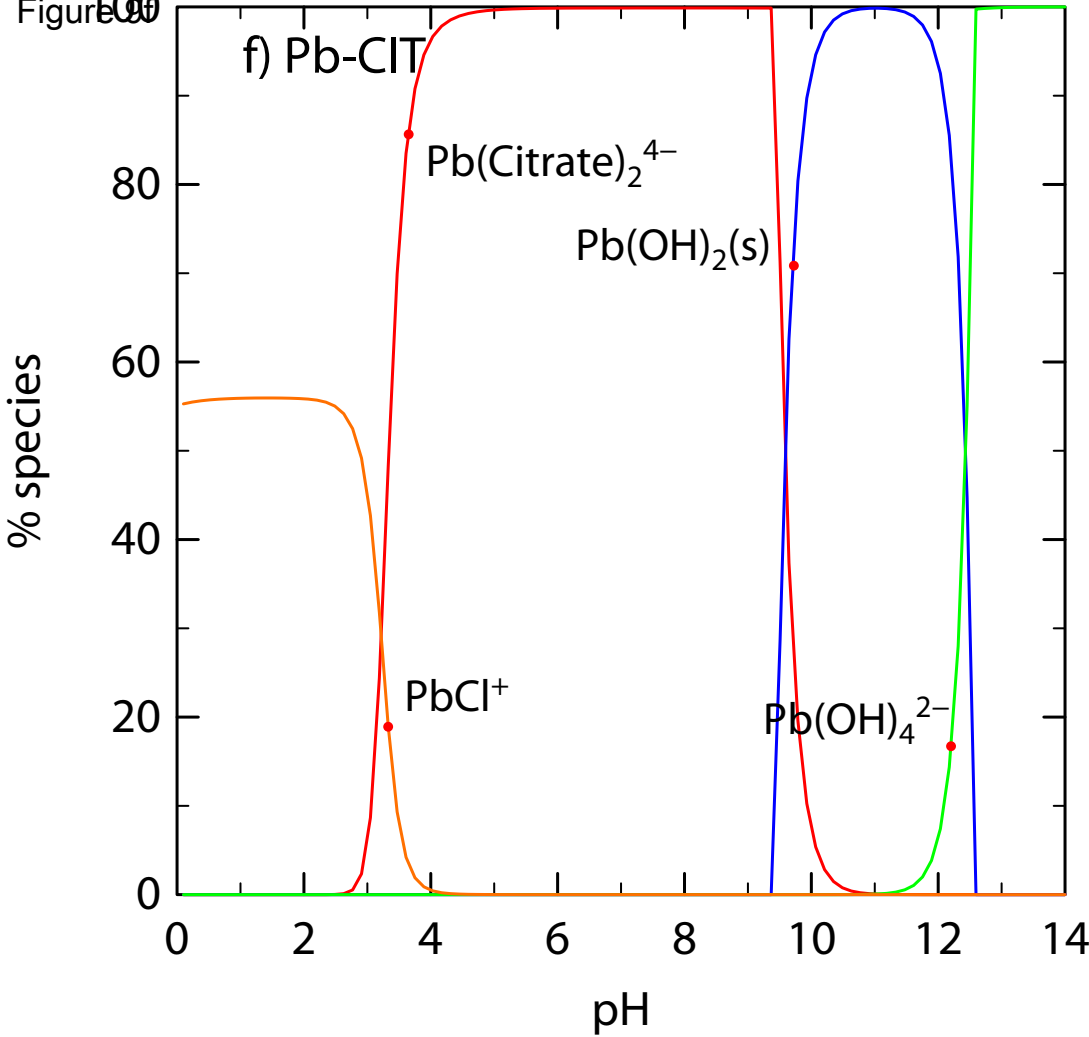

